\title{
Father-Son Family Communication Patterns and Gender Ideologies: A Modeling and Compensation Analysis
}

Kelly G. Odenweller

West Virginia University

Follow this and additional works at: https://researchrepository.wvu.edu/etd

\section{Recommended Citation}

Odenweller, Kelly G., "Father-Son Family Communication Patterns and Gender Ideologies: A Modeling and Compensation Analysis" (2011). Graduate Theses, Dissertations, and Problem Reports. 862.

https://researchrepository.wvu.edu/etd/862

This Thesis is protected by copyright and/or related rights. It has been brought to you by the The Research Repository @ WVU with permission from the rights-holder(s). You are free to use this Thesis in any way that is permitted by the copyright and related rights legislation that applies to your use. For other uses you must obtain permission from the rights-holder(s) directly, unless additional rights are indicated by a Creative Commons license in the record and/ or on the work itself. This Thesis has been accepted for inclusion in WVU Graduate Theses, Dissertations, and Problem Reports collection by an authorized administrator of The Research Repository @ WVU. For more information, please contact researchrepository@mail.wvu.edu. 
Father-Son Family Communication Patterns and Gender Ideologies:

A Modeling and Compensation Analysis

\author{
Kelly G. Odenweller
}

Thesis submitted to the Eberly College of Arts and Sciences

at West Virginia University in partial fulfillment of the requirements

for the degree of

\title{
Master of Arts
}

in

Communication Studies

\author{
Christine E. Rittenour, Ph.D., Chair \\ Maria Brann, Ph.D. \\ Scott A. Myers, Ph.D.
}

Department of Communication Studies

\section{Morgantown, West Virginia \\ 2011}

Keywords: father-son communication, family communication patterns, gender ideologies, modeling and compensation, memorable messages 


\section{ABSTRACT \\ Father-Son Family Communication Patterns and Gender Ideologies: \\ A Modeling and Compensation Analysis}

\section{Kelly G. Odenweller}

The purpose of this study was to advance father-son research by investigating family communication and gender ideologies. Specifically, the study assessed the specific messages fathers transmit to sons regarding gender ideologies, relationships between family communication patterns and gender ideologies, and the utility of modeling and compensation hypotheses in intergenerational transmission of these behaviors and ideologies. Finally, this study addressed the association between gender ideologies and global life satisfaction. Fathers $(N=125)$ completed an online questionnaire to report their living fathers' and their own communication patterns and gender ideologies, as well as their transmission of gender ideologies to their sons. Results revealed a relationship between family communication patterns and gender ideologies within the younger generation of fathers and sons, sons' modeling of fathers' conformity orientations, and no relationship between gender ideologies and global life satisfaction. Overall, the results support the link between communication patterns and gender ideologies and offer several avenues for future exploration. 


\section{DEDICATION}

This thesis is dedicated to the three most important fathers and sons in my life: my father, Dick; my husband, John; and my son, Leighton. At countless points in my life, these three men have shown me the value of and benefits to affectionate, nurturing, and involved fathering. I greatly admire the energy and love you devote to your families. You all have inspired this project and continue to inspire me everyday. 


\section{ACKNOWLEDGEMENTS}

I am grateful to many people for making this thesis project possible. First, I would like to thank Dr. Keith Weber for believing in my research and writing abilities enough to approve my thesis-track program request. Second, I would like to extend my gratitude to Dr. Scott Myers and Dr. Maria Brann for serving on my committee and offering helpful and thought-provoking comments. Next, I would like to thank all of the Communication Studies instructors who permitted me to solicit their undergraduate students for data collection, as well as Sara La Belle and Colleen Malacowski for proofreading my proposal and final manuscripts during their busy semesters. Of course, without Dr. Christine Rittenour this project would not have been nearly as well executed and the final manuscript would not be nearly as well composed. Dr. Rittenour's insightful suggestions, patient guidance, unwavering optimism, and warm friendship over the last six months have truly inspired me to be a better scholar and person. Lastly, I would like to extend the deepest appreciation to my family and friends who helped and encouraged me throughout this lengthy and stressful project. Special thanks to my mother, Robin, for pre-testing my survey, recruiting additional fathers, and assisting with last minute revisions. Like all of my accomplishments, the success of this thesis is shared by those who advised and supported me along this intense journey, so thank you all. 


\section{TABLE OF CONTENTS}

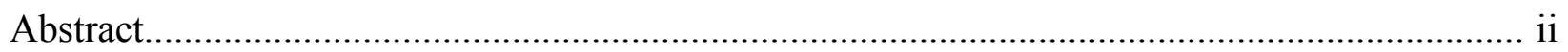

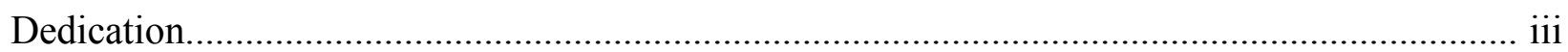

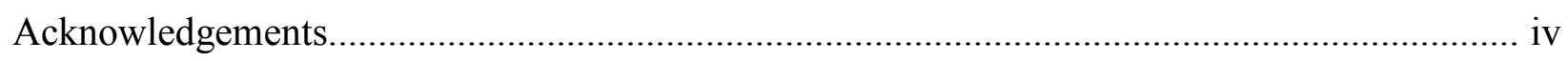

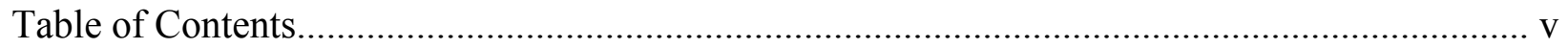

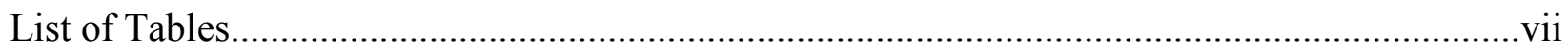

Chapter 1 - Literature Review.................................................................................... 1-22

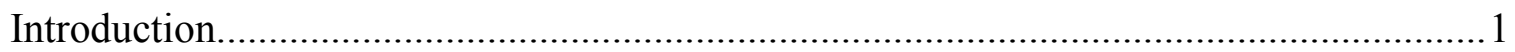

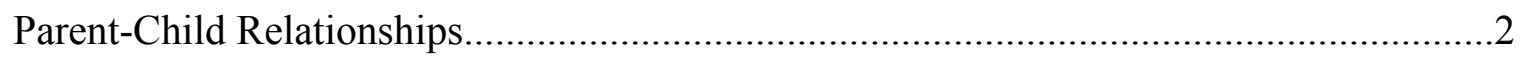

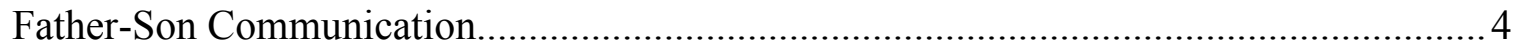

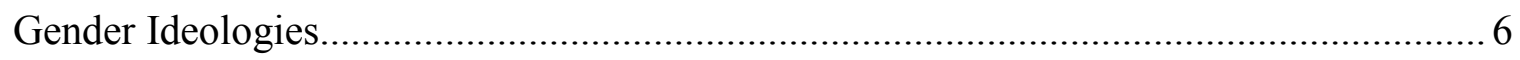

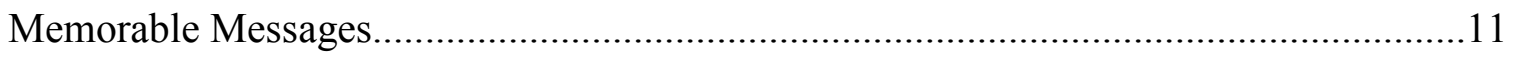

Family Communication Patterns................................................................................ 13

Modeling and Compensation Hypotheses........................................................................18

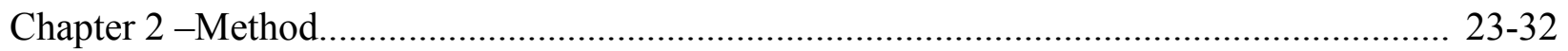

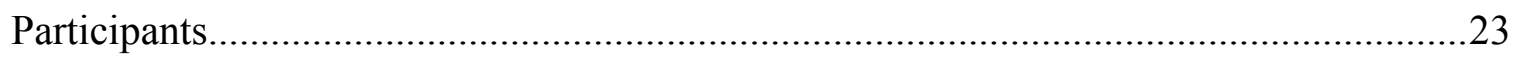

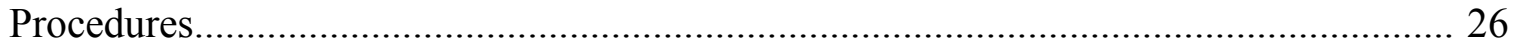

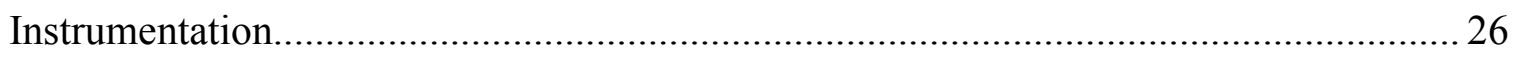

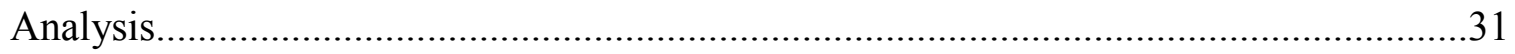

Chapter 3 - Results............................................................................................. 33-39

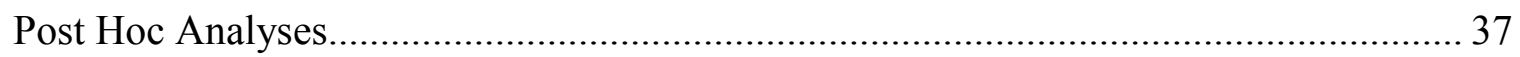

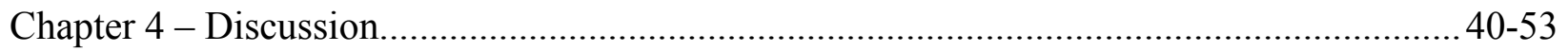

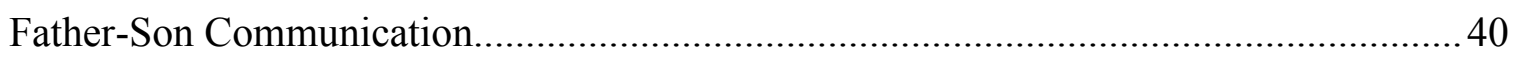




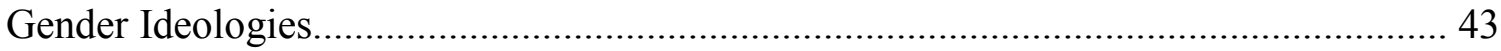

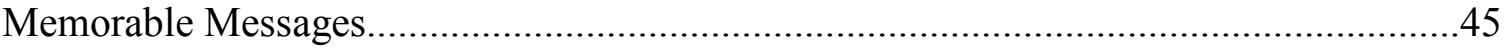

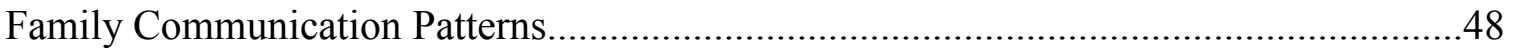

Modeling and Compensation Hypotheses.......................................................... 49

Limitations and Additional Future Considerations................................................. 51

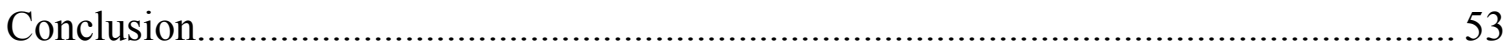

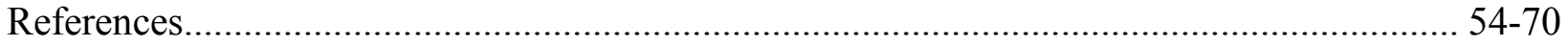

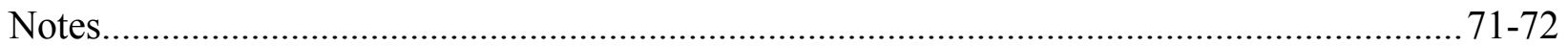

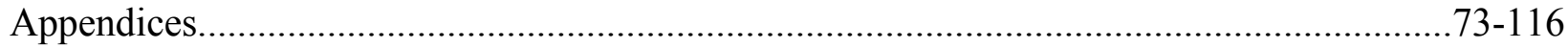

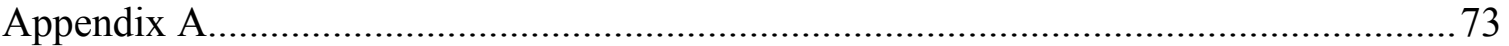

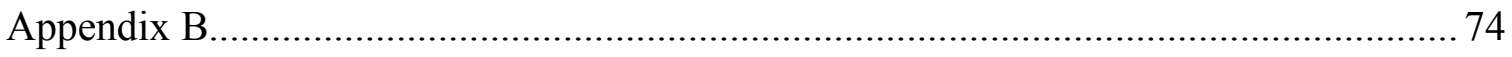

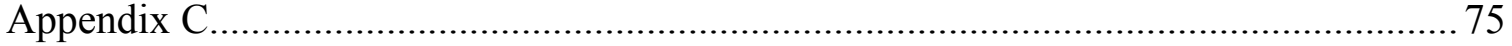

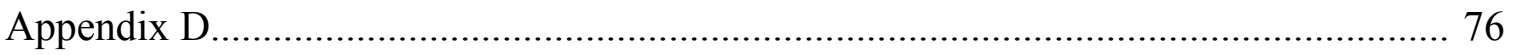

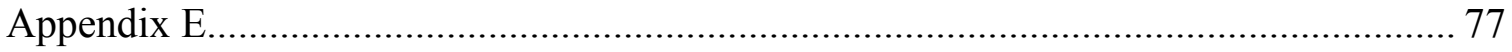

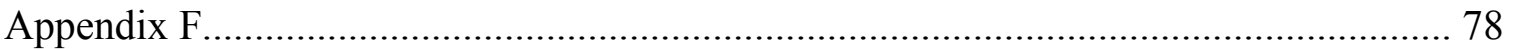

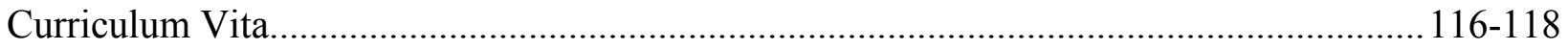


LIST OF TABLES

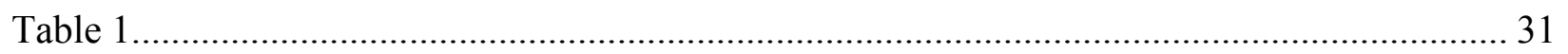




\section{CHAPTER ONE}

\section{Introduction}

During the past four decades, a myriad of communication and psychology scholars have researched the influence of parent-child communication on a wide range of child outcomes including psychological wellbeing (e.g., Barnett, Marshall, \& Pleck, 1992; Taylor \& Segrin, 2010), academic achievements (e.g., Myers, Schrodt, \& Rittenour, 2006), communication within and attitudes about romantic relationships (e.g., Kline, O’Neil, \& Fay, 2005; Koenig Kellas, 2010), and social behavior (e.g., Frisby \& Martin, 2010; Riesch, Anderson, \& Krueger, 2006). With the exception of Floyd and Morman (e.g., 1999; 2000; 2002; 2003; 2005; 2006), previous communication research has given limited attention to the act of fathering and virtually no attention to the impact of fathers' communication on sons' gender ideologies.

These trends are perplexing considering the severe consequences of males' perpetuation of traditional masculine values in our society (e.g., Eisler, Skidmore, \& Ward, 1988; McCreary \& Sasse, 2000; Reidy, Shirk, Sloan, \& Zeichner, 2009) and the positive outcomes associated with androgyny and femininity (e.g., Heilbrun, 1981; Hirokawa, Yagi, \& Miyata, 2004; Stake, 1997). To fill the gap, the purpose of this study was to explore father-son communication patterns and gender ideologies. Such exploration meets the following objectives: to (a) determine the specific messages that fathers transmit to their sons' regarding masculinity,

femininity, and androgyny; (b) assess the association between fathers' and sons' communication patterns and gender ideologies through the modeling and compensation hypotheses; and (c) ascertain a relationship between sons' gender ideologies and global satisfaction with life.

\section{Review of Literature}

The family represents one of the most influential institutions in society, especially in 
regard to family members' communication (Koerner \& Fitzpatrick, 2002b). There are three reasons for this. First, interactions with family members are individuals' first social interactions and it is through these initial interactions that children learn values and norms for family and nonfamily interactions (Berger \& Luckman, 1966). Second, families are characterized by their uniquely shared worldviews, values, and belief systems that define members' social environments (Reiss, 1981). Third, intentionally or unintentionally, family members communicate to and adopt from one another the communication styles, values, worldviews, and behaviors that are expected and accepted in society. The family's profound influence on its members is perhaps best evidenced through the enduring parent-child bond.

\section{Parent-Child Relationships}

The parent-child relationship has an extensive history that encompasses the qualities parents bring to the family based on their upbringing and the aspirations they formulate for their unborn children (Rossi \& Rossi, 1990). Because of this history, no other adult figures are as important to children as their parents; thus, children are more likely to bring their parents' genes, personalities, values, and parenting styles into adulthood than to bring those of any other adult in their lives (Rossi \& Rossi, 1990). It seems then, without the bond of a parent, children lack substantial role models from which to solicit support and use as guides for navigating the social world. In addition, strained relationships between parents and children lead to psychological distress for adult children (Umberson, 1992). Because families share worldviews and values and the presence of parents greatly impacts children, it is important to study the transmission of values from parents to children and the links between such values and children's satisfaction.

Although the majority of parent-child research highlights mothers' powerful influence on their children (e.g., Chodorow, 1978, King, Abrams, Dowling, \& Brinich, 2009), fathers' 
profound and unique role warrants further investigation. The "changing culture of fatherhood" (Morman \& Floyd, 2002, p. 400; Daly, 1995), which is characterized by more involved, nurturing, and affectionate fathers, has altered the patterns of parent-child influence within the family (Lamb, 2010; Lamb \& Lewis, 2010) and might be the impetus for researchers' increased, albeit gradual, focus on fathers. Pleck (2010) described fathers' influence on their children in terms of two hypotheses: the essential father (i.e., fathers make a unique, masculine contribution to child development) and the important father (i.e., good fathering, like good mothering, promotes good child outcomes) hypotheses. Although findings in support of these hypotheses (e.g., Easterbrooks \& Goldberg, 1984; Peck, 1996; Silverstein \& Auerbach, 1999; Sarkadi, Kristiansson, Oberklaid, \& Bremberg, 2007) demonstrate the importance of involved fathers, they do little to articulate "good" and "bad" fathering or the specific communication behaviors that promote positive personal and relational health for fathers and their children.

Much of father-child research has analyzed fathers' influence based on their level of involvement and the type of play they engage in with their young children. Fathers typically specialize in boisterous, physical play (i.e., rough housing), similar to the play preschool-aged children engage in with their peers (Lindsey \& Mize, 2001). Because children view this play as novel and recreational, they crave and cherish the time spent with their fathers. Although physical play becomes less salient as children grow older (Crawley \& Sherrod, 1984), fathers continue to fulfill a unique parenting role as children with highly-involved fathers have high cognitive competence and empathy, fewer sex-stereotyped beliefs, and more internal locus of control, which leads to sons displaying more emotions, compassion, gender-neutral views, and prosocial behaviors (Pleck, 2010; Pruett, 1983). Father engagement has also been shown to reduce behavioral problems in boys and psychological problems in girls, enhance cognitive 
development, and decrease delinquency and economic disadvantage in low socio-economic families (Sarkadi et al., 2007). Boys with involved fathers also express more feelings of vulnerability, warmth, and fear, and fewer feelings of aggression and competitiveness (Brody, 1997; 2001).

In addition to the general finding that highly involved fathers fulfill essential and influential functions as their children's playmates (Lamb, 2010), some scholars have demonstrated specific ways that fathers positively influence children through their communication styles. When fathers, as compared to mothers, talk to their children, they use more directives (i.e., commands; utterances; requests for clarification; what, where, when, and why questions; and references to past events), which help children learn appropriate communicative behaviors for the outside world's social exchanges (Leaper, Anderson, \& Sanders, 1998). Such exchanges are also fostered through sensitive fathering (i.e., responding to, talking to, supporting, and encouraging children to learn) that contributes to children's social, emotional, and cognitive wellbeing (Easterbrooks \& Goldberg, 1984). Based on their functions as roles models, it is difficult to deny the importance of fathers in children's lives.

\section{Father-Son Communication}

Although many scholars (e.g., Lamb, 2010; Lamb, Frodi, Hwang, \& Frodi, 1983; Lindsey

\& Mize, 2001) have researched the impact of father-child relationships on children's wellbeing and general behaviors, fewer have researched the influence of fathers on sons' development. Scholars who have analyzed this unique dyad, most of whom are psychology scholars, have discovered that the father-son relationship is responsible for many noteworthy outcomes in men's lives. For example, Vogt and Surridge (1991) claimed that:

One very key element in the formation of men's relationships is the relationship 
between son and father...this relationship influences everything in a man's life, from the way he sees himself inside to the way he sees all other people, power, economics, politics, and even his vision of the natural world. (p. 6)

In fact, it is through this relationship that sons learn to be masculine as sons find it difficult to acquire masculine qualities from their mothers because of the sex difference (Mussen \& Distler, 1960). However, when fathers assume nurturing roles, sons show more caring behaviors toward friends and siblings and are more comfortable resisting traditional masculine norms, yet are also able to maintain strong feelings of self-acceptance and a confident selfidentity (Pruett, 1983). In addition, positive father-son relationships have been positively associated with sons' academic achievement (Singer \& Weinstein, 2000), adult development and psychosocial adjustment (Snarey, 1993), comfortable relational interaction (Beatty \& Dobos, 1993), emotional health (Berry, 1990), and supportive parenting when they become fathers (Simons, Beaman, Conger, \& Chao, 1993), a line of research this study seeks to advance. This previous research demonstrates fathers' influence on sons' personality and wellbeing but only superficially examines the role of communication.

The limited research focusing on communication within the father-son dyad has not approached this topic from the perspective that fatherhood is a unique, male experience strongly influenced by historical, social, economic, and political factors (Morman \& Floyd, 2006). Rather, most scholars have investigated fathers' communication with their sons and daughters simultaneously (e.g., Martin \& Anderson, 1995; 1997; Petronio \& Bradford, 1993; Wright, 2009), compared fathers' and mothers' communication with their sons (e.g., Horan, Houser, \& Cowan, 2007), or examined the association between sons' romantic relationship dynamics and their fathers' communication during childhood (e.g., Beatty \& Dobos, 1993a; 1993b). This body 
of scholarship has left many openings for researchers to investigate ideal communication within father-son relationships and the role both men play in fatherhood.

Floyd and Morman (e.g., 2000; 2003; 2005; Morman \& Floyd, 1999; 2002; 2006) have dedicated a considerable amount of research to the act of fathering and its associated standards and communication. Their research has uncovered: (a) major themes of love, availability, listening, affection, involvement, support, and role modeling in father-son messages about what it means to be a good father (Morman \& Floyd, 2006); (b) that fathers report being highly affectionate with their sons, while sons report receiving less affection from their fathers in the presence of brothers and sisters (Floyd \& Morman, 2005); and (c) the positive outcomes (i.e., father-son self-disclosure, closeness, and relational satisfaction) associated with affectionate communication between fathers and sons (Floyd \& Morman, 2003; Morman \& Floyd, 1999). In light of Floyd and Morman's good fathering messages and Pleck's (2010) essential father hypothesis (i.e., fathers contribute a unique, masculine influence on children), extending this research to father-to-son communication of gender ideologies is a logical next step.

\section{Gender Ideologies}

Gender ideologies are large, cultural belief systems or attitudes (Colaner \& Warner, 2005) that influence individuals' enactment and evaluations of others' gendered behavior. Gender ideologies are broader forms of gender roles, which Bem (1993) described as recurring patterns of behavior that individuals are expected to enact based on masculine, feminine, or androgynous traits. Because gender roles are typically based on gender ideologies, the current study focuses on the broader belief systems in order to understand the motivations behind fathers' gendered communication and behavior.

The three primary gender ideologies are traditional masculinity, traditional femininity, 
and androgyny. Traditional masculinity is characterized by attributes such as strength, toughness, competiveness, protectiveness, aggressiveness, decisiveness, excessive risk-taking, individualism, courage, and emotional ineptness (Scott-Samuel, Stanistreet, \& Crawshaw, 2009). Emotional ineptness, a critical element of masculinity in regard to communication, can also be described as a restriction of emotions (Levant, Wimer, Williams, Smalley, \& Noronha, 2009) or discomfort with disclosing feelings in discussions with others (Mahalik et al., 2003). Traditional masculinity also requires men to dominate and appear superior to subordinate men and women (Connell \& Messerschmidt, 2005). Traditional femininity is characterized by physical attractiveness, deference, dependence, purity, caretaking, and emotionality (Levant, Richmond, Cook, House, \& Aupont, 2007). Although men are typically taught to value masculinity and women are taught to value femininity, as far back as the early 1970 s, both sexes have adopted more flexible, androgynous gender ideologies that incorporate both masculine and feminine characteristics (Bem, 1974). These androgynous individuals, who represent the third gender ideology, have liberated their personalities and cognitions from rigidly assigned, stereotypical sex roles and culturally imposed definitions of masculinity for males and femininity for females (Bem, 1974; Heilbrun, 1986). In turn, androgynous males and females are simultaneously tough and tender, brave and timid, and commanding and sensitive.

Gender socialization. Although gender is taught through a number of channels including the media, peer relations, interactions with teachers and coaches (Leaper \& Friedman, 2007), religious institutions (Colaner, 2009), and organizations (Duckworth \& Buzzanell, 2009), it is through family communication that children first learn about gender (Leaper \& Friedman, 2007; Medved, Brogan, McClanahan, Morris, \& Shepherd, 2006). As Bruess and Pearson (1996) said, "to understand the family is to understand the deeply embedded meanings of gender 
continuously communicated by parents" (p. 70). Parents directly and indirectly teach children which gender roles are expected and valued in the family and society. This teaching may be specific instructions to assume a particular gender role instead of another role or rewarding certain gendered behaviors over other behaviors (e.g., girls may receive rewards for participating in household chores, while boys may receive rewards for excelling at physical sports). Other forms of gender communication are evidenced by the toys parents give their children, the decorations they hang in their children's rooms, or the clothes in which they dress their children (Pomerleau, Bolduc, Malcuit, \& Crossette, 1990; Shakin, Shakin, \& Sternglanz, 1985). From as early as preschool, children can differentiate between the stereotyped roles of their parents as children typically say mothers are responsible for childcare and housework, and fathers are responsible for supporting the family financially (Lamb \& Lewis, 2010). Although it is evident that gender ideologies are transmitted through family interactions, much is still unknown about the role of fathers' communication on sons' gender ideologies and the link between gender ideologies and wellbeing.

Gender ideologies and wellbeing. Although gender ideologies are inherent in individuals' self-concepts, beliefs, social interactions, and experiences (Leaper \& Friedman, 2007), research regarding the influence of gender ideologies on wellbeing and satisfaction has been inconsistent. Compared to femininity and androgyny, masculinity has been the most widely studied gender ideology and has been associated with both positive and negative outcomes and mental wellbeing. Scholars have associated many more positive outcomes with femininity and androgyny but have yet to establish a direct link between wellbeing and femininity. The various positive and negative outcomes associated with each gender ideology are explained here. 
First, masculinity and femininity have been linked to negative consequences for men and those with whom they interact. Morman and Floyd (2002) described the father-son relationship as the most socially significant same-sex relationship in men's lives, yet they recognized that this relationship is often burdened by conflict, competition, aggression, and emotional distance due to societal pressures placed on men to assume traditional masculine roles. In fact, compared to their female or less masculine male counterparts, highly masculine males commit more aggressive, harmful, and violent acts (Brownmiller, 1975; Reidy, Shirk, Sloan, \& Zeichner, 2009; Thompson, 1991); experience higher levels of stress and anger (Eisler et al., 1988); engage in high-risk sexual activity (Pleck, Sonenstein, \& Ku, 1993); possess a fear or distaste for gay men (Stark, 1991); and practice poor physical health care (Courtenay, 2000). Moreover, masculine gender role stress (i.e., social pressure to be masculine) has been associated with greater use of tobacco, alcohol, and illegal drugs (McCreary, Newcomb, \& Sadava, 1999), lower self esteem and higher depression (McCreary \& Sasse, 2000), and decreased relational satisfaction with female partners (Burn \& Ward, 2005). Femininity has also been associated with negative outcomes such as reciprocation of negative behaviors among husbands and wives (Sayers \& Baucom, 1991) and communication apprehension (Pearson \& Turner, 1982).

Second, masculinity, androgyny, and femininity have been linked to positive outcomes. The traditional masculinity ideology has been positively related to men's organizational commitment (Gelade, Dobson, \& Auer, 2008), marital satisfaction (Baucom \& Aiken, 1984), satisfaction in social interactions (Thompson \& Whearty, 2004), and mental health (Bassoff \& Glass, 1982). It is possible that men perceive their embodiment of traditional masculinity to be rewarding insofar that being dominant and competitive affords them higher paying jobs, power over relational partners, and admiration from other men, all of which may leads men to feel 
secure about themselves. Androgyny has also been associated with positive outcomes, such as effective communication and stress-coping skills (Hirokawa et al., 2004; Stake, 1997), empathy and cognitive complexity (Heilbrun, 1981), resourcefulness and adaptability in social interactions (Berzins, Welling, \& Wetter, 1978), and high self-esteem (Spence, Helmreich, \& Stapp, 1975). Femininity has been linked to the preservation of relational partners' feelings and withholding negative evaluations (Kim \& Aune, 1997), which helps individuals' maintain relationships over time. However, in their meta-analysis of 26 studies on sex roles, Bassoff and Glass (1982) were unable to uncover a relationship between femininity and mental health. Because the influence of gender ideologies on wellbeing and satisfaction levels is unclear, the following research question is posed:

RQ1: What type of relationship, if any, exists between sons' global satisfaction with life and sons' identification with the masculinity, androgyny, or femininity gender ideologies?

Fathers' changing gender ideologies. Although masculinity has been associated with a few positive outcomes and it continues to pervade American culture, there is evidence that fatherhood grows less gendered with the passing of time. The "changing culture of fatherhood" (Morman \& Floyd, 2002, p. 400; see also Daly, 1995) suggests that today's fathers are becoming more nurturing, loving, and involved in raising their children. In addition, Morman and Floyd (2002) found that fathers reported more closeness, relational satisfaction, and affection with their sons than with their own fathers. This suggests that sons would be more likely to adopt more flexible gender ideologies compared to their fathers; thus, the following hypotheses are posited:

H1: As perceived by sons, fathers' identification with the traditional masculinity gender ideology is greater than sons' identification with the traditional 
masculinity gender ideology.

H2: As perceived by sons, fathers' identification with the androgyny gender ideology is less than sons' identification with the androgyny gender ideology.

H3: As perceived by sons, fathers' identification with the traditional femininity gender ideology is less than sons' identification with the traditional femininity gender ideology.

As previously mentioned, there is evidence that fathers influence their sons' communication and gender ideologies, the ideologies are associated with both positive and negative outcomes, and fathers' role is shifting. Thus, an investigation of father-to-son transmission of gender ideologies may be fruitful as findings could clarify the benefits to each gender ideology and provide tools to help more men and their partners experience positive, healthier, and satisfying lives.

\section{Memorable Messages}

There are two distinct perspectives to consider when examining father-to-son transmission of gender ideologies. The first perspective involves the use of memorable messages to assess specific and punctual forms of communication. Knapp, Stohl, and Rearson (1981) defined memorable messages as recalled and prescriptive messages transmitted in private settings from respected elders. Memorable messages are not limited to explicit verbal statements, as they may also include any meaningful communicative act that has had a significant impact on another person (Knapp et al.). These messages are highly regarded and enduring because they typically come from individuals with higher status and more relational power than the recipient, contain information or advice that is personally relevant to the recipient, and elicit changes in recipients' cognitions and behaviors (Holladay, 2002; Knapp et 
al; Stohl, 1986). In the last 30 years, many scholars have demonstrated the effectiveness of analyzing memorable messages to uncover specific communication behaviors, values, and beliefs related to aging (Holladay, 2002), gendered experiences of first-year university faculty (Dallimore, 2003), organizational socialization (Barge \& Schlueter, 2004; Stohl, 1986), coaching (Kassing \& Pappas, 2007), and breast cancer prevention and detection (Smith et al., 2009). Most notable for the current study are the memorable messages transmitted within the family. Because older adults typically pass memorable messages to younger generations (Knapp et al. 1981), several scholars have investigated the messages parents transmit to their children that have influenced children's worldviews, behaviors, and personal relationships. Although some scholars who have investigated parent-child memorable messages did not intend to uncover gendered messages, by asking parents to recall messages they shared with their children regarding mothering (Heisler \& Ellis, 2008), work and family (Medved et al., 2006), romantic relationships (Koenig Kellas, 2010), and fathering (Morman \& Floyd, 2006), scholars have demonstrated how parents' memorable messages socialize children about gender.

Specifically, mothers' memorable messages about being a good mother, such as "good mothers listen to their kids and dialogue with them," "because [being a good mother] is expected," and "good moms stay home with their kids" (Heisler \& Ellis 2008, p. 453) help shape the "mommy identity" (Heisler \& Ellis, 2008, p. 465) of future mothers and reinforce the traditional femininity ideology. Memorable messages related to gender roles, work, and family, such as "choose a job that you can easily spend time with family," "have a career and be established before you start a family," and "you can be a mom and have a career" (Medved et al., 2006, pp. 171-172), demonstrate parents' desire to raise androgynous children who value both work and family. In addition, mothers' memorable messages about love and romance, such as 
"do not have sex before marriage," "find someone who has similar goals and aspirations as you," and "marry a rich man" (Koenig Kellas, 2010, pp. 468-469), demonstrate mothers' transmission of both androgyny and femininity values. Further, Morman and Floyd (2006) uncovered fathers' and sons' memorable messages about being a good father (although they did not refer to them as memorable messages), such as "[a good father] provides authority, leadership, control, determines the rules," "[a good father] is responsible, committed to fathering, reliable, [and a] good provider," and "a good father loves his son and communicates to him that he loves him" (p. 122). These messages suggest that ideal fathering includes all three gender ideologiesmasculinity, femininity, and androgyny. Because gender ideologies have been subtly embedded in previous scholars' studies of memorable messages in the family, the following research question is forwarded:

RQ2: What types of memorable messages are communicated from fathers to sons regarding gender ideologies?

\section{Family Communication Patterns}

The second perspective to consider when examining fathers' transmission of gender ideologies to their sons involves family communication patterns. As compared to specific, memorable messages, these communication patterns represent more global and recurring forms of communication. According to the general theory of family communication (Koerner \& Fitzpatrick, 2002a), family communication patterns consist of two orientations: conformity and

conversation. Based on research conducted by Chaffee, McLeod, and Atkin (1971), Ritchie and Fitzpatrick (1990) conceptualized these orientations as central beliefs or norms governing relational communication in families.

Conformity orientations. Conformity orientations create environments in which 
children are encouraged to overtly obey parental authority (Ritchie \& Fitzpatrick, 1990). In these environments parents tell children what to believe and how to view the world and children accept their parents' views without question or argument (Ritchie, 1988). Families high in this orientation stress homogeny of attitudes, values, and beliefs; avoidance of conflict; interdependence of members; and obedience to parents and other familial adults (Koerner \& Fitzpatrick, 2002a).

Although Koerner and Fitzpatrick (2002a) and Ritchie and Fitzpatrick (1990) hesitated to deem one orientation superior, the negative outcomes associated with the conformity orientation imply the discouragement of this orientation. High conformity orientations have been negatively associated with children's interpersonal skills in romantic relationships (Koesten \& Anderson, 2004), parental confirmation and affection (Schrodt, Ledbetter, \& Ohrt, 2007), and parents' and children's use of constructive conflict management skills (Koerner \& Fitzpatrick, 1997). Further, high conformity orientations have been positively associated with children's aggressive behavior outside of the home, as well as between the child and other family members, such as parents and siblings (McLeod, Atkin, \& Chaffee, 1972), communication apprehension and reticence (e.g., Elwood \& Schrader, 1998; Kelly et al., 2002), conflict avoidance (Koerner \& Fitzpatrick, 1997), perceived stress and low self-esteem (Schrodt et al., 2007), and weak selfconcepts (Sillars, Koerner, \& Fitzpatrick, 2005).

The current study seeks to uncover an association between conformity orientations and the traditional masculinity ideology. As mentioned previously, traditional masculinity is built on the premise that males should dominate females and subordinate males, refrain from showing emotion, be rational and decisive, demonstrate strength and toughness, and be competitive and aggressive. Similarly, conformity orientations are based on a hierarchical family structure with 
closed or one-way communication through which parents assume dominant positions, dictate children's values and beliefs, make all decisions for the family unit, and forbid children to express their individual ideas or feelings. It seems likely that conformity orientation parents would also exhibit physical and mental strength to maintain power over their children, especially when their children resist and disobey orders. To that end, traditional masculinity and conformity orientations share common themes of control, dominance, and restricted emotions.

Support for the proposed association between the conformity orientation and traditional masculinity ideology can be inferred in Colaner's (2009) study. Colaner found that Evangelical parents who endorsed a complementarian family gender role ideology (i.e., the man is considered the head of the household and holds ultimate authority in family matters) were likely to use the conformity orientation in their families. Because the complementarian ideology is similar to traditional masculine qualities, the following hypothesis is forwarded:

H4: As perceived by sons, a positive relationship exists between fathers' conformity orientations and sons' enforcement of the traditional masculinity gender ideology with their own sons.

Conversation orientations. Conversation orientations create environments in which children are encouraged to openly express autonomous opinions and ideas (Ritchie \& Fitzpatrick, 1990). In these environments children are encouraged to question others' views in order to arrive at an understanding of the world through discussion and reasoning (Ritchie, 1988). Families high in this orientation frequently and spontaneously engage in unrestrained interactions with one another, discuss a wide array of topics, and make decisions as a family unit (Koerner \& Fitzpatrick, 2002a). Parents who promote high conversation orientations believe open dialogue is a means for educating and socializing their children (Koerner \& Fitzpatrick, 
2002a). Unlike conformity orientations, many positive outcomes have been associated with conversation orientations, such as interpersonal competence and the ability to adapt to changing environments (Koesten \& Anderson, 2004), high self-esteem, low perceived stress, and overall wellbeing (Schrodt et al., 2007), interpersonal satisfaction between fathers and daughters (Punyanunt-Carter, 2008), and adult children's romantic relationship maintenance (Fowler, Pearson, \& Beck, 2010).

The current study seeks to reveal an association between conversation orientations and the androgyny ideology. As aforementioned, androgyny is based on a rejection of strict masculine and feminine roles insofar that androgynous individuals adopt a blend of both gendered behaviors and respect others' gender values. Similarly, conversation orientations are based on a less rigid and hierarchical family structure and two-way communication environments in which there is open and frequent communication between adults and children, who are treated as equal family members with valuable ideas. To that end, conversation orientation parents would likely encourage both male and female children to express their feelings and ideas and participate in a wide range of family decisions and activities.

Support for the proposed association between the conversation orientation and androgyny ideology can be inferred in Colaner's (2009) study. Colaner found that Evangelical parents who endorsed an egalitarian family gender role ideology (i.e., men and women are considered equal in family interactions and decisions) were likely to use the conversation orientation in their families. Because the egalitarian ideology is similar to androgynous qualities, the following hypothesis is forwarded:

H5: As perceived by sons, a positive relationship exists between fathers' conversation orientations and sons' enforcement of the androgyny gender ideology with their 
own sons.

In accordance with the proposed associations between the conformity and conversation orientations and traditional masculinity and androgyny ideologies, respectively, the current study also aims to investigate the relationship between family communication patterns and the traditional femininity ideology. However, because past research has demonstrated femininity to be associated with a range of communication behaviors, such as preservation of partners' feelings (Kim \& Aune, 1997), communication apprehension (Pearson \& Turner), and reciprocation of negative behaviors between husbands and wives (Sayer \& Baucom, 1991), it is difficult to hypothesize a relationship between this gender ideology and family communication patterns. On the one hand, femininity may be associated with conformity orientations because this gender ideology encourages obedience, submissiveness, and powerlessness. However, it seems unlikely that conformity orientation fathers would enact feminine behaviors themselves; rather, their enforcement of conformity orientations might result in their children demonstrating feminine behaviors to respect and comply with their parents. On the other hand, femininity may be associated with conversation orientations because this gender ideology encourages nurturance, emotional expression, and relational maintenance. Thus, it would seem that feminine individuals would encourage conversation orientations in their families in order to maintain open communication and close relationships. Because a definitive prediction cannot be asserted regarding the association between family communication patterns and the traditional femininity ideology, the following research questions are posed to illuminate any potential relationship involving this third, relatively underexamined, gender ideology:

RQ3: What type of relationship, if any, exists between fathers' conformity orientations and sons' enforcement of the femininity gender ideology with their own sons? 
RQ4: What type of relationship, if any, exists between fathers' conversation orientations and sons' enforcement of the femininity gender ideology with their own sons?

In addition to investigating the links between the conformity and conversation orientations and fathers' enforced gender ideologies, the current study focuses on sons' acceptance or rejection of these communication patterns and gender ideologies. Specifically, the transmission of these communication patterns and gender ideologies are examined across three generations of fathers and sons.

\section{Modeling and Compensation Hypotheses}

The process of purposively or unintentionally relaying parenting attitudes and behaviors to future generations has been frequently referred to as "intergenerational transmission" (Van Ijzendoorn, 1992, p. 76). This phenomenon has been explored within many family relationships, such as grandparent-grandchild (e.g., Pratt, Norris, Hebblethwaite, \& Arnold, 2008), parent-child (e.g., Campbell \& Gilmore, 2007; Soenens et al., 2005), mother-daughter (e.g., Moen, Erickson, \& Dempster-McClain, 1997; Obegi, Morrison, \& Shaver, 2004), and father-daughter (e.g., Greenspun, 1994).

Two intergenerational transmission perspectives that have demonstrated utility in previous father-son research are the modeling and compensation hypotheses (Beaton, Doherty, \& Rueter, 2003; Floyd \& Morman, 2000). The modeling hypothesis, an enduring and prevailing view of parenting, posits that "individuals replicate the parenting styles they received in their families of origin" (Floyd \& Morman, 2000, p. 348). Modeling, which is often a natural, effortless, or even unconscious activity, has been associated with a myriad of parent-child behaviors. Moen et al. (1997) found that mothers who held traditional (or egalitarian) gender role attitudes in the 1950 s were likely to have adult daughters in the late 1980 s with more 
traditional (or egalitarian) attitudes. Similarly, fathers' constructive parenting (i.e., parenting that includes age-appropriate and consistent discipline, nurturance, involvement, supervision, and communication) of sons in the sons' late childhood predicted sons' constructive parenting of their own children in their children's early and middle childhood (Kerr, Capaldi, Pears, \& Owen, 2009). In addition, fathers and sons, as compared to mothers and daughters, are more likely to display similar parenting styles, especially when both are authoritarian rather than permissive (Campbell \& Gilmore, 2007). Although the aforementioned findings are only correlational and, thus, it cannot be assumed that modeling occurred between these parent-child dyads, these findings suggest that gender roles and authoritarian parenting styles are highly transmittable and fathers have considerable influence over sons' future child-rearing attitudes.

However, not all children model their parents' behaviors. Instead, these children reject what they have learned from their parents' behavior and engage in the opposite behavior with their own children. Floyd and Morman (2000) labeled this view the compensation hypothesis. This hypothesis posits that, "when individuals are exposed to negative parental behaviors in their families of origin, they attempt to compensate for those patterns by taking a more positive role in raising their children" (Floyd \& Morman, p. 348). As evidence of the shift in fatherhood, some sons compensate for their fathers' negative behaviors, such as psychological distance or low involvement (Beaton et al., 2003), recognizing that replicating their fathers' parenting styles is not always the healthiest choice for their own children. However, despite many fathers' desire to be better role models to their sons than their fathers were to them (Daly, 1995), few scholars have focused on the compensation perspective.

Two prominent communication scholars who have tested both the modeling and compensation hypotheses, Floyd and Morman (2000), predicted a curvilinear relationship 
between the level of affection men received from their fathers and the level of affection they give their sons. This pattern was based on the assumption that affection is a positive behavior and its presence is worth modeling (i.e., highly affectionate fathers have highly affectionate sons, which represents half of the curve) and its absence worth compensating (i.e., highly unaffectionate fathers have highly affectionate sons, which represents the other half of the curve). After controlling for the gender roles of the fathers, which is the focus of the current study, Floyd and Morman's (2000) findings offered support for both the modeling and compensation hypotheses. Sons modeled their fathers' highly affectionate communication, whereas other sons compensated for their fathers' unaffectionate communication, which resulted in affection increasing overall between fathers and sons and, then, sons with their own sons.

The modeling and compensation approaches offer considerable utility in the current context of family communication patterns. By applying Floyd and Morman's (2000) research findings to the conformity and conversation orientations, it is feasible that sons would model what they consider to be fathers' positive communication patterns and reject those they consider negative. For example, sons who value rigid structure and rules may model their fathers' conformity orientations with their own sons, while sons who value unorthodox views and variation of opinions may compensate for their fathers' conformity orientations with their own sons. Conversely, sons who value uninhibited and nonjudgmental communication may model their fathers' conversation orientations with their own sons, while sons who value introversion and reticence may compensate for their fathers' conversation orientations with their own sons. Because the current study seeks to demonstrate merit for both the modeling and compensation hypotheses as intergenerational transmission approaches, the following hypotheses are predicted:

H6: As perceived by sons, fathers' conformity orientations have a curvilinear 
relationship with sons' conformity orientations.

H7: As perceived by sons, fathers' conversation orientations have a curvilinear relationship with sons' conversation orientations.

Although children's values may affect their decision to model or compensate for their parents' behaviors (e.g., sons' conformity and conversation values outlined previously), the enactment of these transmission processes depends more so on the strength of children's identification with their parents. Identification is the extent to which individuals feel similar to or positively toward the source of a particular behavior (Bandura, 1961; Floyd \& Morman, 2000). According to social learning theory (Bandura, 1961), children are socialized through the identification process by imitating parents' attitudes and patterns of behavior, which parents typically teach by rewarding and punishing instrumental responses.

Children strongly identify with their parents for two reasons. First, children perceive adults as capable of controlling their environments; thus, they think engaging in identification will give them feelings of power over their own environments (Kagan, 1958). Second, children believe that responding with the attitudes and behaviors adults expect will lead to receiving love and affection from adults (Kagan, 1958), which are primary needs for all humans.

When children identify with or feel similar to their parents, a greater chance of modeling exists; however, if children do not identify with or feel similar to their parents, they are more likely to compensate for their parents' behavior by performing the opposite behavior (Bandura, 1961). In other words, modeling should occur only in the presence of strong identification and compensation should occur only in its absence (Floyd \& Morman, 2000). For instance, when sons identify with their fathers, sons report holding authoritarian attitudes similar to their fathers' authoritarian attitudes (i.e., modeling; Peretti \& Statum, 1984), whereas, when sons do not 
identify with their fathers, sons report expressing high affection with their sons when they received little affection from their fathers (i.e., compensation; Floyd \& Morman, 2000). If sons' level of identification with their fathers determines whether they transmit authoritarian attitudes (Peretti \& Statum, 1984) or affectionate communication (Floyd \& Morman, 2000) to future generations, it is likely that sons who identify with their fathers would also transmit, or model, their fathers' conformity or conversation orientations with future generations. Conversely, sons who do not identify with their fathers should be more likely to compensate for their father's conformity or conversation orientations and enforce the opposite orientation with their own sons. Thus, the following hypothesis is forwarded:

H8: As perceived by sons, the relationship between fathers' conformity or conversation orientations and sons' conformity or conversation orientations is mediated by sons' identification with their fathers. 


\section{CHAPTER TWO}

\section{Method}

The aforementioned review of literature highlighted the importance of father-child relationships, the influence of gender on communication and behaviors, the changing culture of fatherhood, and the gaps regarding father-son communication patterns and gender ideologies. The following method section outlines the participants, procedures, instrumentation, and analyses employed in the current study.

\section{Participants}

Participant criteria. During recruitment, the researcher specified that participants (i.e., the second generation fathers, referred to as "sons" moving forward) must be: male; at least 18 years old; have a living father (i.e., the first generation male, referred to as "fathers" moving forward); and have at least one biological, step-, or adopted son (i.e., the third generation male, referred to as "grandsons" moving forward) over the age of seven.

The current study benefited from a wide age range of fathers and sons. Fathers' ages ranged from 48 to 98 years old $(M=75.04, S D=7.96)$, sons' ages ranged from 27 to 65 years old $(M=47.95, S D=8.79)$, and grandsons' ages ranged from seven to 40 years old $(M=19.36$, $S D=7.45)$. One $(.8 \%)$ son did not report his age and five $(4 \%)$ sons did not report the grandsons' age.

One hundred and eleven (88.8\%) sons reported on biological fathers, five (4\%) reported on adoptive fathers, and four (3.2\%) reported on step-fathers, with five (4\%) non-reports. The majority of sons reported on biological grandsons $(n=116,92.8 \%)$, four $(3.2 \%)$ reported on step-grandsons, and one (.8\%) reported on an adopted grandson, with four (3.2\%) non-reports.

The majority of sons identified themselves as Caucasian $(n=111,88.8 \%)$, four $(3.2 \%)$ as 
Hispanic, four (3.2\%) as African American, two (1.6\%) as Asian, two (1.6\%) as Middle Eastern, one $(.8 \%)$ as Native American, and one (.8\%) as Cajun. One hundred and ten (88\%) sons identified their fathers' as Caucasian, four (3.2\%) as Hispanic, four (3.2\%) as African American, two (1.6\%) as Asian, two (1.6\%) as Middle Eastern, one (.8\%) as Native American, and one $(.8 \%)$ as Cajun. The majority of sons identified grandsons as Caucasian $(n=119,87.2 \%)$, four (3.2\%) as Hispanic, three (2.4\%) as African American, two (1.6\%) as Asian, two (1.6\%) as Middle Eastern, one (.8\%) as Native American, one (.8\%) as Cajun, and one $(.8 \%)$ as mixed race of White and Asian, with seven (5.6\%) non-reports.

Most sons were married to the grandsons' biological mothers $(n=85,68 \%), 18(14.4 \%)$ were divorced, $12(9.6 \%)$ were married to someone other than the grandsons' biological mother, seven $(5.6 \%)$ were single, and one $(.8 \%)$ was widowed, with two $(1.6 \%)$ non-reports. The majority of fathers were married to the sons' biological mothers $(n=73,58.4 \%), 22(17.6 \%)$ were married to someone other than the sons' biological mothers, 17 (13.6\%) were widowed, three $(2.4 \%)$ were divorced, and one $(.8 \%)$ was single.

In terms of household income, $59(47.2 \%)$ sons reported $\$ 100,000$ or more, $22(17.6 \%)$ reported $\$ 75,000-\$ 99,999,21(16.8 \%)$ reported $\$ 50,000-\$ 74,999,15(12 \%)$ reported $\$ 30,000$ $\$ 49,999$, and four $(3.2 \%)$ reported $\$ 0-\$ 29,999$. Some sons $(n=36,28.8 \%)$ reported having additional male and female biological, step-, and adopted grandchildren, who ranged in age from two to 41 years old.

Recruitment of participants. One hundred and seventy-four sons were recruited through convenience and network sampling in undergraduate, introductory communication classes at a large mid-Atlantic university, on social networking sites, and by family and friend referrals. Forty-nine questionnaires were eliminated either because sons did not meet all of the criteria $(n=$ 
$10)$, they only completed a small portion of the questionnaire $(n=6)$, or they left the entire questionnaire blank after providing their consent $(n=32)$. Thus, the recruitment efforts yielded a useable sample of 125 sons.

A considerable number of sons $(n=93)$ were recruited through undergraduate students in communication classes (see Appendix A for recruitment script). After obtaining Institutional Review Board approval, the researcher visited the classes and distributed a textual flyer that described the purpose of the study, participation criteria, instructions for obtaining the online questionnaire link, and researcher's email address. Students were instructed to give the flyer to sons who fit the participation criteria. Participating sons, then, emailed the researcher for the questionnaire link (see Appendix B for email script). This process ensured that the responses were representative of the target sample (i.e., not student responses) and confidential. The last question of the survey asked sons to provide the name and course number for the student who referred them to the study so the researcher could assign extra credit accordingly. The students' and sons' names were never connected to one another and the questionnaires were completely anonymous.

After collecting data from sons recruited via communication classes, the researcher recruited through social networking sites $(n=14)$, as well as family and friend referrals $(n=18)$. To recruit through social networking sites, the researcher posted a message on her personal Facebook page (see Appendix C Facebook recruitment script) and, following permission from site moderators, on various parenting websites and discussion forums ${ }^{1}$ (see Appendix D for website and forum recruitment script). To recruit through family and friends, the researcher distributed personal emails to qualified fathers in her social network (see Appendix E for email script). The researcher included the link to the online questionnaire in each recruitment script 
and email that was disseminated.

\section{Procedures}

All sons completed a 40-minute, confidential, online questionnaire that assessed the variables of interest and demographics (see Appendix F for full questionnaire). To standardize responses, sons were instructed to report on the oldest grandson. Before beginning the questionnaire, sons read a consent form and provided their consent by checking a box at the bottom of the form.

\section{Instrumentation}

The specific properties of the instruments used to measure the current study's variables are discussed below. Following several data cleaning procedures (i.e., exploratory factor analysis $^{2}$, tests of skewness and kurtosis ${ }^{3}$, and item-by-item reliability assessment), all instruments were considered normally distributed, consistent, and reliable unless otherwise noted. All instruments were based on a 5-point, Likert scale, ranging from strongly disagree (1) to strongly agree (5), with higher scores representing stronger endorsement of the measured construct. When necessary, instruments were modified to address the father-son-grandson ${ }^{4}$ context. The means, standard deviations, and Cronbach's alphas for each instrument appear in Table 1.

Masculinity. The Male Role Norms Inventory-Revised (MRNI-R; Levant et al., 2007), a 7-factor, 53-item scale, was designed as a composite measure of individuals' traditional masculinity ideology. Examples of the MRNI-R's items include: "Men should excel at contact sports," "A man should never admit when others hurt his feelings," and "A man must be able to make his own way in the world." The MRNI-R has been shown to produce a variety of Cronbach's alphas, such as .96 for both sexes combined on the whole scale, .75 or above for both 
sexes combined on each subscale, and .94 for women and .95 for men on the whole scale (Levant et al., 2007). In their study of masculinity and attitudes toward seeking psychological help among college men, Levant, Wimer, and Williams' (2011) alphas for the subscales and total scale ranged from .83 to .97 .

For this study, each item on the MRNI-R (Levant et al., 2007) was applied to three sets of questions. The first set of questions asked sons to report on their perceptions of their fathers' masculinity values. The second set of questions asked the sons to report on their own masculinity values. The third set of questions asked if sons intend to or have already passed this value onto the grandsons.

Femininity. The Femininity Ideology Scale (FIS; Levant et al., 2007), a 5-factor, 45-item scale, was designed as a composite measure of individuals' traditional femininity ideology. Examples of the FIS's items include: "A man should not make more money than his partner," "Men should be gentle," and "It is expected that men will not think logically." From a sample of 407 male and female undergraduates, Levant et al. (2007) obtained a Cronbach's alphas of .93 for the total scale, .89 for the stereotypic image and activities subscale, .83 for the dependence/deference subscale, .85 for the purity subscale, .80 for the caretaking subscale, and .82 for the emotionality subscale. Each item on the FIS scale was applied to the same three sets of questions (i.e., fathers' values, sons' values, and transmission of values to grandsons) as the MRNI-R (Levant et al., 2007).

Androgyny. Sons' and their fathers' androgyny gender ideologies were measured by a 19-item scale created specifically for this study. The items were inspired by words and phrases used on the MRNI-R (Levant et al., 2007), Femininity Identity Development Scale (FIDS; Fischer et al., 2000), and Bem Sex-Role Inventory (BSRI; Bem, 1974), each of which is based 
on research of gender identity, norms, and equality. Examples of this scale's items include: "Society should not look down on people for doing activities that are traditionally performed by the other sex," "Both sexes can be assertive," and "Both sexes can participate in housework." The reliability of the MRNI was previously addressed, Fischer et al. (2000) demonstrated convergent and discriminant validity of the FIDS, and the reliability of the BSRI's (Bem, 1974) androgyny scores calculated for two different samples were .85 and .86 . As with the MRNI-R (Levant et al., 2007) and FIS (Levant et al., 2007) scales, each item on the androgyny scale was applied to three sets of questions (i.e., fathers' values, sons' values, and transmission of values to grandsons).

Memorable messages. One open-ended question assessed the messages fathers transmit to sons regarding gender ideologies. Following instructions used by Koenig Kellas (2010), the question asked sons to recall and type a message that their fathers' communicated to them, had a lasting impression on them, and reflected their fathers' explanation for how to "be a man." The instructions provided a few examples (e.g., "Boys do not cry when they get hurt" and "Real men show their love for their families") to illustrate what a memorable message might entail, but sons were advised not to let these examples limit their own messages. The instructions also mentioned that recalling a memorable message did not imply that the participants took their fathers' advice or that the messages were positive, negative, or neutral.

After writing a memorable message, sons rated six items (e.g., "My son will be better off not learning this memorable message about masculinity" and "I will be sure to deliver this memorable message to my son") to report the extent to which they intend to pass the messages they wrote onto the grandsons. Although this scale was originally used in Koenig Kellas' (2010) study of mother-daughter memorable messages of worldviews, no reliability assessment was 
reported.

Family communication patterns. The Revised Family Communication Patterns (RFCP) Instrument (Ritchie \& Fitzpatrick, 1990) includes 17 items (e.g., "I can tell my parents almost anything" and "My parents encourage me to express my feelings") to assess conversation orientation and 11 items (e.g., "My parents feel that it is important to be the boss" and "When I am at home, I am expected to obey my parents' rules") to assess conformity orientation.

In the RFCP's first use, Ritchie and Fitzpatrick (1990) reported Cronbach's alphas for children in 7 th, 9 th, and 11 th grade and their parents ranging from .67 to .81 for the conversation orientation and .76 to .83 for the conformity orientation. Although the lowest alpha reported for the conversation orientation was initially below .70, Ritchie and Fitzpatrick reported the scale's internal consistency and test-retest reliability coefficients in a range of .73 to .93 for conversation orientation and close to 1.0 for conformity orientation.

Other family communication researchers have consistently reported Cronbach's alphas similar to, or even higher than, those reported by Ritchie and Fitzpatrick (1990). Schrodt et al. (2007) reported Cronbach's alphas of .91 for conversation orientation and .78 for conformity orientation in their study of family communication patterns and children's mental wellbeing, Punyanunt-Carter (2008) reported Cronbach's alphas of .93 for conversation orientation and .86 for conformity orientation in her study of family communication patterns and father-daughter interpersonal satisfaction, and Ledbetter (2010) reported Cronbach's alphas ranging from .91 for conversation orientation and .84 for conformity orientation in his study of family communication patterns and communication competence.

Similar to the layout of the MRNI-R, androgyny scale, and FIS, each item on the RFCP (Ritchie \& Fitzpatrick, 1990) was applied to two sets of questions to assess fathers' and sons' 
communication patterns. Each item on the scale was adapted to reflect the appropriate generation (e.g., "I could tell my father almost anything," and "I encourage my son to express his feelings"). Based on the researcher's exploratory factor analyses and reliability tests, one conversation orientation and two conformity orientation items were eliminated from the version of the RFCP for which sons were the target and one conformity orientation item was eliminated from the version of the RFCP for which fathers were the target ${ }^{5}$.

Identification with fathers. The Identity Fusion scale (Swann, Gomez, Seyle, Morales, \& Huici, 2009), a single item pictorial measure, was designed to measure individuals' perceived relationship with a particular group based on the degree to which two circles symmetrically overlap in a series of five Venn diagrams. Each of the five diagrams represents a point on the scale. The low end of the scale, represented by circles that do not overlap at all, designates a disconnected relationship with another person or group, while the high end of the scale, represented by circles that overlap completely, designates an inseparable relationship with another group. Swann et al. (2009) conducted five preliminary studies and three experiments to ensure that completion of the scale reflected verbal measures of identification, a unique state of oneness with a group that is entirely distinct from non-identification. In the current study, the Identity Fusion scale measured sons' identification with their fathers in terms of the degree of similarity sons feel with their fathers.

Satisfaction with life. Unlike other satisfaction scales that measure a general physical or emotional state, the Satisfaction with Life Scale (SWLS; Diener, Emmons, Larsen, \& Griffin, 1985) measures participants' global, more abstract, and more meaningful life satisfaction. The scale includes five items, such as "In most ways my life is close to my ideal" and "So far I have gotten the important things I want in life." The mean Cronbach's alpha across 76 studies 
utilizing the SWLS was .78 (Vassar, 2008).

Table 1

Means, Standard Deviations, and Cronbach's Alphas for Instruments

\begin{tabular}{llll}
\hline Instrument & $M$ & $S D$ & $\alpha$ \\
\hline Male Role Norms Inventory (MRNI-R) & 3.38 & .60 & .96 \\
$\quad$ Fathers & 2.98 & .56 & .96 \\
$\quad$ Sons & 3.06 & .61 & .96 \\
$\quad$ Transmission to Grandsons & & & \\
Femininity Ideology Scale (FIS) & 2.47 & .27 & .81 \\
$\quad$ Fathers & 2.48 & .24 & .79 \\
$\quad$ Sons & 2.61 & .36 & .90 \\
$\quad$ Transmission to Grandsons & & & \\
Androgyny Scale & 3.61 & .63 & .93 \\
$\quad$ Fathers & 4.06 & .45 & .91 \\
$\quad$ Sons & 4.04 & .45 & .91 \\
$\quad$ Transmission to Grandsons & 3.92 & .99 & .93 \\
Memorable Messages & & & \\
Revised Family Communication Patterns (RFCP) & & & \\
$\quad$ Conformity Orientation & 3.20 & .60 & .85 \\
$\quad$ Fathers & 2.61 & .51 & .80 \\
$\quad$ Sons & & & \\
Conversation Orientation & 2.47 & .68 & .93 \\
$\quad$ Fathers & 3.17 & .37 & .83 \\
$\quad$ Sons & 2.92 & .98 &.-- \\
Identity Fusion & 3.57 & .83 & .88 \\
Satisfaction with Life & & & \\
\hline
\end{tabular}

Note: All instruments were based on a 5-point, Likert scale, ranging from strongly disagree (1) to strongly agree (5).

\section{Analysis}

Responses to the aforementioned measures were examined to address the proposed hypotheses and research questions. RQ1 was analyzed with a Pearson product-moment correlation.

In order to answer the second research question (RQ2), sons' responses to the open-ended 
question regarding gender ideologies were coded based on the following general guidelines.

First, the researcher examined and opened-coded each response and generated categories using guidelines set forth by Corbin and Strauss (2008). From these initial categories, the researcher developed a codebook comprised of mutually exclusive and exhaustive themes and subcategories. Next, to establish intercoder reliability, the researcher solicited the help of an independent coder who was unaware of the objectives of the study. After receiving a thorough explanation of the codebook, the independent coder analyzed 10 randomly selected responses (also 10\% of all responses). The researcher individually analyzed the same 10 responses. Each response given was assigned a code, thus, if one participant provided multiple responses (i.e., messages), they were assigned multiple codes. Next, the researcher and independent coder discussed the discrepancies within their 10 responses and modified the codebook to rectify the discrepancies. Next, the researcher and independent coder separately coded 25 randomly selected responses (also 25\% of all responses). Afterward, the researcher calculated Scott's pi (1955), which yielded a reliability value of .90. Having established reliability, the researcher coded the remaining responses.

H1, H2, and H3 were analyzed with paired samples t-tests. H4, H5, RQ3, and RQ4 were analyzed with Pearson product-moment correlations. For H6 and H7, the following steps were followed to explore the relationships between fathers' and sons' communication patterns. First, the researcher conducted Pearson product-moment correlations between the orientations and gender ideologies. Second, the resulting scatter plots were examined to determine (curvi)linear relationships. Third, based on the presence or absence of (curvi)linear relationships, proper regression techniques were employed to assess the potential mediation of identification for H8. The results of these research questions and hypotheses are addressed in the following section. 


\section{CHAPTER THREE}

\section{Results}

The first research question (RQ1) asked about the type of relationships that exist between sons' global satisfaction with life and sons' identification with masculinity, androgyny, and femininity gender ideologies. Given insignificant correlations, there is no evidence to suggest any relationships exist between sons' global satisfaction with life and son's identification with the masculinity $(r=.05, p=.65)$, androgyny $(r=-.006, p=.95)$, or femininity $(r=.04, p=.71)$ gender ideologies.

The first hypothesis (H1) posited that fathers' masculinity gender ideologies would be greater than sons' masculinity gender ideologies. Because fathers' masculinity $(M=3.38 ; S D=$ $.61)$ was significantly higher than sons' masculinity $(M=2.98 ; S D=.56 ; t[100]=8.25, p<$ $.001)$, H1 was supported.

The second hypothesis (H2) posited that fathers' androgyny gender ideologies would be less than sons' androgyny gender ideologies. Because sons' androgyny $(M=4.06 ; S D=.45)$ was significantly higher than their fathers' androgyny $(M=3.61 ; S D=.63 ; t[112]=-8.89, p<$ $.001), \mathrm{H} 2$ was supported.

The third hypothesis (H3) posited that fathers' femininity gender ideologies would be less than sons' femininity gender ideologies. Because fathers' femininity $(M=2.72 ; S D=.27)$ was not significantly different from sons' femininity $(M=2.71 ; S D=.29 ; t[104]=-.69, p=.49)$, H3 was not supported.

The second research question (RQ2) sought to determine the types of memorable messages that fathers communicate to their sons about being a man. The seven themes that emerged from 103 messages, which were broken into 154 responses, included: achievement $(n=$ 
$45,29.22 \%)$, strength $(n=32,20.78 \%)$, moral conduct $(n=27,17.53 \%)$, family provider $(n=19$, $12.34 \%)$, maturity $(n=16,10.39 \%)$, enjoy life $(n=8,5.19 \%)$, and general "be a man" responses $(n=4,2.60 \%)$. Two $(1.30 \%)$ nonsensical responses that included phrases unrelated to the topic (e.g., "You will feel better about this later on, and you'll be glad that you did it" and "You talk like a man with a paper asshole") were eliminated. The percentages reported reflect the proportion of all responses provided by participants.

As previously mentioned, the memorable messages participants provided were grouped into seven themes. The achievement theme reflected both positive and negative valence of striving for success. The positive messages included the value of working diligently (e.g., "Men should work hard"), reaching individual potential No matter what you do in life, always do your best., pursuing new skills (e.g., "Always keep moving forward in your job”), being the best (e.g., "Failure is not acceptable"), and showing resilience (e.g., "Never quit, no matter how hard the task may be." The negative messages included the idea that winning does not always have to be the goal, which was demonstrated by: "Winning is not as important as how you play the game."

The strength theme reflected both positive and negative valence of demonstrating physical and emotional stamina. The positive behaviors included demonstrating physical toughness (e.g., "The men in this family are strong”), concealing weaknesses (e.g., "Real men do not show their weaknesses"), being proud of and standing up for one's beliefs (e.g., "Be true to yourself”), and facing adversity (e.g., "Men never back down from a challenge”). The negative behaviors included expressing emotions (e.g., "Real men cry and show love") and submitting to authority (e.g., "Do as you're told and you won't get in trouble”).

The moral conduct theme reflected values related to respectful and fair treatment of others, as well as qualities that would make someone an honorable person, such as showing 
integrity, faith, and serving the community. These messages included: "Do things right in life and you will be a better man," "Real men never lay a hand on women," and "Trust in God."

The family provider theme reflected both positive and negative valence of sons' responsibility to be the leader of their households. The positive behaviors were consistent with the "breadwinner" stereotype, which included sons' obligation to provide financial and emotional support to their families. Examples of this theme included: "Men should always be the head of the household," "Men should choose a career that supports their family," and "[Men] take care of their families." The negative behaviors, which were reflected in one message (e.g., "It is okay to leave your children without any father figure"), relinquished sons from their roles as involved fathers.

The maturity theme stressed self-sufficiency in the context of accomplishing tasks, not seeking support from others, as well as being responsible and making smart decisions. The messages that expressed maturity were: "[Men] take care of themselves instead of relying on others for support," "The right choices you make can make or break your future," and "Real men take care of their responsibilities."

The enjoy life theme reflected the importance of living life to its fullest, having fun, and thinking positively. Messages that communicated the enjoy life theme included: "Keep your head up," "Have no regrets," and "[A man should] play hard."

The general "be a man" responses theme reflected abstract and unexplained ideas about manhood, such as "Be a man at all times, "Son...be a man," and "To be a man is to be conflicted." These messages implied that "being a man" was universally understood and did not require elaboration.

The fourth hypothesis (H4) forwarded a positive relationship between fathers' conformity 
orientations and sons' enforcement of the traditional masculinity gender ideology with grandsons. Because there was no evidence to suggest fathers' conformity orientation were related to sons' enforcement of the traditional masculinity gender ideology with grandsons ( $r=$ $.11, p=.30), \mathrm{H} 4$ was not supported.

The fifth hypothesis (H5) forwarded a positive relationship between fathers' conversation orientations and sons' enforcement of the androgyny gender ideology with grandsons. Because there was no evidence to suggest fathers' conversation orientations were related to sons' enforcement of androgyny gender ideology with grandsons $(r=.10, p=.32)$, H5 was not supported.

The third research question (RQ3) asked about the type of relationship that exists between fathers' conformity orientations and sons' enforcement of the traditional femininity gender ideology with grandsons. Fathers' conversation orientations were not related to sons' enforcement of the traditional femininity gender ideology $(r=-.01, p=.95)$.

The fourth research question (RQ4) asked about the type of relationship that exists between fathers' conversation orientations and sons' enforcement of the traditional femininity gender ideology with grandsons. Fathers' conversation orientations were not related to sons' enforcement of the traditional femininity gender ideology $(r=.11, p=.17)$.

The sixth hypothesis (H6) predicted that fathers' conformity orientations with sons would have a curvilinear relationship with sons' conformity orientations with grandsons. Because the results of a Pearson product-moment correlation and subsequent scatter plots indicated that a moderate, positive relationship between fathers' and sons' conformity orientations $(r=.32, p=$ $.001)$ was linear in nature, H6 was not supported.

The seventh hypothesis (H7) predicted that fathers' conversation orientations with sons 
would have a curvilinear relationship with sons' conversation orientations with grandsons. Because the results of an insignificant Pearson product-moment correlation and subsequent scatter plots provided no evidence for a relationship between fathers' and sons' conversation orientations $(r=.18, p=.08), \mathrm{H} 7$ was not supported.

The eighth hypothesis (H8) forwarded that the relationship between fathers' conformity or conversation orientations and sons' conformity or conversation orientations would be mediated by sons' identification with their fathers. Because there was no evidence to confirm the mediating role of sons' identification with fathers, H8 was not supported. However, the results of a multiple regression revealed an independent contribution from each variable in that both fathers' conformity orientation $(\beta=.39)$ and identification $(\beta=.33)$ predict and account for $45 \%$ of the variance in sons' conformity orientation $(\mathrm{F}=(2,112)=14.44, p<.001)$. Because there was neither a linear nor curvilinear relationship between fathers' and sons' conversation orientations (see results of $\mathrm{H7}$ ), it was not necessary to conduct a multiple regression for the conversation orientation.

\section{Post Hoc Analyses}

Although the analysis for H4, H5, RQ3, and RQ4 revealed that family communication patterns and gender ideologies are not transmitted across three generations (i.e., fathers to sons to grandsons ${ }^{5}$ ), a series of post-hoc tests were conducted to further examine the transmission within generations (i.e., fathers to sons and sons to grandsons), as well as to address the links between family communication patterns and sons' self-reported gender ideologies.

The first post hoc analyses examined the conformity orientation and traditional masculinity gender ideology. The results of an insignificant Pearson product-moment correlation provided no evidence for a relationship between fathers' conformity orientations and sons' 
identification with the traditional masculinity gender ideology $(r=.18, p=.06)$. The results of a Pearson product-moment correlation revealed a moderate, positive relationship between sons' conformity orientations and their enforcement of the traditional masculinity gender ideology with grandsons $(r=.47, p<.001)$. The results of a Pearson product-moment correlation revealed a strong, positive relationship between sons' conformity orientations and their identification with the traditional masculinity gender ideology $(r=.64, p<.001)$.

The second post hoc analyses examined the conversation orientation and androgyny gender ideology. The results of a Pearson product-moment correlation revealed a moderate, positive relationship between fathers' conversation orientations and son's identification with the androgyny gender ideology $(r=.43, p<.001)$. The results of a Pearson product-moment correlation revealed a moderate, positive relationship between sons' conversation orientations and their enforcement of the androgyny gender ideology with grandsons $(r=.43, p<.001)$. The results of a Pearson product-moment correlation revealed a moderate, positive relationship between sons' conversation orientations and their identification with the androgyny gender ideology $(r=.46, p<.001)$.

The third post hoc analyses examined both conformity and conversation orientations and the traditional femininity gender ideology. The results of Pearson product-moment correlations provided no evidence for relationships between fathers' conformity $(r=.11, p=.27$ ) or conversation $(r=.11, p=.28)$ orientations and sons' identification with the traditional femininity gender ideology. The results of Pearson product-moment correlations provided no evidence for relationships between sons' conformity $(r=.09, p=.39)$ or conversation $(r=-.07, p=.50)$ orientations and their enforcement of the traditional femininity gender ideology with grandsons. The results of Pearson product-moment correlations provided evidence for a weak, positive 
relationship between sons' conformity orientations and their identification with the traditional femininity gender ideology $(r=.26, p=.01)$, but no evidence for a relationship between sons' conversation orientations and their identification with the traditional femininity gender ideology $(r=-.003, p=.97)$ 


\section{CHAPTER FOUR}

\section{Discussion}

Considering the important and unique role fathers play in sons' social, emotional, and cognitive development and the impact gender ideologies have on worldviews, communication, and behaviors, this study's investigation of father-son communication of gender ideologies is warranted. The objectives of this study were to investigate several areas of inquiry: the specific messages fathers transmit to their sons regarding gender ideologies, relationships between gender ideologies and family communication patterns, utility of modeling and compensation in intergenerational transmission of gender ideologies and communication patterns, "changing culture of fatherhood," and relationships between gender ideologies and wellbeing. Although many of the proposed hypotheses were not supported, additional analyses revealed unhypothesized links between fathers' communication and sons' acceptance and transmission of gender ideologies. The explanations and implications of specific results and directions for future research are addressed as they pertain to the major content areas of this discussion: (a) father-son communication, (b) gender ideologies, (c) memorable messages, (d) family communication patterns, (e) modeling and compensation, and (f) limitations and additional future considerations.

\section{Father-son Communication}

Previous father-child research has demonstrated that fathers' involvement has a positive and powerful influence on children's, especially sons', academic performance (Singer \& Weinstein, 2000), psychological wellbeing (Easterbrooks \& Goldberg, 1984; Sarkadi et al., 2007), communication styles (Leaper et al., 1998), and romantic relationships (Beatty \& Dobos, 1993). The current study sought to extend these findings by assessing the ways in which fathers' communication with their sons - through both specific, punctuated messages and more abstract, 
recurring patterns of communication—affects sons' gender ideologies.

Although the results did not provide evidence for the hypothesized transmission of gender ideologies across three generations (i.e., fathers to sons to grandsons as mentioned in the methods section), the communication between sons and grandsons, as compared to fathers and sons, was shown to be more predictive of sons' identification with and enforcement of gender ideologies. This unhypothesized finding suggests that several factors in and outside of the family may have more influence on sons than their fathers, such as mother's communication, grandsons' communication, and societal pressures.

First, mothers' communication may play a role in shaping sons' communication and gender ideologies. Although there is evidence that fathers' increased involvement helps raise sons who are less competitive and aggressive and more emotionally expressive (Brody, 1997), mothers' strong presence and influence on sons' general patterns of behavior and self-esteem (Chodorow, 1999) may also extend to gendered communication. For instance, mothers' use of affiliative, supportive, and non-assertive communication (Leaper, 2000) may work to reduce sons' masculinity in concert with fathers' involvement. Because $76 \%$ of fathers in the current study were married, albeit not all were sons' biological mothers, it is likely that the presence of women in sons' lives influenced their communication behaviors.

Second, in addition to mothers' potential influence on sons, grandsons' communication may exercise some degree of influence on sons' communication and gender ideologies. Morman and Floyd (2006) claimed that the father-son relationship is the most influential same-sex bond either man can form over his lifetime, demonstrating that sons have the ability to affect their fathers' lives. When sons challenge fathers' authority or position in the family, fathers respond with traditional masculine responses of competition, criticism, and control (Kindlon \& 
Thompson, 1999). Likewise, if sons learn to be more emotionally expressive, affectionate, and nurturing through their relationship with their mothers or by watching their parents interact, they may communicate those values to their fathers (e.g., by giving hugs and kisses, saying "I love you," helping others). Because some fathers seek their sons' approval (Morman \& Floyd, 2006), fathers may reciprocate their sons' gendered sentiments in order to achieve this goal. Although intergenerational transmission is typically assessed as a downward phenomenon (i.e., from older to younger generations; Knapp et al., 1981), these findings provide evidence that transmission also occurs upwardly (i.e., from younger to older generations) and reciprocally (i.e., to and from both older and younger generations). Future research might address the intentional and/or unintentional messages sons transmit upwardly to fathers and the influence of sons' messages on fathers' gender ideologies and other parenting behaviors.

Lastly, societal pressures to be masculine may influence sons' communication and gender ideologies. Although many of today's parents may desire to raise more androgynous children, the expectations for men to be strong, competitive, self-sufficient, and emotionally reserved continue to pervade American culture. Fathers' gendered messages may only resonate with sons insofar that they do not contradict the messages sons receive from society (i.e., the media, peers, school, work, and church). Because many of children's television shows and books portray gender-stereotyped characters (Diekman \& Murnen, 2004; Leaper, Breed, Hoffman, \& Perlman, 2002) and boys' peer groups, especially during adolescence, encourage strong conformity to traditional gender norms (Leaper, 1994), it is likely that these societal messages play a role in shaping sons' gender ideologies. Thus, to the degree that men perceive benefits (e.g., social acceptance) from their enactment of masculine behaviors, they would feel compelled to identify with the masculinity gender ideology regardless of their fathers' wishes. 
Following the discovery that sons' gender ideologies are influenced by messages from fathers and other sources (e.g., mothers, grandsons, and society), the following section illuminates the role gender ideologies play in sons" wellbeing and the "changing culture of fatherhood."

\section{Gender Ideologies}

In light of the roles family members play in shaping sons' gender ideologies, it is no wonder that family's communicated gender values have considerable influence on children's self-concepts, beliefs, interactions, and experiences (Leaper \& Friedman, 2007). The results of the current study demonstrate that sons' communication is related to the gender ideologies they identify with and pass onto grandsons but is unrelated to sons' wellbeing. The results suggest that the power of the father-son bond inspires men to prioritize their roles as their sons' lenses to the gendered world above their feelings about their own lives as men.

Gender ideologies and wellbeing. Previous research has associated masculinity with many destructive behaviors, such as violence, high-risk sexual activity, and excessive drug use (McCreary, Newcomb, \& Sadava, 1999; Pleck, Sonenstein, \& Ku, 1993; Thompson, 1991), and androgyny and femininity with many positive outcomes, such as effective communication and stress-coping skills, high self-esteem, and consideration for relational partners' feelings (Hirokawa et al., 2004; Kim \& Aune, 1997; Spence, Helmreich, \& Stapp, 1975). Based on these findings, the current study sought to explore the potential link between sons' gender ideologies and wellbeing. The results of the first research question (RQ1) revealed that sons' life satisfaction was not related to their identification with any of the three gender ideologies (i.e., the traditional masculinity, traditional femininity, nor androgyny). These findings may be due to men experiencing both advantages and disadvantages to being masculine, feminine, and 
androgynous, regardless of the links between masculinity and destructive behaviors and the links between femininity and androgyny and prosocial behaviors in previous research. For example, some men's masculinity may decrease satisfaction by impeding their ability to express emotions and develop mutually satisfying relationships, while other men's masculinity may increase satisfaction by enabling them to maintain their power positions at work and home. Conversely, some men's femininity or androgyny may increase satisfaction by eliminating stress related to being the family's primary financial provider, while other men's femininity or androgyny may decrease satisfaction by inhibiting conformity to masculine norms. To untangle the complexity of the satisfying and dissatisfying outcomes of the three gender ideologies, future research should address men's perceptions of their masculinity, femininity, and androgyny, especially in light of the changing culture.

Changing culture of gender ideologies. The results of the current study confirm the "changing culture of fatherhood" on two accounts. First, sons reported higher identification with androgyny and lower identification with masculinity as compared to their fathers' identification with androgyny and masculinity, respectively (see results for $\mathrm{H} 1$ and $\mathrm{H} 2$ ). In this sense, the changing culture seems contingent upon fathers' gender ideologies. Second, similar to Morman and Floyd's (2000) top four themes of fathers' and sons' definitions of a good father (i.e., love, availability, role model, and involvement), fathers' messages in the current study included androgynous and femininity values. Although the majority of fathers' messages about being a man portrayed masculine values, sons' increased androgyny scores suggest that their messages to grandsons might reveal even more femininity and androgyny themes than their fathers' messages did. As such, assessments of sons' memorable messages might reveal that grandsons are encouraged to embrace more flexible gender values compared to the generations before them, 
which may influence grandsons to engage in less destructive behaviors. Given the aforementioned trends between androgyny and prosocial interpersonal behaviors, a decrease in men's destructive masculine behavior would benefit men, their partners and children, and society as a whole.

Though not considered at the onset of this piece, the generational stake hypothesis (e.g., Bengtson \& Kuyers, 1971; Morman \& Floyd, 2002) lends valuable insight into the findings. This hypothesis posits that parents report their parent-child relationships more favorably than their children because parents wish to present their families as supportive and enduring, whereas children wish to separate themselves from their parents and establish their independence (Acock \& Bengtson, 1980; Noller \& Fitzpatrick, 1993). As mentioned previously, the communication between sons and grandsons (i.e., the younger generation) emerged as more powerful than the communication between sons and fathers (i.e., the older generation). As such, sons only moderately identified with their fathers and choose to transmit gender ideologies to grandsons (i.e., their own sons) independent from their fathers' communication of gender values to them. Thus, it is possible that sons distance themselves from their fathers in an effort to cast their own father-son relationship as more positive and cohesive. Future research should address exactly why this pattern of intergenerational transmission occurs. Understanding sons' motives for valuing androgyny and instilling androgynous values in grandsons, especially if fathers value a different gender ideology, would further explain the "changing culture of fatherhood."

Also indictors of the changing culture are the specific, gendered messages fathers transmit to their sons. These messages and their implications are discussed in the next section.

\section{Memorable Messages}

Similar to Morman and Floyd's (2006) fathering messages, the current study uncovered 
specific, gendered messages fathers communicate to their sons about being a man. These messages were categorized into eight themes: (a) family provider, (b) emotionality, (c) strength, (d) achievement, (e) maturity, (f) moral conduct, (g) enjoy life, and (h) general responses. As expected, though not formally categorized as such, these messages emanated aspects of the traditional masculinity, androgyny, and traditional femininity gender ideologies.

Demonstrating the pervasiveness of masculine norms even in a changing culture, the majority of the fathers' messages communicated a desire that sons' embody masculine behaviors, such as providing for one's family, displaying physical and emotional strength, competing in order to be the best, and being self-reliant (see Table 2 for a complete list of masculine responses). One might conclude that sons' exposure to and acceptance of highlymasculine norms caused them to call upon such blanket statements. Given the links between masculinity and destructive behaviors and the social pressures for men to be masculine, the pervasiveness of masculine norms may be problematic for men who wish to abandon their traditional gender values, but simultaneously desire acceptance from the larger society in which masculinity is valued.

As evidence of the "changing culture of fatherhood," a substantial number of responses contained fathers' desires for sons' to enact androgynous behaviors. These messages, which include ideas about responsibility, being an honorable and respectful individual, standing up for one's beliefs, and taking chances and enjoying life (see Table 2 for a complete list of androgynous responses), integrate both masculine and feminine qualities. Through these messages, fathers' place more emphasis on their son as people, not as men, and express a desire for their sons to be less restricted by society's masculine stereotypes. In fact, although intended to address "being a man," these messages conveyed more applicability to both sons and 
daughters than Morman and Floyd's (2006) messages that pertained only to fathering sons.

Lastly, a smaller number of responses represented fathers' desire for their sons to embrace feminine qualities, such as encouraging one's family, expressing emotions to and love for others, and being submissive to authority (see Table 2 for a complete list of feminine responses). Although not the predominant gender ideology present in the messages, the fact that fathers communicated the value of femininity to their sons is most likely related to some fathers' sensitive parenting style (i.e., responsiveness and emotional support; Easterbrooks \& Goldberg, 1984).

Given the prominent gendered themes within fathers' messages, future research may consider examining father-son memorable messages from the perspectives of attributions and communication standards. Although sons' gender ideologies are not related to their life satisfaction, it is possible that sons' internalization of their fathers' gendered messages contributes to sons' wellbeing in another way. Because individuals use attributions to make sense of their interpersonal relationships and experiences (Heider, 1958), it is possible that sons' interpretations of their fathers' motives for sending such messages may influence sons' perceptions of their father-son relationships more so than the actual words contained in the messages. In other words, some sons may interpret their fathers' memorable messages as genuine encouragement or guidance, while others may interpret these messages as unrealistic expectations and feel unworthy if they cannot maintain superiority over others. In addition, it is likely that many of the attributions we assign to our relationships originate from our standards for ideal relationships. In light of Caughlin's (2006) discovery that unattainable family communication standards leads to family dissatisfaction, future research should investigate how sons' attributions and expectations about ideal father-son relationships influence sons' 
evaluations of their own father-son relationships and communication between fathers and sons.

The resulting themes of fathers' memorable messages advances father-son communication research by providing insight into the punctuated ways fathers transmit gender values to their sons. For a more complete view of gendered communication within the father-son dyad, the following section addresses the results related to recurring patterns of communication.

\section{Family Communication Patterns}

The results supported the hypothesized link between family communication patterns and gender ideologies. However, similar to gender transmission, this relationship emerged withinnot across-generations. Specifically, sons' conformity orientations were positively related to sons' identification with and enforcement of the traditional masculinity ideology with grandsons, and fathers' and sons' conversation orientations were positively related to sons' identification with the androgyny ideology (post hoc analyses). These findings confirm that the conformity orientation coincides with the traditional masculinity ideology and the conversation orientation coincides with the androgyny ideology. Thus, to instill flexible gender values in their sons, fathers should provide frequent opportunities for open dialogue, welcome their sons' contributions to family decisions, and encourage their sons to share their views and opinions on a variety of topics. This communication style is in line with previous research that emphasizes the positive outcomes of the conversation orientation (e.g., Fowler et al., 2010; Koesten \& Anderson, 2004; Punyanunt-Carter, 2008; Schrodt et al., 2007). However, when fathers enforce strict rules, limit communication with their sons, and exercise their authority as the parent, it is likely that they will raise masculine sons. Despite the negative outcomes associated with the conformity orientations (e.g., Elwood \& Schrader, 1998; Koerner \& Fitzpatrick, 1997; McLeod, Atkin, \& Chaffee, 1972; Schrodt et al., 2007; Sillars, Koerner, \& Fitzpatrick, 2005), this trend 
appears highly probable given the strength of intergenerational transmission of the conformity orientation, which is described in the next section.

\section{Modeling and Compensation Hypotheses}

Although the current study was inspired by Floyd and Morman's (2000) investigation of fathers' and sons' modeling and compensation of affectionate communication, the results revealed that sons model their fathers' conformity orientations but neither model nor compensate for their fathers' conversation orientations. This may be explained by the very nature of the orientations as the conformity orientation emphasizes children's adherence to parents' rules and attitudes (i.e., modeling), whereas conversation orientation encourages children's independent decision making skills, which may lead to modeling and compensation depending on the situation.

According to Floyd and Morman (2000), the occurrence of modeling or compensation is based solely on children's identification with their parents. However, the results of the current study demonstrated that sons' identification with their fathers was a second predictor of sons' conformity orientation, along with fathers' conformity orientations, but neither a predictor nor a mediator of sons' conversation orientations. The inconsistencies between the two studies may be due to different operationalizations of identification. Floyd and Morman employed the Inclusion of Other in Self (IOS) scale (Aron et al., 1992) to measure relational closeness, though they refer to this construct as identification throughout their piece. Although identification and closeness are often positively correlated (e.g., Rittenour \& Soliz, 2009; Soliz, Thorson, \& Rittenour, 2009), the two constructs are not synonymous. In fact, as previously noted, closeness consists of multiple factors (i.e., frequency, diversity, and strength of interactions among partners), whereas identification is merely a feeling of oneness with another person or group. By using the IOS 
scale to measure identification, Floyd and Morman (2000) may have actually captured sons' perceptions of the frequency of interactions with, the range of topics discussed with, and their influence over their fathers. These perceptions seem closely related to sons' attachment with fathers, which may explain why Floyd and Morman were able to uncover identification's mediating role between fathers' and sons' affectionate communication through a measure of closeness.

Although not in the precise way it was hypothesized, identification played a role in this study. Specifically, both identification and fathers' conformity orientations predict sons' modeling of their fathers' conformity orientations. To that end, identification is important, but other factors, such as ease of modeling and biology influences, offer insight into why identification is not solely responsible for the link between fathers' and son' conformity orientations.

First, identification may not be necessary for modeling because modeling is simply the easier route. Modeling requires less cognitive activity and allows the individual to mimic what they have learned. Fathers react to their son's defiance with competition, criticism, and control (Kindlon \& Thompson, 1999), which suggests fathers use reflexive or effortless responses, perhaps because they are simply modeling their fathers' conformity orientations, instead of reflecting on the optimal way to change or understand their sons' behavior. Additionally, when this reaction occurs for extended periods of time, fathers may find it impossible to break the cycle of modeling their fathers' conformity orientations.

Second, sons' modeling of their fathers' parenting styles may be due to biological influences. Through their communibiology perspective, Beatty, McCroskey, and Heisel (1998) posit that $80 \%$ of human communication is influenced by biology, while only $20 \%$ is subject to 
environmental influences. In this sense, sons' modeling of their fathers' parenting styles may be a subconscious or even reflexive behavior that is at least partially driven by biological similarities between fathers and sons. Even if sons' do not endorse or identify with their fathers' communication patterns or gender values, it may be difficult for sons' to unlearn the messages they received as a child and prevent modeling.

\section{Limitations and Additional Future Considerations}

Although many of the results advance father-son and gender communication research, there are several limitations to the current study. There are also several phenomenon that, though not appearing to undermine this investigation, might be useful to consider in future exploration. This final section addresses the limitations and additional considerations.

Five limitations, two related to the father-son dyad and three related to the sons as participants, might have influenced the current findings. The first limitation is the lack of information regarding the frequency of father-son contact. Future research should assess this contact variable as it is possible that some fathers and sons maintain emotionally and geographically close relationships in adulthood.

Second, single-source reporting bias (i.e., gathering one family member's perceptions or reactions to family issues; Coley, 2001), may have limited or distorted the results as fathers and sons tend to report different interpretations and evaluations of the same, shared experience nearly $50 \%$ of the time (Kindlon \& Thompson, 1999). Future research that obtains reports from all three generations (i.e., fathers, sons, and grandsons) should prove to be a more effective assessment of intergenerational transmission.

A third limitation involves sons' demographics. Because over $64 \%$ of sons reported a household income of $\$ 75,000$ or more, these sons (and their spouses) may be better educated, 
employ more positive communication with their children, and perform less gender stereotyped roles than lower income parents. Future research should investigate, and/or potentially control for, parents' socioeconomic status and their relationships with communication and gender ideologies.

The fourth limitation is related to sons' reactions to the instrumentation. Several orthodox Christian sons told the researcher that the MRNI scale items (e.g., "Gay should never marry" and "A man should always be the boss") challenged their religious values regarding homosexuality and male supremacy. In turn, these sons refused to participate in the study. Future research should focus recruitment to religious and social groups with polarized gender values in order to capture a wide range of opinions and garner more opportunities to influence positive communication styles and flexible gender ideologies.

The final limitation worth addressing is attrition. The extensiveness of the questionnaire (i.e., 193 questions) may explain why 48 sons either skipped a few questions near the end of the survey or chose to leave the entire survey blank. Future researchers who employ the MRNI and FIS scales should consider eliminating items in order to keep the overall questionnaire at a manageable length for participants, minimize fatigue, and prevent attrition.

In addition to the aforementioned limitations, there are three overarching phenomena worth considering in future father-son research: positivity bias, social desirability bias, and cohort effects. First, positivity bias (i.e., the tendency for individuals to report positive statements about themselves or others; Sears, 1983) might influence sons to report their fatherson relationship and fathers' behaviors in a positive light because they both belong to the same family "in-group." Future research should consider the power of the family in sons' reports. Second, social desirability bias (i.e., the tendency for individuals to report statements that 
conform with social norms; Mick, 1996) might influence sons to report themselves as more masculine or satisfied than they actually are in order to adhere to society's expectations for men. Future research that gathers multiple family members' perspectives, as previously mentioned in terms of single-source reporting, should reduce positivity and single-source reporting biases. Lastly, cohort effects related to sons' age groups might influence recall ability and gender identification. To eliminate cohort effects, future research should consider a longitudinal design in order to compare data across multiple generations. Although these factors did not appear to harm the credibility of this study's results (i.e., data cleaning procedures indicated scale reliability and normal distribution), future father-son researchers might find it useful to consider the potential effects of these phenomena.

\section{Conclusion}

This project extends previous father-son communication research because it uncovered the specific gendered messages fathers transmit to their sons, as well as the relationships between fathers' and sons' communication patterns and gender ideologies, and the gender ideologies transmitted to future generations of grandsons. In addition, unexpected findings revealed novel information regarding the strong bonds between younger generations of fathers and sons and upward intergenerational transmission. Further, this study serves as additional support for the “changing culture of fatherhood" and suggests that these changes are due to fathers' and sons' gender ideologies. To this end, by incorporating gender communication into the role of fatherhood, this project presents fathers and sons as gendered individuals whose lives are influenced by the ideologies they accept and transmit to future generations. 


\section{References}

Acock, A. C., \& Bengtson, V. L. (1980). Actual versus perceived similarity among parents and youth. Journal of Marriage and Family, 42, 501-515.

Aron, A., Aron, E. N., \& Smollan, D. (1992). Inclusion of Other in the Self Scale and the structure of interpersonal closeness. Journal of Personality and Social Psychology, 63, 596-612.

Bandura, A. (1961). Psychotherapy as a learning process. Psychological Bulletin, 58, 143-159.

Barge, J. K., \& Schlueter, D. W. (2004). Memorable messages and newcomer socialization. Western Journal of Communication, 68, 233-256.

Barnett, R. C., Marshall, N. L., \& Pleck, J. H. (1992). Adult son-parent relationships and their associations with sons' psychological distress. Journal of Family Issues, 13, 505-525.

Bassoff, E. S., \& Glass, G. V. (1982). The relationship between sex roles and sexual orientation: A conceptual analysis and quantitative review. Developmental Psychology, 31, 43-55.

Baucom, D. H., \& Aiken, P. A. (1984). Sex role identity, marital satisfaction, and response to behavioral marital therapy. Journal of Consulting and Clinical Psychology, 52, 438-444.

Beaton, J. M., Doherty, W. J., \& Rueter, M. A. (2003). Family of origin processes and attitudes of expectant fathers. Fathering: A Journal of Theory, Research, and Practice about Men as Fathers, 1, 149-168.

Beatty, M. J., \& Dobos, J. A. (1993a). Adult males' perceptions of confirmation and relational partner communication apprehension: Indirect effects of fathers on sons' partners. Communication Quarterly, 41, 66-76.

Beatty, M. J., \& Dobos, J. A. (1993b). Direct and mediated effects of perceived father criticism and sarcasm on females' perceptions of relational partners' disconfirming behavior. 
Communication Quarterly, 41, 187-197.

Beatty, M. J., McCroskey, J. C., \& Heisel, A. D. (1998). Communication apprehension as temperamental expression: A communobiological paradigm. Communication Monographs, 65, 197-219.

Bem, S. L. (1974). The measurement of psychological androgyny. Journal of Consulting and Clinical Psychology, 42, 155-162.

Bem, S. L. (1993). The lenses of gender: Transforming the debate on sexual inequality. New Haven, CT: Yale University Press.

Bengtson, V. L., \& Kuypers, J. A. (1971). Generational difference and the developmental stake. Aging \& Human Development, 2, 249-260.

Berger, P. L., \& Luckmann, T. (1966). The social construction of reality: A treatise in the sociology of knowledge. Garden City, NY: Doubleday.

Berry, P. (1990). Fathers and mothers. Dallas, TX: Spring.

Berzins, J. I., Welling, M. A., \& Wetter, R. E. (1978). A new measure of psychological androgyny based on the Personality Research Form. Journal of Consulting and Clinical Psychology, 46, 126-138.

Boorstein, M. (2006, September 12). Americans may be more religious than they realize. The Washington Post, p. A12.

Brody, G. H., \& Shaffer, D. R. (1982). Contributions of parents and peers to children's moral socialization. Developmental Review, 2, 31-75.

Brody, L. R. (1997). Gender and emotion: Beyond stereotypes. The Society for the Psychological Study of Social Issues, 53, 369-393. doi:10.1111/j.1540-4560.1997.tb02448.x

Brody, L. R. (2001). Gender, emotion, and the family. Cambridge, MA: Harvard University. 
Brownmiller, S. (1975). Against our will: Men, women, and rape. New York, NY: Ballantine.

Bruess, C. J. S., \& Pearson, J. C. (1996). Gendered patterns in family communication. In J. T. Wood (Ed.), Gendered relationships (pp. 59-78). Mountain View, CA: Mayfield.

Burn, S. M., \& Ward, A. Z. (2005). Men's conformity to traditional masculinity and relationship satisfaction. Psychology of Men \& Masculinity, 6, 254-263.

Campbell, J., \& Gilmore, L. (2007). Intergenerational continuities and discontinuities in parenting styles. Australian Journal of Psychology, 59, 140-150.

Chaffee, S. H., McLeod, J. M., \& Atkin, C. K. (1971). Parental influences on adolescent media use. The American Behavioral Scientist, 14, 323-340.

Chodorow, N. (1978). The reproduction of mothering: Psychoanalysis and the sociology of gender. Berkeley, CA: University of California Press.

Colaner, C. W. (2009). Exploring the communication of Evangelical families: The association between Evangelical gender role ideology and family. Communication Studies, 60, 97113. doi:10.1080/10510970902834833

Colaner, C. W., \& Warner, S. C. (2005). The effects of egalitarian and complementarian gender role attitudes on career aspirations in evangelical female undergraduate college students. Journal of Psychology and Theology, 33, 224-229.

Connell, R. W., \& Messerschmidt, J. W. (2005). Hegemonic masculinity: Rethinking the concept. Gender \& Society, 19, 829-859. doi:10.1177/0891243205278639

Corbin, J. M., \& Strauss, A. L. (2008). Basics of qualitative research: Techniques and procedures for developing grounded theory (3rd ed.). Thousand Oaks, CA: Sage.

Courtenay, W. H. (2000). Engendering health: A social constructionist examination of men's health beliefs and behaviors. Psychology of Men and Masculinity, 1, 4-15. 
doi:10.1037//1524-9220.1.1.4

Dallimore, E. J. (2003). Memorable messages as discursive formations: The gendered socialization of new university faculty. Women's Studies in Communication, 26, 214-265.

Daly, K. (1995). Reshaping fatherhood: Finding the models. In W. Marisglio (Ed.), Fatherhood: Contemporary theory, research, and social policy (pp. 21-40). Newbury Park, CA: Sage.

Diekman, A. B., \& Murnen, S. K. (2004). Learning to be little women and little men: The inequitable gender equality of nonsexist children's literature. Sex Roles, 50, 373-385.

Diener, E., Emmons, R. A., Larsen, R. J., \& Griffin, S. (1985). The satisfaction with life scale. Journal of Personality Assessment, 49, 71-75.

Duckworth, J. D., \& Buzzanell, P. M. (2009). Constructing work-life balance and fatherhood: Men's framing of the meanings of both work and family. Communication Studies, 60, 558-573. doi: $10.1080 / 10510970903260392$

Easterbrooks, M. A., \& Goldberg, W. A. (1984). Toddler development in the family: Impact of father involvement and parenting characteristics. Child Development, 55, 740-752.

Eisler, R. M., Skidmore, J. R., \& Ward, C. H. (1988). Masculine gender-role stress: Predictor of anger, anxiety, and health-risk behaviors. Journal of Personality Assessment, 52, 133144.

Elwood, T. D., \& Schrader, D. C. (1998). Family communication patterns and communication apprehension. Journal of Social Behavior and Personality, 13, 493-502.

Fischer, A. R., Tokar, D. M., Mergl, M. M., Good, G. E., Hill, M. S., \& Blum, S. A. (2000). Assessing women's feminist identity development: Studies of convergent, discriminant, and structural validity. Psychology of Women Quarterly, 24, 15-29.

Floyd, K., \& Morman, M. T. (2000) Affection received from fathers as a predictor of men's 
affection with their own sons: Tests of the modeling and compensation hypotheses. Communication Monographs, 67, 347-361.

Floyd, K., \& Morman, M. T. (2003). Human affection exchange: II. Affectionate communication in father-son relationships. Journal of Social Psychology, 143, 599-612.

Floyd, K., \& Morman, M. T. (2005). Fathers' and sons' reports of fathers' affectionate communication: Implications of a navïe theory of affection. Journal of Social and Personal Relationships, 22, 99-109. doi:10.1177/0265407505049323

Fowler, M., Pearson, J. C., \& Beck, S. J. (2010). Family communication patterns influence on adult children's romantic rituals and relational maintenance. Journal of the Communication, Speech \& Theatre Association of North Dakota, 23, 1-11.

Frisby, B. N., \& Martin, M. M. (2010). Interpersonal motives and supportive communication. Communication Research Reports, 27, 320-329. doi: 10.1080/08824096.2010.518913

Gelade, G. A., Dobson, P., \& Auer, K. (2008). Individualism, masculinity, and the sources of organizational commitment. Journal of Cross-Cultural Psychology, 39, 599

Greenspun, W. S. (1994). Internal and interpersonal: The family transmission of father-daughter incest. Journal of Child Sexual Abuse, 3, 1-14.

Greenstein, T. N. (1996). Husbands' participation in domestic labor: Interactive effects of wives' and husbands' gender ideologies. Journal of Marriage and Family, 58, 585-595.

Grusec, J. E., \& Goodnow, J. J. (1994). Impact of parental discipline methods on the child's internalization of values: A reconceptualization of current points of view. Developmental Psychology, 30, 4-19.

Heider, F. (1958). The psychology of interpersonal relations. New York: Wiley. Heilbrun, A. B. (1981). Gender differences in the functional linkage between androgyny, social 
cognition, and competence. Journal of Personality and Social Psychology, 41, 11061118.

Heilbrun, A. B. (1986). Androgyny as type and androgyny as behavior: Implications for gender schema in males and females. Sex roles, 14, 123-139.

Heisler, J. M., \& Ellis, J. B. (2008). Motherhood and the construction of "'mommy identity": Messages about motherhood and face negotiation. Communication Quarterly, 56, 445467. doi:10.1080/01463370802448246

Hirokawa, K., Yagi, A., \& Miyata, Y. (2004). An examination of masculinity-femininity traits and their relationships to communication skills and stress-coping skills. Social Behavior and Personality, 32, 731-740.

Holladay, S. J. (2002). "Have fun while you can," "you're only as old as you feel," and "don’t ever get old!": An examination of memorable messages about aging. Journal of Communication, 52, 681-697.

Honeycutt, J. M., \& Cantrill, J. G. (2001). Cognition, communication, and romantic relationships. Mahwah, NJ: Lawrence Erlbaum Associates.

Horan, S. M., Houser, M. L., \& Cowan, R. L. (2007). Are children communicated with equally? An investigation of parent-child sex composition and gender role communication differences. Communication Research Reports, 24, 361-372.

doi:10.1080/08824090701624262

Johnson, H. D., Brady, E., Mcnair, R., Congdon, D., Niznik, J., \& Anderson, S. (2007). Identity as a moderator of gender differences in the emotional closeness of emerging adults' sameand cross-sex friendships. Adolescence, 42, 1-23.

Kagan, J. (1958). The concept of identification. Psychological Review, 65, 296-305. 
Kassing, J. W., \& Pappas, M. E. (2007). “Champions are built in the off season”: An exploration of high school coaches memorable messages. Human Communication, 10, 537-546.

Kelly, L., Keaten, J. A., Finch, C., Duarte, I. B., Hoffman, P., \& Michels, M. M. (2002). Family communication patterns and the development of reticence. Communication Education, 51, 202-209.

Kerr, D. C. R., Capaldi, D. M., Pears, K. C., \& Owen, L. D. (2009). A prospective three generational study of fathers' constructive parenting: Influences from family of origin, adolescent adjustment, and offspring temperament. Developmental Psychology, 45, 12571275. doi:10.1037/a0015863

Kim, M., \& Aune, K. S. (1997). The effects of psychological gender orientations on the perceived salience conversational constraints. Sex Roles, 37, 935-953.

Kindlon, D., \& Thompson, M. (1999). Raising Cain: Protecting the emotional life of boys. New York, NY: Random House.

King, R. A., Abrams, S., Dowling, S. A., \& Brinich, P. M. (2009). The psychoanalytic study of the child (Vol 64). New Haven, CT: Yale University Press.

Kline, S., O’Neil, N. B., \& Fay, M. (2005, May). The influence of family communication on love attitudes of young adults. Paper presented at the meeting of the International Communication Association, New York, NY.

Knapp, M. L., Stohl, C., \& Reardon, K. K. (1981). “Memorable” messages. Journal of Communication, 31, 27-41. doi:10.1111/j.1460-2466.1981.tb00448.x

Koenig Kellas, J. (2010). Transmitting relational worldviews: The relationship between motherdaughter memorable messages and adult daughters' romantic relational schemata. Communication Quarterly, 58, 458-479. 
Koerner, A. F., \& Fitzpatrick, M. A. (1997). Family type and conflict: The impact of conversation orientation and conformity orientation on conflict in the family. Communication Studies, 48, 59-75. doi:10.1080/10510979709368491

Koerner, A. F., \& Fitzpatrick, M. A. (2002a). Toward a theory of family communication. Communication Theory, 12, 70-91.

Koerner, A. F., \& Fitzpatrick, M. A. (2002b). Understanding family communication patterns and family functioning: The roles of conversation orientation and conformity orientation. Communication Yearbook, 26, 36-68.

Koesten, J., \& Anderson, K. (2004). Exploring the influence of family communication patterns, cognitive complexity, and interpersonal competence on adolescent risk behaviors. The Journal of Family Communication, 4, 99-121.

Lamb, M. E. (2010). The role of the father in child development (5th ed.). Hoboken, NJ: John Wiley and Sons.

Lamb, M. E., Frodi, M., Hwang, C. P., \& Frodi, A. M. (1983). Effects of paternal involvement on infant preferences for mothers and fathers. Child Development, 54, 450-458.

Lamb, M. E., \& Lewis, C. (2010). The development and significance of father-son relationships in two-parent families. In M. E. Lamb (Ed.), The role of the father in child development (5th ed., pp. 94-153). Hoboken, NJ: John Wiley and Sons.

Leaper, C. (1994). Exploring the consequences of gender segregation on social relationships. In C. Leaper (Ed.), Childhood gender segregation: Causes and consequences (New Directions for Child Development, No. 65, pp. 67-86). San Francisco: Jossey-Bass.

Leaper, C. (2000). Gender, affiliation, assertion, and the interactive context of parent-child play. Developmental Psychology, 36, 381-393. 
Leaper, C., Anderson, K. J., \& Sanders, P. (1998). Moderators of gender effects on parents' talk to their children: A meta-analysis. Developmental Psychology, 34, 3-27.

Leaper, C., Breed, L., Hoffman, L., \& Perlman, C. A. (2002). Variations in the genderstereotyped content of children's television cartoons across genres. Journal of Applied Social Psychology, 32, 1653-1662.

Leaper, C., \& Friedman, C. K. (2007). The socialization of gender. In J. E. Grusec \& P. D. Hastings (Eds.), Handbook of socialization: Theory and research (pp. 561-587). New York, NY: Guilford.

Ledbetter, A. M. (2009). Family communication patterns and relational maintenance behavior: Direct and mediated associations with friendship closeness. Human Communication Research, 35, 130-147.

Ledbetter, A. M. (2010). Family communication patterns and communication competence as predictors of online communication attitude: Evaluating a dual pathway model. Journal of Family Communication, 10, 99-115. DOI: 10.1080/15267431003595462

Ledbetter, A. M., Stassen-Ferrara, H. M., \& Dowd, M. D. (2010, November). Comparing equity and self expansion theory approaches to relational maintenance. Paper presented at the meeting of the National Communication Association, San Francisco, CA.

Levant, R., Richmond, K., Cook, S., House, T., \& Aupont, M. (2007). The femininity ideology scale: Factor structure, reliability, convergent and discriminant validity, and social contextual variation. Sex Roles, 57, 373-383. doi:10.1007/s11199-007-9258-5

Levant, R. F., Smalley, K. B., Aupont, M., House, A. T., Richmond, K., \& Noronha, D. (2007). Initial validation of the male role norms inventory-revised (MRNI-R). The Journal of Men's Studies, 15, 83-100. 
Levant, R. F., Wimer, D. J., \& Williams, C. M. (2011). An evaluation of the Health Behavior Inventory-20 (HBI-20) and its relationships to masculinity and attitudes towards seeking psychological help among college men. Psychology of Men \& Masculinity, 12, 26-41.

Levant, R. F., Wimer, D. J., Williams, C. M., Smalley, K. B., \& Noronha, D. (2009). The relationships between masculinity variables, health risk behaviors and attitudes toward seeking psychological help. International Journal of Men's Health, 8, 3-21.

Lindsey, E. W., \& Mize, J. (2001). Contextual differences in parent-child play: Implications for children's gender role development. Sex Roles, 44, 155-176.

Mahalik, J R., Locke, B. D., Ludlow, L. H., Diemer, M A., Scott, R. P. J., Gottfried, M., \& Freitas, G. (2003). Development of the conformity to masculine norms inventory. Psychology of Men \& Masculinity, 4, 3-25. doi:10.1037/1524-9220.4.1.3

Martin, M. M., \& Anderson, C. M. (1995). The father-young adult relationship: Interpersonal motives, self-disclosure, and satisfaction. Communication Quarterly, 43, 119-130.

Martin, M. M., \& Anderson, C. M. (1997). Aggressive communication traits: How similar are young adults and their parents in argumentativeness, assertiveness, and verbal aggressiveness. Western Journal of Communication, 61, 299-314.

Mazur, M. A., \& Hubbard, A. S. E. (2004). “'Is there something I should know??: Topic avoidant responses in parent-adolescent communication. Communication Reports, 17, 27 38.

McCreary, D. R., Newcomb, M. D., \& Sadava, S. W. (1999). The male role, alcohol use, and alcohol problems: A structural modeling examination in adult women and men. Journal of Counseling Psychology, 46, 109-124.

McCreary, D. R., \& Sasse, D. K. (2000). An exploration of the drive for muscularity in 
adolescent boys and girls. Journal of American College Health, 48, 297-304.

McLeod, J. M., Atkin, C. K., \& Chaffee, S. H. (1972). Adolescents, parents, and television use: and other-report measures from the Wisconsin sample. In G. A. Comstock \& E. A. Rubinstein (Eds.), Television and social behavior, reports and papers: Vol. 3. Television and adolescent aggressiveness (pp. 239-313). Rockville, MD: National Institute of Mental Health.

Medved, C. E., Brogan, S. M., McClanahan, A. M., Morris, J. F., \& Shepherd, G. J. (2006). Family and work socializing communication: Messages, gender, and ideological implications. The Journal of Family Communication, 6, 161-180.

Mick, D. G. (1996). Are studies of dark side variables confounded by socially desirable responding? The case of materialism. Journal of Consumer Research, 23, 106-119.

Moen, P., Erickson, M. A., \& Dempster-McClain, D. (1997). Their mother's daughters? The intergenerational transmission of gender attitudes in a world of changing roles. Journal of Marriage and Family, 59, 281-293.

Morman, M. T., \& Floyd, K. (1999). Affectionate communication between fathers and young adults sons: Individual and relational-level correlates. Communication Studies, 50, 294309.

Morman, M. T., \& Floyd, K. (2002). A “changing culture of fatherhood”: Effects on affectionate communication, closeness, and satisfaction in men's relationship with their fathers and their sons. Western Journal of Communication, 66, 395-411.

Morman, M. T., \& Floyd, K. (2006). Good fathering: Father and son perceptions of what it means to be a good father. Fathering, 4, 113-136.

Mussen, P., \& Distler, L. (1960). Child-rearing antecedents of masculine identification in 
kindergarten boys. Child Development, 31, 89-100.

Myers, S. A., Schrodt, P., \& Rittenour, C. E. (2006). The impact of parents' use of hurtful messages on adult children's self-esteem and educational motivation. In L. H. Turner \& R. West (Eds.), The family communication sourcebook (pp. 425-445). Thousand Oaks, CA: Sage.

Noller, P., \& Fitzpatrick, M. A. (1993). Communication in family relationships. Englewood Cliffs, NJ: Prentice Hall.

Obegi, J. H., Morrison, T. L., \& Shaver, P. R. (2004). Exploring intergenerational transmission of attachment style in young female adults and their mothers. Journal of Social and Personal Relationships, 21, 625-638.

Parkes, C. M. (1972). Bereavement: Studies of grief in adult life. New York, NY: International Universities Press.

Pearson, J. C., \& Turner, L. H. (1982, February). The relationship between psychological sex type and communication apprehension. Paper presented at the meeting of the Western Speech Communication Association, Denver, CO.

Peck, S. D. (1996). What is a good father? An exploratory look at men's beliefs about the paternal role. Journal of Men's Studies, 4, 375-383.

Peretti, P. O., \& Statum, J. A. (1984). Father-son intergenerational transmission of authoritarian parental attitudes. Social Behavior and Personality, 12, 85-90.

Petronio, S., \& Bradford, L. (1993). Issues interfering with the use of written communication as a means of relational bonding between absentee, divorced fathers and their children. Journal of Applied Communication Research, 21, 163-175.

Pleck, J. H. (2010). Fatherhood and masculinity. In M. E. Lamb (Ed.), The role of the father in 
child development (5th ed., pp. 27-57). Hoboken, NJ: John Wiley and Sons.

Pleck, J. H., Sonenstein, F. L., \& Ku, L. C. (1993). Masculinity ideology and its correlates. In S. Oskamp \& M. Costanzo (Eds.), Gender issues in contemporary society (pp. 85-110). Newbury Park, CA: Sage.

Pomerleau, A., Bolduc, D., Malcuit, G., \& Crossette. L. (1990). Pink or blue: Environmental gender stereotypes in the first two years of life. Sex Roles, 22, 359-367.

Pratt, M. W., Norris, J. E., Hebblethwaite, S., \& Arnold, M. L. (2008). Intergenerational transmission of values: Family generativity and adolescents' narratives of parent and grandparent value teaching. Journal of Personality, 76, 171-198. doi: 10.1111/j.14676494.2007.00483.x

Pruett, K. D. (1983). Infants of primary nurturing fathers. Psychoanalytic Study of the Child, 38, 257-277.

Punyanunt-Carter, N. M. (2008). Father-daughter relationships: Examining family communication patterns and interpersonal communication satisfaction. Communication Research Reports, 25, 23-33. doi: 10.1080/08824090701831750

Reidy, D. E., Shirk, S. D., Sloan, C. A., \& Zeichner, A. (2009). Men who aggress against women: Effects of feminine gender role violation on physical aggression in hypermasculine men. Psychology of Men \& Masculinity, 10, 1-12

Reiss, D. (1981). The family's construction of reality. Cambridge, MA: Harvard University Press.

Riesch, S. K., Anderson, L. S., \& Krueger, H. A. (2006). Parent-child communication processes: Preventing children's health-risk behavior. Journal for Specialists in Pediatric Nursing, 11, 41-56. doi: 10.1111/j.1744-6155.2006.00042.x 
Ritchie, L. D. (1988, July). Family communication patterns and the flow of information in the family. Paper presented at the meeting of the Association for Education in Journalism and Mass Communication, Portland, OR.

Ritchie, L. D., \& Fitzpatrick, M. A. (1990). Family communication patterns: Measuring intrapersonal perceptions of interpersonal relationships. Communication Research, 17, 523-544.

Rittenour, C. E., \& Soliz, J. (2009). Communicative and relational dimensions of shared family identity and relational intentions in mother-in-law/daughter-in-law relationships: Developing a conceptual model for mother-in-law/daughter-in-law research. Western Journal of Communication, 73, 67-90.

Rossi, A. S., \& Rossi, P. H. (1990). Of human bonding: Parent-child relations across the life course. Hawthorne, NY: Aldine de Gruyter.

Sarkadi, A., Kristiansson, R., Oberklaid, F., \& Bremberg, S. (2007). Fathers' involvement and children's developmental outcomes: A systematic review of longitudinal studies. Acta Paediatrica, 97, 153-158. doi:10.1111/j.1651-2227.2007.00572.x

Sayers, S. L., \& Baucom, D. H. (1991). Role of femininity and masculinity in distressed couples' communication. Journal of Personality and Social Psychology, 61, 641-647.

Schrodt, P., Ledbetter, A. M., Jernberg, K. A., Larson, L., Brown, N., \& Glonek, K. (2009). Family communication patterns as mediators of communication competence in the parent-child relationship. Journal of Social and Personal Relationships, 26, 853-874. doi:10.1177/0265407509345649

Schrodt, P., Ledbetter, A. M., \& Ohrt, J. K. (2007). Parental confirmation and affection as mediators of family communication patterns and children's mental well-being. The 
Journal of Family Communication, 7, 23-46.

Schrodt, P., Witt, P. L., \& Messersmith, A. S. (2008). A meta-analytical review of family communication patterns and their associations with information processing, behavioral, and psychosocial outcomes. Communication Monographs, 75, 248-269.

Scott, W. (1955). Reliability of content analysis: The case of nominal scale coding. Public Opinion Quarterly, 19, 321-325.

Scott-Samuel, A., Stanistreet, D., \& Crawshaw, P. (2009). Hegemonic masculinity, structural violence and health inequalities. Critical Public Health, 19, 287-292.

Sears, D. O. (1983). The person-positivity bias. Journal of Personality and Social Psychology, $44,233-250$.

Shakin, M., Shakin, D., \& Sternglanz, S. (1985). Infant clothing: Sex labeling for strangers. Sex Roles, 12, 955-964.

Shmotkin, D. (1999). Affective bonds of adult children with living versus deceased parents. Psychology and Aging, 14, 473-482.

Simons, R. L., Beaman, J., Conger, R. D., \& Chao, W. (1993). Childhood experience, conceptions of parenting, and attitudes of spouse as determinants of parental behavior. Journal of Marriage and the Family, 55, 91-106.

Sillars, A., Koerner, A. F., \& Fitzpatrick, M. A. (2005). Communication and understanding in parent-adolescent relationships. Human Communication Research, 31, 103-128.

Silverstein, L., \& Auerbach, C. (1999). Deconstructing the essential father. American Psychologist, 55, 397-407.

Singer, A. T. B., \& Weinstein, R. S. (2000). Differential parental treatment predicts achievement and self-perceptions in two cultural contexts. Journal of Family Psychology, 14, 491-509. 
Smith, S. W., Nazione, S., Kotowski, M. R., Atkin, C., Skubisz, C. M., \& Stohl, C. (2009). Topics and sources of memorable breast cancer messages and their impact on prevention and detection behaviors. Journal of Health Communication, 14, 293-307. doi:10.1080/10810730902805903

Snarey, J. (1993). How fathers care for the next generation: A four decade study. Cambridge, MA: Harvard University Press.

Soenens, B., Elliot, A. J., Goossens, L., Vansteenkiste, M., Luyten, P., \& Duriez, B. (2005). The Intergenerational transmission of perfectionism: Parents' psychological control as an intervening variable. Journal of Family Psychology, 19, 358-366.

Soliz, J., Thorson, A. R., \& Rittenour, C. E. (2009). Communicative correlates of satisfaction, family identity, and group salience in multiracial/ethic families. Journal of Marriage and Family, 71, 819-832.

Spence, J. T., Helmreich, R., \& Stapp, J. (1975). Ratings of self and peers on sex role attributes and their relation to self-esteem and conceptions of masculinity and femininity. Journal of Personality and Social Psychology, 32, 29-39.

Stake, J. E. (1997). Integrating expressiveness and instrumentality in real-life settings: A new perspective on the benefits of androgyny. Sex Roles, 37, 541-564.

Stark, L. P. (1991). Traditional gender role beliefs and individual outcomes: An exploratory analysis. Sex Roles, 24, 639-650.

Stohl, C. (1986). The role of memorable messages in the process of organizational socialization. Communication Quarterly, 34, 231-249.

Strauss, W., \& Howe, N. (1991). Generations: The history of America's future, 1584 to 2069. New York, NY: William Morrow. 
Swann, W. B., Gomez, A., Seyle, D. C., Morales, J. F., \& Huici, C. (2009). Identity fusion: The interplay of personal and social identities in extreme group behavior. Journal of Personality and Social Psychology, 96, 995-1011. doi:10.1037/a0013668

Taylor, M., \& Segrin, C. (2010). Perceptions of parental gender roles and conflict styles and their association with young adults' relational and psychological well-being. Communication Research Reports, 27, 230-242. doi:10.1080/08824096.2010.496326

Thompson, E. H. (1991). The maleness of violence in dating relationships: An appraisal of stereotypes. Sex Roles, 24, 261-278.

Thompson, E. H., \& Whearty, P. M. (2004). Older men's social participation: The importance of masculinity ideology. The Journal of Men's Studies, 13, 5-24.

Umberson, D. (1992). Relationships between adult children and their parents: Psychological consequences for both generations. Journal of Marriage and Family, 54, 664-674.

Van Ijzendoorn, M. H. (1992). Intergenerational transmission of parenting: A review of studies in nonclinical populations. Development Review, 12, 76-99.

Vassar, M. (2008). A note on the score reliability for the Satisfaction With Life Scale: an RG study. Social Indicators Research, 86, 47-57. doi:10.1007/s11205-007-9113-7

Vogt, G. M., \& Surridge, S. T. (1991). Like son, life father: Healing father-son wounds in men's lives. New York, NY: Plenum Press.

Wright, P. J. (2009). Father-child sexual communication in the United States: A review and synthesis. Journal of Family Communication, 9, 33-250.

doi: $10.1080 / 15267430903221880$ 


\section{Notes}

${ }^{1}$ The researcher was given permission to post recruitment information on the following parenting websites and discussion forums: www.parkslopeparents.com, www.parents.berkeley.edu, www.momsupport.org, www.raisingthem.com, www.fathers.com, and various Facebook pages (i.e., Dads in Difficulty, Parenting.com, Parents Magazine, Hamilton Attachment Parenting Group, The Average Parent, The National Association for the Education of Young Children, Student Parents Movement, The Black Parent Group, and WVU Parents Club).

${ }^{2}$ In order to demonstrate that scale items loaded on their expected subscales, items had to receive .80 or above during each instrument's exploratory factor analysis. If a scale item was below .80 on its expected subscale, the item was eliminated from subsequent analyses.

${ }^{3}$ The skewness and kurtosis tests for all instruments fit within the specified criteria of -2 to +2 .

${ }^{4}$ The terms "father," "son," and "grandson" are used to avoid confusion over which father-son relationship is referenced in regard to the current study's results. When the older generation is referenced, the terms "father" and "son" will be used. When the younger generation is referenced the terms "son" and "grandson" will be used. However, when the terms "father" and "son" are used in relation to other scholars' findings, it should be assumed that these findings can be applied to all father-son relationships regardless of the generation.

${ }^{5}$ The following items were eliminated from the sons' RFCP conformity and conversation subscales: "I believe my son should give in on arguments rather than risk making people mad," "If I don't approve of it, I don't want to know about it," and "My son usually tells me what he's thinking about things." The following item was eliminated from the fathers' RFCP conformity 
subscale: "My father often said something like, 'you should give in on arguments rather than risk making people mad'." 
Appendix A

\section{Undergraduate Classroom Recruitment Script}

Hello class. My name is Kelly Odenweller and I am a Master's student in the Department of Communication Studies. In order to fulfill requirements for my Master's thesis, I am conducting an IRB approved research study (Tracking \#H-23117) under the supervision of Dr. Christine Rittenour, through which I am investigating fathers' communication with their sons. For my study, "father" is meant to be an inclusive term that represents any male figure that raised you, which could include your biological father, stepfather, or adoptive father.

This study is completely voluntary and any father who is at least 18 years old, has a son who is at least seven years old, and has a living father can participate. Participation for fathers will entail filling out an online survey, which should take them approximately 40 minutes. If you have a father who fits these criteria, please give him this sheet (researcher will pass out "Call for Participant" sheet at this time) and ask him to email me if he is interested in participating in the study. I will, then, respond to your father through email with instructions for completing the survey and the link to access the online survey.

If you or your fathers have questions about this study, please feel free to contact me at kodenwel@mix.wvu.edu or Dr. Rittenour at christine.rittenour@mail.wvu.edu. Thank you very much for your time. 
Appendix B

\section{Response Email for Fathers Recruited through WVU Students}

Dear [participant's first name],

My name Kelly Odenweller and I am a Master's student in the Department of

Communication Studies at West Virginia University. I am conducting an IRB approved research study (Tracking \#H-23117) under the supervision of Dr. Christine Rittenour to examine fathers' and sons' communication of gender values.

Thank you for expressing interest in this study. Your participation in this study is completely voluntary. If you are a father who is at least 18 years old, has a son who is at least 7years old, and has a living father, please click

www.surveymonkey.com/father_son_communication to read the full instructions and complete a 30-minute online survey.

I greatly appreciate your participation as this research will fulfill requirements toward earning my M.A. in Communication Studies. If you have any questions regarding this study or the online survey, please do not hesitate to email me at kodenwel@mix.edu or Dr. Christine Rittenour at christine.rittenour@mail.wvu.edu.

Best Regards, Kelly Odenweller 


\section{Appendix C}

\section{Facebook Recruitment Script}

CALL FOR PARTICIPANTS: In order to fulfill requirements for my M.A. in Communication Studies from West Virginia University, I am conducting an IRB approved study (Tracking \#H-23117) under the supervision of Dr. Christine Rittenour to examine fathers' and sons' communication of gender values. Participation in this study is completely voluntary. If you would like to participate and you are a father who is at least 18 years old, have a son who is at least 7 years old, and have a living father, please click www.surveymonkey.com/father_son_communication_v1 to read the full instructions and complete a confidential, 30-40 minute online survey. The deadline to complete the survey is Friday, April 22, 2011. I greatly appreciate your participation. If you have any questions, please do not hesitate to email me at kodenwel@mix.edu. 
Appendix D

\section{Website and Forum Recruitment Script}

Need Fathers Parenting Opinions!

In order to fulfill requirements for my M.A. in Communication Studies from West Virginia University, I am conducting an IRB-approved study (Tracking \#H-23117) under the supervision of Dr. Christine Rittenour to examine fathers' and sons' communication of gender values. Participation in this study is completely voluntary.

If you are willing to participate and you are a father who is at least 18 years old, has a son who is at least 7 years old, and has a living father, please click www.surveymonkey.com/father_son_communication_v1 to read the full instructions and complete a confidential, 30-40 minute online survey. The deadline to complete the survey is this Friday, April 22, 2011.

If you don't personally qualify, I would greatly appreciate you passing this information onto someone in your social network that does qualify. Thank you all very much for your help! If you have any questions, please contact me at:

Kelly Odenweller

M.A. Student

Department of Communication Studies

West Virginia University

kodenwel@mix.wvu.edu 
Appendix E

\section{Email Script for Family and Friend Referrals}

Hi all:

As many of you already know, I'm currently working on my thesis with Dr. Rittenour. I'm looking for a very specific population to take a 30-40 minute online survey about fathers' and sons' communication of gender values. After recruiting in several Communication classes at WVU over the last few weeks, I've only been able to collect $1 / 4$ of the sample I need. So, I'm turning to you all to see if you would be willing help me out.

If you know a father who is at least 18 years old, has a son who is at least 7-years old, and has a living father that you think would be interested in participating, can you please forward this link (www.surveymonkey.com/father_son_communication_v1) to them. I'd like to have the surveys completed no later than Friday, April 22, 2011.

I would greatly appreciate your help. Let me know if you have any questions. Thank you!

Best Regards, Kelly 


\section{Father-Son Communication \& Gender Ideologies: Version 1}

* 1. Dear Participant:

You are being asked to participate in an IRB approved research study (Tracking \#H23117) conducted by Kelly Odenweller, a Master's student in the Department of Communication Studies at West Virginia University and co-investigator, under the supervision of Dr. Christine Rittenour, an Assistant Professor in the Department of Communication Studies at West Virginia University and the principal investigator. This research will fulfill requirements toward earning a M.A. in Communication Studies for the co-investigator.

This research is centered around fathers' and sons' communication and gender ideologies. In order to participate, you must: be male, be at least 18 -years-old, have a son who is at least 7-years-old, and have a living father.

This survey should be completed in any safe and private location where you have secure Internet access. Participation is completely voluntary. This survey will take approximately $\mathbf{3 0}$ minutes to complete. Please do not put your name on this survey in order to ensure anonymity. The responses you provide, which will be identified only by code number, will not be made available to anyone except the researchers.

Although no known benefits exist for you as a participant, we hope that this research will allow us to better meet the needs of other fathers and sons. If you wish to discontinue your participation in the study, you may do so at any time without harming your relationship with the researchers, the Department of Communication Studies, or West Virginia University. Your decision will not result in any loss of benefits for which you are otherwise entitled.

We do not anticipate that participating in this study will pose any risks beyond those of everyday life, but you may experience feelings of sadness, discomfort, or anxiety when thinking about your relationships with your father and son. In the event that these feelings emerge, free assistance is available to you through the WVU Carruth Center for Psychological and Psychiatric Services (1-304-293-4431) or the National Alliance on Mental Illness (1-800-950-6264).

If you would like more information regarding this research project, please contact Kelly Odenweller at (614) 296-5569 and kodenwel@mix.wvu.edu or Dr. Christine Rittenour at (304) 293-3905 and christine.rittenour@mail.wvu.edu. 


\section{Father-Son Communication \& Gender Ideologies: Version 1}

You are voluntarily making a decision whether or not to participate in this research study. By clicking in the "I accept" box, you are agreeing to the terms and conditions of this study. Thank you.

Sincerely,

Kelly Odenweller

MA Student \& Co-Investigator

Department of Communication Studies

West Virginia University

kodenwel@mix.wvu.edu

I accept these terms 


\section{Father-Son Communication \& Gender Ideologies: Version 1}

Directions: The following scale will address gender values. Each item on the scale will be associated with three separate questions: your perception of YOUR FATHER'S level of agreement with the value, YOUR level of agreement with the value, and your level of agreement regarding your PASSING of the value onto your oldest son.

\section{Gay men should never marry.}

Strongly disagree

MY FATHER would:

I:

I have PASSED this value

onto my oldest son:
Neither agree nor disagree

Agree

Strongly agree

o

C
0

\section{The President of the U.S. should always be a man.}

$\begin{array}{lcccc} & \text { Strongly disagree } & \text { Disagree } & \begin{array}{c}\text { Neither agree nor } \\ \text { disagree }\end{array} & \text { Agree } \\ \text { MY FATHER would: } & 0 & 0 & 6 & 0 \\ \text { I: } & 0 & 0 & 6 & 0 \\ \begin{array}{l}\text { I have PASSED this value } \\ \text { onto my oldest son: }\end{array} & 0 & 0 & & 0\end{array}$

\section{Men should be the leader in any group.}

Strongly disagree

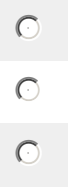

Disagree

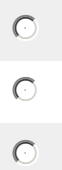

Neither agree nor disagree

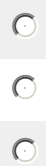

Agree

Strongly agree

MY FATHER would:

I:

I have PASSED this value

onto my oldest son:

\section{A man should be able to perform his job even if he is physically ill or hurt.}

Strongly disagree

MY FATHER would:

I:

I have PASSED this value onto my oldest son:
Disagree

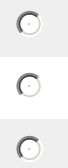

Neither agree nor disagree

Agree

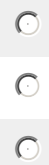

\section{Men should not talk with a lisp because this is a sign of being gay.}

$\begin{array}{lcccc} & \text { Strongly disagree } & \text { Disagree } & \begin{array}{c}\text { Neither agree nor } \\ \text { disagree }\end{array} & \text { Agree } \\ \text { MY FATHER would: } & 0 & 0 & 6 & 0 \\ \text { I: } & 0 & 0 & 0 & 6\end{array}$


Father-Son Communication \& Gender Ideologies: Version 1

\section{Men should not wear make-up, cover-up, or bronzer.}

Strongly disagree

Disagree

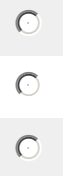

I have PASSED this value

onto my oldest son:
Neither agree nor disagree

Agree

$$
0
$$

\section{Men should watch football games instead of soap operas.}

Strongly disagree

MY FATHER would:

I:

I have PASSED this value onto my oldest son:
Neither agree nor disagree

Agree

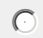

6

O

\section{All gay bars should be closed down.}

$$
\text { Strongly disagree }
$$

○

MY FATHER would:

I:

I have PASSED this value

onto my oldest son:

\section{Disagree}

6

6

c
Neither agree nor disagree

O

6

○

\section{Men should not be interested in talk shows such as "Oprah."}

Strongly disagree

Disagree

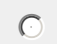

MY FATHER would:

I:

I have PASSED this value

onto my oldest son:
Neither agree nor disagree

Agree

Strongly agree

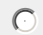

O

O

10. Men should excel at contact sports.

Strongly disagree

Disagree

MY FATHER would:

$\mathrm{I}:$

I have PASSED this value

onto my oldest son:
Neither agree nor disagree

Agree

Strongly agree

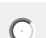

O

○

\section{Boys should play with action figures not dolls.}

Strongly disagree

MY FATHER would:

I:

I have PASSED this value onto my oldest son:
Disagree

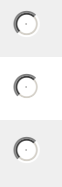

Neither agree nor disagree

Agree

Strongly agree

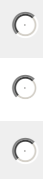

Strongly agree

$$
0
$$

Strongly agree

$$
\begin{aligned}
& 0 \\
& 0 \\
& 0
\end{aligned}
$$

$$
\begin{aligned}
& 0 \\
& 0
\end{aligned}
$$

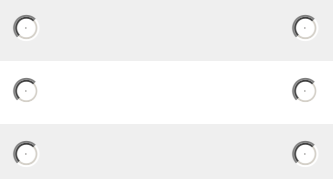


Father-Son Communication \& Gender Ideologies: Version 1

12. Men should not borrow money from friends or family members.

Strongly disagree

Disagree

Neither agree nor disagree

Agree

Strongly agree

MY FATHER would:

I:

I have PASSED this value

onto my oldest son:

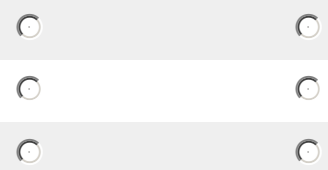

13. Men should have home improvement skills.

Strongly disagree

MY FATHER would:

I:

I have PASSED this value onto my oldest son:
Disagree

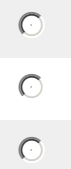

Neither agree nor disagree

O

C

c

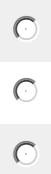

\section{Men should be able to fix most things around the house.}

Strongly disagree

MY FATHER would:
I:
I have PASSED this value
onto my oldest son:
Disagree

6

6

○
Neither agree nor disagree

Agree

Strongly agree

C

6

c
Agree

0
0

15. A man should prefer watching action movies to reading romantic novels.

Strongly disagree

MY FATHER would:

I:

I have PASSED this value

onto my oldest son:
Disagree

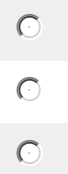

16. Men should always like to have sex.

Strongly disagree

MY FATHER would:

I:

I have PASSED this value

onto my oldest son:
Neither agree nor disagree

Agree

Strongly agree

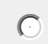

O

O

0

0
Neither agree nor disagree

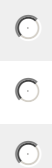

17. Gay men should not be allowed to serve in the military.

Strongly disagree

MY FATHER would:

I:

I have PASSED this value

onto my oldest son:
Disagree

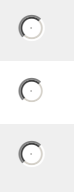

Neither agree nor disagree

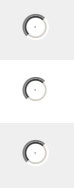

Agree

Agree

Strongly agree

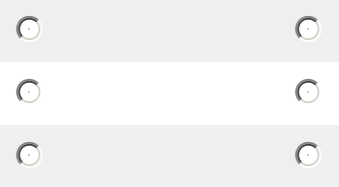

Strongly agree

$$
\begin{aligned}
& 0 \\
& 0 \\
& 0
\end{aligned}
$$


Father-Son Communication \& Gender Ideologies: Version 1

18. Men should never compliment or flirt with another male.

Strongly disagree

Disagree

Neither agree nor disagree

Agree

Strongly agree

MY FATHER would:

I:

I have PASSED this value

onto my oldest son:

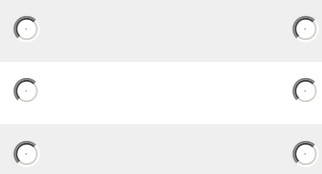

19. Boys should prefer to play with trucks rather than dolls.
Strongly disagree

I:

I have PASSED this value

onto my oldest son:
MY FATHER would:
Disagree

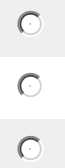

Neither agree nor disagree

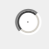

○

○

\section{A man should not turn down sex.}

$\begin{array}{lcccc} & \text { Strongly disagree } & \text { Disagree } & \begin{array}{c}\text { Neither agree nor } \\ \text { disagree }\end{array} & \text { Agree } \\ \text { MY FATHER would: } & 0 & 0 & 0 & 0 \\ \text { I: } & 0 & 0 & 0 & 0\end{array}$

\section{A man should always be the boss.}

Strongly disagree

Disagree

MY FATHER would:
I:
I have PASSED this value
onto my oldest son:

\section{A man should provide the discipline in the family.}

Strongly disagree

MY FATHER would:

I:

I have PASSED this value

onto my oldest son:
Neither agree nor disagree
Agree

0
Strongly agree

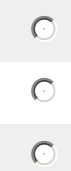

○

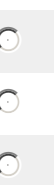

Neither agree nor disagree

Agree

Strongly agree

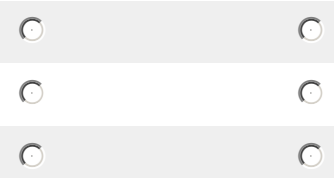

Strongly agree

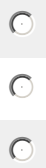

\section{Men should never hold hands or show affection toward another.}

Strongly disagree

MY FATHER would:

I:

I have PASSED this value

onto my oldest son:
Disagree

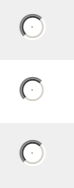


Father-Son Communication \& Gender Ideologies: Version 1

24. It is ok for a man to use any and all means to "convince" a woman to have sex.

Strongly disagree

MY FATHER would:

I:

I have PASSED this value

onto my oldest son:

6
Neither agree nor

disagree

Agree

0
0

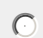

O

0

C

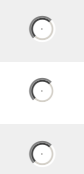

\section{Gay men should never kiss in public.}

Strongly disagree

MY FATHER would:

I:

I have PASSED this value onto my oldest son:
Disagree

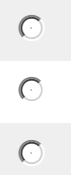

Neither agree nor disagree

O

6

c

\section{A man should avoid holding his wife's purse at all times.}

$\begin{array}{lcccc} & \text { Strongly disagree } & \text { Disagree } & \begin{array}{c}\text { Neither agree nor } \\ \text { disagree }\end{array} & \text { Agree } \\ \text { MY FATHER would: } & 0 & 0 & 0 & 6 \\ \text { I: } & 0 & 0 & 0 & 0\end{array}$

27. A man must be able to make his own way in the world.

$\begin{array}{lcccc} & \text { Strongly disagree } & \text { Disagree } & \begin{array}{c}\text { Neither agree nor } \\ \text { disagree }\end{array} & \text { Agree } \\ \text { MY FATHER would: } & 0 & 0 & 0 & 0 \\ \text { I: } & 0 & 0 & 0 & 0 \\ \begin{array}{l}\text { I have PASSED this value } \\ \text { onto my oldest son: }\end{array} & 0 & 0 & & 0\end{array}$

28. Men should always take the initiative when it comes to sex.

Strongly disagree

Disagree

Neither agree nor disagree

Agree

Strongly agree

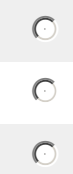

1 
Father-Son Communication \& Gender Ideologies: Version 1

30. Boys should not throw baseballs like girls.

Strongly disagree

Disagree

Neither agree nor disagree

Agree

Strongly agree

MY FATHER would:
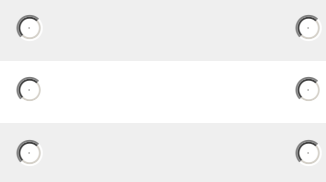

I have PASSED this value

onto my oldest son:

31. A man should not react when other people cry.

$\begin{array}{lcccc} & \text { Strongly disagree } & \text { Disagree } & \begin{array}{c}\text { Neither agree nor } \\ \text { disagree }\end{array} & \text { Agree } \\ \text { MY FATHER would: } & 0 & 0 & 0 & 0 \\ \text { I: } & 0 & 0 & 0 & 0\end{array}$

\section{A man should not continue a friendship with another man if he finds out that the} other man is gay.

$\begin{array}{lcccc} & \text { Strongly disagree } & \text { Disagree } & \begin{array}{c}\text { Neither agree nor } \\ \text { disagree }\end{array} & \text { Agree } \\ \text { MY FATHER would: } & 0 & 0 & 0 & 0 \\ \text { I: } & 0 & 0 & 0 & 0 \\ \begin{array}{l}\text { I have PASSED this value } \\ \text { onto my oldest son: }\end{array} & 0 & 0 & \text { Strongly agre }\end{array}$

33. Being a little down in the dumps is not a good reason for a man to act depressed.

$\begin{array}{lcccc} & \text { Strongly disagree } & \text { Disagree } & \begin{array}{c}\text { Neither agree nor } \\ \text { disagree }\end{array} & \text { Agree } \\ \text { MY FATHER would: } & 0 & 0 & 0 & 0 \\ \text { I: } & 0 & 0 & 0 & 0\end{array}$

\section{If another man flirts with the women accompanying a man, this is a serious} provocation and the man should respond with aggression.

$\begin{array}{lcccc} & \text { Strongly disagree } & \text { Disagree } & \begin{array}{c}\text { Neither agree nor } \\ \text { disagree }\end{array} & \text { Agree } \\ \text { MY FATHER would: } & 0 & 0 & 0 & 0\end{array}$


Father-Son Communication \& Gender Ideologies: Version 1

35. Boys should be encouraged to find a means of demonstrating physical prowess.

MY FATHER would:
I:
I have PASSED this value
onto my oldest son:

Strongly disagree

Disagree

Neither agree nor disagree

Agree

Strongly agree

36. A man should know how to repair his car if it should break down.

$\begin{array}{lcccc} & \text { Strongly disagree } & \text { Disagree } & \begin{array}{c}\text { Neither agree nor } \\ \text { disagree }\end{array} & \text { Agree } \\ \text { MY FATHER would: } & 0 & 0 & 0 & 0 \\ \text { I: } & 0 & 0 & 0 & 0 \\ \begin{array}{l}\text { I have PASSED this value } \\ \text { onto my oldest son: }\end{array} & 0 & 0 & \end{array}$

37. Gay men should be barred from the teaching profession.

$\begin{array}{lccccc} & \text { Strongly disagree } & \text { Disagree } & \begin{array}{c}\text { Neither agree nor } \\ \text { disagree }\end{array} & \text { Agree } & \text { Strongly agree } \\ \text { MY FATHER would: } & 0 & 0 & 0 & 0 & 0 \\ \text { I: } & 0 & 0 & 0 & 0 & 0 \\ \begin{array}{l}\text { I have PASSED this value } \\ \text { onto my oldest son: }\end{array} & 0 & 0 & 0 & 0 & 0\end{array}$

38. A man should never admit when others hurt his feelings.

$\begin{array}{lccccc} & \text { Strongly disagree } & \text { Disagree } & \begin{array}{c}\text { Neither agree nor } \\ \text { disagree }\end{array} & \text { Agree } & \text { Strongly agree } \\ \text { MY FATHER would: } & 0 & 0 & 0 & 0 & 0 \\ \text { I: } & 0 & 0 & 0 & 0 & 0 \\ \begin{array}{l}\text { I have PASSED this value } \\ \text { onto my oldest son: }\end{array} & 0 & 0 & 0 & 0 & 0\end{array}$

39. Men should get up to investigate if there is a strange noise in the house at night.

$\begin{array}{lccccc} & \text { Strongly disagree } & \text { Disagree } & \begin{array}{c}\text { Neither agree nor } \\ \text { disagree }\end{array} & \text { Agree } & \text { Strongly agree } \\ \text { MY FATHER would: } & 0 & 0 & 0 & 0 & 0 \\ \text { I: } & 0 & 0 & 0 & 0 & 0 \\ \begin{array}{l}\text { I have PASSED this value } \\ \text { onto my oldest son: }\end{array} & 0 & 0 & 0 & 0 & 0\end{array}$

40. A man shouldn't bother with sex unless he can achieve orgasm.

Strongly disagree

MY FATHER would:

I:

I have PASSED this value

onto my oldest son:
Disagree

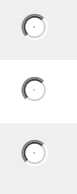

Neither agree nor disagree

Agree

Strongly agree

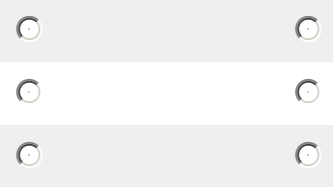


Father-Son Communication \& Gender Ideologies: Version 1

41. Men should be detached in emotionally charged situations.

Strongly disagree

Disagree

Neither agree nor disagree

Agree

Strongly agree

MY FATHER would:

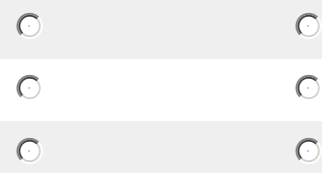

0

I have PASSED this value onto my oldest son:

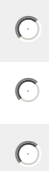

42. It is important for a man to take risks, even if he might get hurt.

$\begin{array}{lcccc} & \text { Strongly disagree } & \text { Disagree } & \begin{array}{c}\text { Neither agree nor } \\ \text { disagree }\end{array} & \text { Agree } \\ \text { MY FATHER would: } & 0 & 0 & 0 & 0 \\ \text { I: } & 0 & 0 & 0 & 0\end{array}$

\section{A man should always be ready for sex.}

$\begin{array}{lcccc} & \text { Strongly disagree } & \text { Disagree } & \begin{array}{c}\text { Neither agree nor } \\ \text { disagree }\end{array} & \text { Agree } \\ \text { MY FATHER would: } & 0 & 0 & 0 & 0 \\ \text { I: } & 0 & 0 & 0 & 0 \\ \begin{array}{l}\text { I have PASSED this value } \\ \text { onto my oldest son: }\end{array} & 0 & & \end{array}$

\section{A man should always be the major provider in his family.}

$\begin{array}{lcccc} & \text { Strongly disagree } & \text { Disagree } & \begin{array}{c}\text { Neither agree nor } \\ \text { disagree }\end{array} & \text { Agree } \\ \text { MY FATHER would: } & 0 & 0 & 6 & 0 \\ \text { I: } & 0 & 0 & 0 & 0 \\ \begin{array}{l}\text { I have PASSED this value } \\ \text { onto my oldest son: }\end{array} & 0 & 0 & \end{array}$

45. When the going gets tough, men should get tough.

$\begin{array}{lcccc} & \text { Strongly disagree } & \text { Disagree } & \begin{array}{c}\text { Neither agree nor } \\ \text { disagree }\end{array} & \text { Agree } \\ \text { MY FATHER would: } & 0 & 0 & 0 & 0 \\ \text { I: } & 0 & 0 & 0 & 0 \\ \text { I have PASSED this value } & 0 & 0 & \end{array}$


Father-Son Communication \& Gender Ideologies: Version 1

46. I might find it a little silly or embarrassing if a male friend of mine cried over a sad love story.

Strongly disagree

Disagree

Neither agree nor

disagree

Agree

Strongly agree

MY FATHER would:

I:

I have PASSED this value

onto my oldest son:

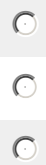

C

C

C

47. Fathers should teach their sons to mask fear.

$\begin{array}{lcccc} & \text { Strongly disagree } & \text { Disagree } & \begin{array}{c}\text { Neither agree nor } \\ \text { disagree }\end{array} & \text { Agree } \\ \text { MY FATHER would: } & 0 & 0 & 6 & 0 \\ \text { I: } & 0 & 0 & 6 & 0\end{array}$

48. I think a young man should try to be physically tough, even if he's not big.

$\begin{array}{lcccc} & \text { Strongly disagree } & \text { Disagree } & \begin{array}{c}\text { Neither agree nor } \\ \text { disagree }\end{array} & \text { Agree } \\ \text { MY FATHER would: } & 0 & 0 & 0 & 0 \\ \text { I: } & 0 & 0 & 0 & 0 \\ \begin{array}{l}\text { I have PASSED this value } \\ \text { onto my oldest son: }\end{array} & 0 & 0 & \end{array}$

49. In a group, it is up to the men to get things organized and moving ahead.

$\begin{array}{lcccc} & \text { Strongly disagree } & \text { Disagree } & \begin{array}{c}\text { Neither agree nor } \\ \text { disagree }\end{array} & \text { Agree } \\ \text { MY FATHER would: } & 0 & 0 & 0 & 0 \\ \text { I: } & 0 & 0 & 0 & 0 \\ \begin{array}{l}\text { I have PASSED this value } \\ \text { onto my oldest son: }\end{array} & 0 & 0 & 0\end{array}$

50. One should not be able to tell how a man is feeling by looking at his face.

$\begin{array}{lcccc} & \text { Strongly disagree } & \text { Disagree } & \begin{array}{c}\text { Neither agree nor } \\ \text { disagree }\end{array} & \text { Agree } \\ \text { MY FATHER would: } & 0 & 0 & 0 & 0 \\ \text { I: } & 0 & 0 & 0 & 0 \\ \text { I have PASSED this value } & 0 & & \end{array}$




\section{Father-Son Communication \& Gender Ideologies: Version 1}

\section{Men should make the final decision involving money.}

Strongly disagree

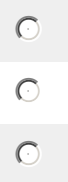

Disagree

MY FATHER would:

I:

I have PASSED this value onto my oldest son:
○

Neither agree nor disagree

Agree

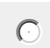

○

6
O

O
C

O

○

52. It is disappointing to learn that a famous athlete is gay.

Strongly disagree

MY FATHER would:

I:

I have PASSED this value onto my oldest son:
Disagree

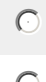

c

6
Neither agree nor disagree

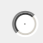

O

○
Agree

0
Strongly agree
○
O
○

53. Men should not be too quick to tell others that they care about them.

$\begin{array}{lcccc} & \text { Strongly disagree } & \text { Disagree } & \begin{array}{c}\text { Neither agree nor } \\ \text { disagree }\end{array} & \text { Agree } \\ \text { MY FATHER would: } & 0 & 0 & 0 & 0 \\ \text { I: } & 0 & 0 & 0 & 0 \\ \begin{array}{l}\text { I have PASSED this value } \\ \text { onto my oldest son: }\end{array} & 0 & 0 & \end{array}$




\section{Father-Son Communication \& Gender Ideologies: Version 1}

Directions: The following scale addresses your perceptions of your father's communication patterns. For each item, please indicate YOUR level of agreement regarding YOUR FATHER'S or family of origin's enactment of these attitudes and behaviors when you were growing up.

1. My father often asked my opinion when the family was talking about something.
Strongly disagree
Disagree
Neither agree nor
Agree
Strongly agree disagree

2. My father often said something like "My ideas are right and you should not question them."
Strongly disagree
Disagree
Neither agree nor
Agree
Strongly agree disagree

3. My father often said something like "Every member of the family should have some say in family decisions."
Strongly disagree
Disagree
6 Neither agree nor
Agree
Strongly agree disagree

4. In my family we often talked about topics like politics and religion where some persons disagreed with others.

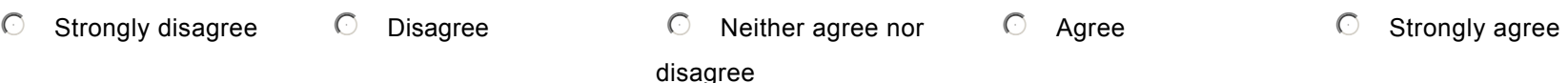

5. My father often said something like "A child should not argue with adults."
Strongly disagree
Disagree
Neither agree nor
Agree
Strongly agree disagree

6. My father encouraged me to challenge his ideas and beliefs.
Strongly disagree
Disagree
Neither agree nor disagree
Agree
Strongly agree

7. My father often said something like "There are some things that just shouldn't be talked about."

$\begin{array}{cccccc} & \text { Strongly disagree } \quad \text { Disagree } & 0 & \text { Neither agree nor } & 0 & \text { Agree } \\ \text { disagree } & \text { Strongly agree }\end{array}$

8. My father often said something like "You should give in on arguments rather than risk making people mad."
Strongly disagree
Disagree
Neither agree nor
Agree
Strongly agree
disagree 
Father-Son Communication \& Gender Ideologies: Version 1

9. When anything really important was involved, my father expected me to obey without question.

Strongly disagree

Disagree

Neither agree nor
disagree

Agree

Strongly agree

10. My father often said something like "You should always look at both sides of an issue."

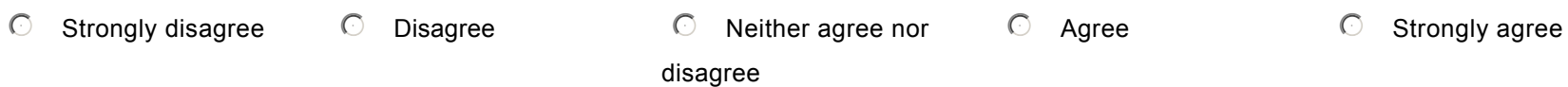

11. In our home, my father usually had the last word.

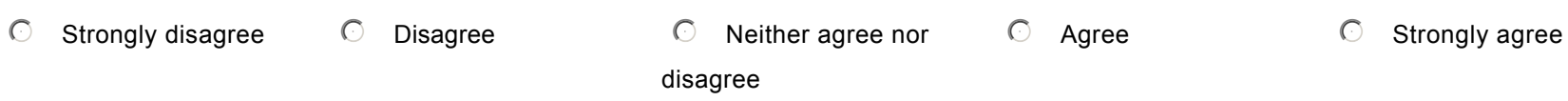

12. I usually told my father what I was thinking about things.

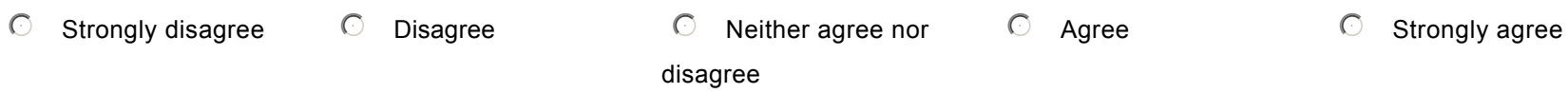

13. I could tell my father almost anything.

$\begin{array}{llllll}0 & \text { Strongly disagree } \quad 0 \text { Nisagree } & \text { Neither agree nor } & 0 & \text { Agree } & \text { Strongly agree }\end{array}$

14. In my family we often talked about our feelings and emotions.

$\begin{array}{llllll}0 & \text { Strongly disagree } \quad \text { Disagree } & & \text { Neither agree nor } & 0 & \text { Agree } \\ \text { disagree } & \text { Strongly agree }\end{array}$

15. My father felt that it was important to be the boss.

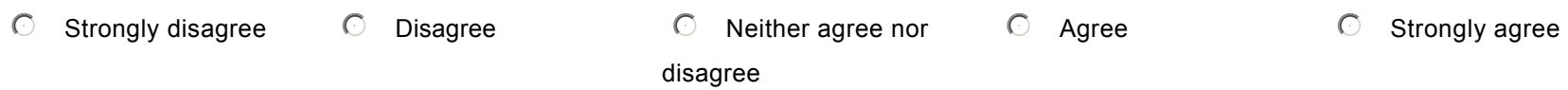

16. My father and I often had long, relaxed conversations about nothing in particular.

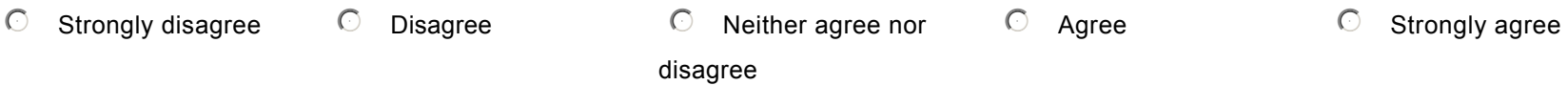

17. I really enjoyed talking with my father, even when we disagreed.

$\begin{array}{llllll}0 & \text { Strongly disagree } \quad \text { Disagree } & & \text { Neither agree nor } & 0 & \text { Agree } \\ \text { disagree } & \text { Strongly agree }\end{array}$ 


\section{Father-Son Communication \& Gender Ideologies: Version 1}

18. My father liked to hear my opinions, even when he didn't agree with me.

$\begin{array}{cccccc} & \text { Strongly disagree } \quad \text { Disagree } & 0 & \text { Neither agree nor } & 0 & \text { Agree } \\ \text { disagree } & \text { Strongly agree }\end{array}$

19. My father encouraged me to express my feelings.
Strongly disagree
D Disagree
Neither agree nor
Agree
Strongly agree disagree

20. My father sometimes became irritated with my views if they differed from his.

Strongly disagree $\quad 0$ Disagree
Neither agree nor disagree

Strongly agree

21. If my father didn't approve of it, he didn't want to know about it.
Strongly disagree
Disagree
6 Neither agree nor
Agree
Strongly agree disagree

22. My father tended to be very open about his emotions.
Strongly disagree
Disagree
Neither agree nor
Agree
Strongly agree disagree

23. We often talked as a family about things we had done during the day.

Strongly disagree $\quad$ Disagree
Neither agree nor $\quad$ Agree disagree

24. In our family we often talked about our plans and hopes for the future.
Strongly disagree
Disagree
Neither agree nor
Agree
Strongly agree disagree

25. When I was home, I was expected to obey my father's rules.
Strongly disagree
D Disagree
Neither agree nor
Agree
Strongly agree disagree

26. My father often said something like "You'll know better when you grow up."
Strongly disagree
Disagree
Neither agree nor
Agree
Strongly agree disagree 


\section{Father-Son Communication \& Gender Ideologies: Version 1}

Directions: The following scale addresses your communication patterns. For each item, please indicate YOUR level of agreement regarding YOUR enactment of these attitudes and behaviors with your own family.

1. I often ask my son's opinion when the family is talking about something.
Strongly Disagree $\quad$ Disagree
Neither agree nor
Agree
Strongly Agree disagree

2. I often tell my son not to argue with adults.
Strongly Disagree
Disagree
Neither agree nor
Agree
Strongly Agree disagree

3. When anything really important is involved, I expect my son to obey without question.
Strongly Disagree
Disagree
Neither agree nor
Agree
Strongly Agree disagree

\section{My son usually tells me what he's thinking about things.}
Strongly Disagree
Disagree
Neither agree nor disagree
Strongly Agree

5. My son and I often have long, relaxed conversations about nothing in particular.
Strongly Disagree
Disagree
Neither agree nor
Agree
Strongly Agree disagree

6. When my son is home, he is expected to obey my rules.

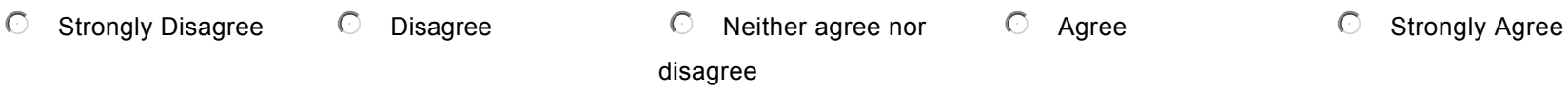

\section{I encourage my son to express his feelings.}
Strongly Disagree
Disagree
Neither agree nor disagree
Agree
Strongly Agree

8. We often talk as a family about things we have done during the day.

$\begin{array}{cccccc}0 & \text { Strongly Disagree } & 0 & \text { Neither agree nor } & 0 & \text { Agree } \\ \text { disagree } & \text { Strongly Agree }\end{array}$

9. I like to hear my son's opinions, even when he doesn't agree with me.
Strongly Disagree
Disagree
Neither agree nor disagree
Agree
Strongly Agree


Father-Son Communication \& Gender Ideologies: Version 1

10. I feel that it is important for me to be the boss.

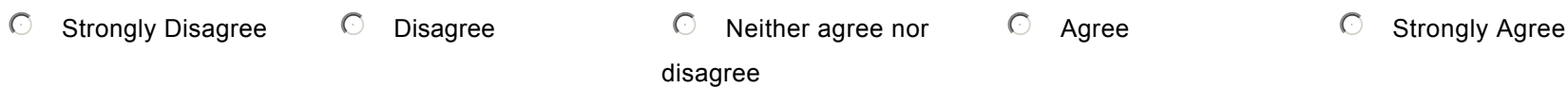

11. I sometimes become irritated when my son's views are different from mine. $\begin{array}{ccccccc} & \text { Strongly Disagree } \quad \text { Disagree } & 0 & \text { Neither agree nor } & 0 & \text { Agree } & \text { Strongly Agree }\end{array}$

12. I often tell my son, "You'll know better when you grow up."

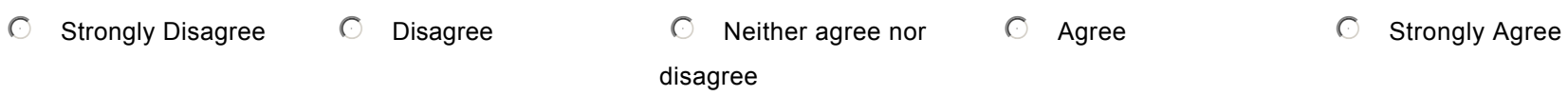

13. I believe every member of my family should have some say in family decisions.

Strongly Disagree $\quad$ Disagree $\quad 0$ Neither agree nor $\odot$ Agree $\quad 0$ Strongly Agree disagree

14. I encourage my son to challenge my ideas and beliefs.

Strongly Disagree $\quad 0$ Disagree $\quad 0$ Neither agree nor $\quad \bigcirc$ Agree $\quad$ Strongly Agree

15. I tell my son to always look at both sides of an issue.

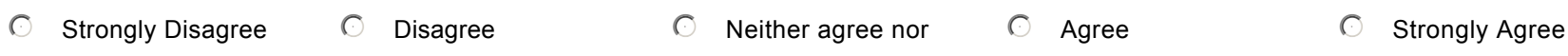
disagree

16. I believe my son should give in on arguments rather than risk making people mad.

$\begin{array}{llllll}0 & \text { Strongly Disagree } \quad 0 & \text { Disagree } & \text { Neither agree nor } \quad & \text { Agree } & \text { Strongly Agree }\end{array}$ disagree

17. In our home, I usually have the last word.

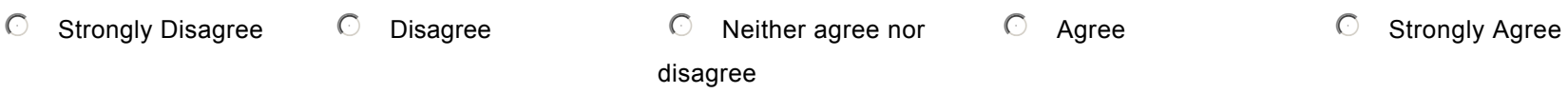

18. I really enjoy talking with my son, even when we disagree.

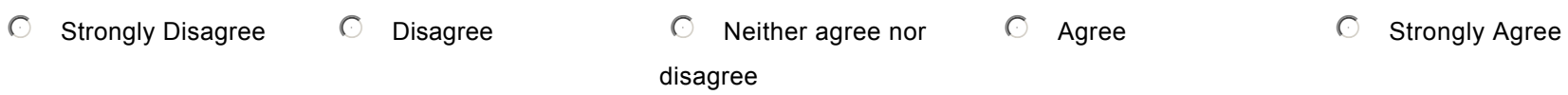

19. I tend to be very open about my emotions.

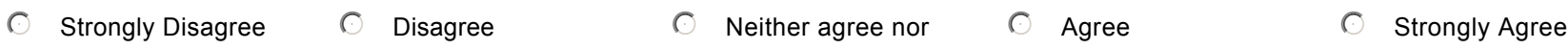
disagree 
Father-Son Communication \& Gender Ideologies: Version 1

20. I believe that there are some things that just shouldn't be talked about.

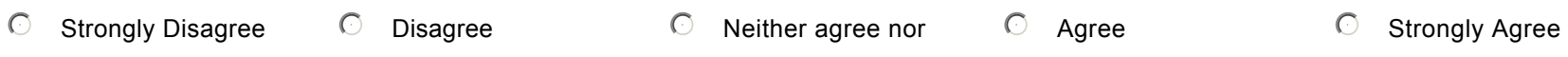
disagree

21. In our family we often talk about our plans and hopes for the future.

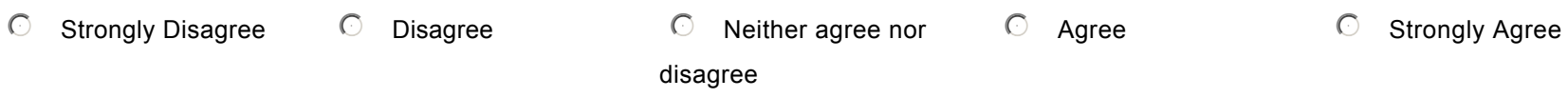

22. In our family we often talk about our feelings and emotions.

Strongly Disagree $\quad$ Disagree

Neither agree nor $\bigcirc$ Agree disagree

23. I believe that my ideas are right and my son should not question them.

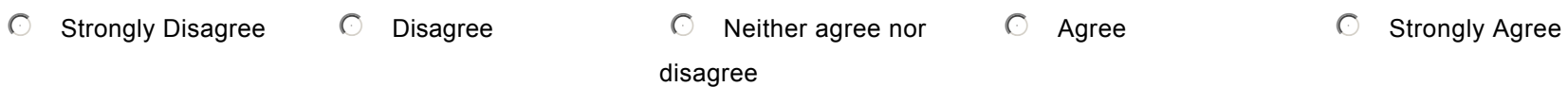

24. My son can tell me almost anything.

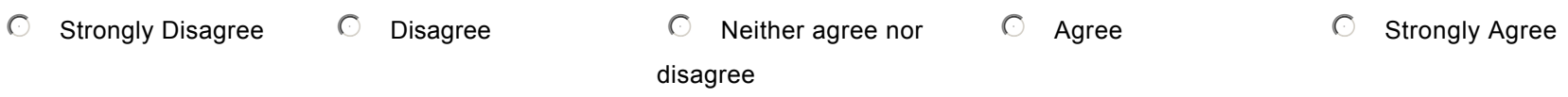

25. In my family we often talk about topics like politics and religion where some persons disagree with others.

Strongly Disagree $\quad 0$ Disagree Neither agree nor $\quad$ Agree
disagree

Strongly Agree

26. If I don't approve of it, I don't want to know about it.

$\begin{array}{ccccccc} & \text { Strongly Disagree } & \text { Disagree } & \text { Neither agree nor } & & \text { Agree } & \text { Strongly Agree } \\ \text { disagree } & & & \end{array}$ 
Father-Son Communication \& Gender Ideologies: Version 1

Directions: The following scale will address gender values. Each item on the scale will be associated with three separate questions: your perceptions of YOUR FATHER'S level of agreement with the value, YOUR level of agreement with the value, and your level of agreement regarding your PASSING of the value onto your oldest son.

\section{Both sexes can be nurturing.}

$\begin{array}{lccccc} & \text { Strongly disagree } & \text { Disagree } & \begin{array}{c}\text { Neither agree nor } \\ \text { disagree }\end{array} & \text { Agree } & \text { Strongly agree } \\ \text { MY FATHER would: } & 0 & 0 & 0 & 0 & 0 \\ \text { I: } & 0 & 0 & 0 & 0 & 0 \\ \text { I have PASSED this value } & 0 & 0 & 0 & 0 & 0\end{array}$

\section{On some level, my daily activities are motivated by my desire for a world free of gender biases.}

$\begin{array}{lccccc} & \text { Strongly disagree } & \text { Disagree } & \begin{array}{c}\text { Neither agree nor } \\ \text { disagree }\end{array} & \text { Agree } & \text { Strongly agree } \\ \text { MY FATHER would: } & 0 & 0 & 0 & 0 & 0 \\ \text { I: } & 0 & 0 & 0 & 0 & 0 \\ \text { I have PASSED this value } & 0 & 0 & 0 & 0 & 0 \\ \text { onto my oldest son: } & & & & \end{array}$

\section{Both sexes can participate in housework.}

$\begin{array}{lccccc} & \text { Strongly disagree } & \text { Disagree } & \begin{array}{c}\text { Neither agree nor } \\ \text { disagree }\end{array} & \text { Agree } & \text { Strongly agree } \\ \text { MY FATHER would: } & 0 & 0 & 0 & 0 & 0 \\ \text { I: } & 0 & 0 & 0 & 0 & 0 \\ \begin{array}{l}\text { I have PASSED this value } \\ \text { onto my oldest son: }\end{array} & 0 & 0 & 0 & 0 & 0\end{array}$

\section{It is ok for both sexes not to be physically tough.}

$\begin{array}{lccccc} & \text { Strongly disagree } & \text { Disagree } & \begin{array}{c}\text { Neither agree nor } \\ \text { disagree }\end{array} & \text { Agree } & \text { Strongly agree } \\ \text { MY FATHER would: } & 0 & 0 & 0 & 0 & 0 \\ \text { I: } & 0 & 0 & 0 & 0 & 0 \\ \begin{array}{l}\text { I have PASSED this value } \\ \text { onto my oldest son: }\end{array} & 0 & 0 & 0 & 0 & 0\end{array}$

\section{Both sexes can be sensitive.}

$\begin{array}{lccccc} & \text { Strongly disagree } & \text { Disagree } & \begin{array}{c}\text { Neither agree nor } \\ \text { disagree }\end{array} & \text { Agree } & \text { Strongly agree } \\ \text { MY FATHER would: } & 0 & 0 & 0 & 0 & 0 \\ \text { I: } & 0 & 0 & 0 & 0 & 0 \\ \begin{array}{l}\text { I have PASSED this value } \\ \text { onto my oldest son: }\end{array} & 0 & 0 & 0 & 0 & 0\end{array}$


Father-Son Communication \& Gender Ideologies: Version 1

\section{I care about masculine and feminine individuals having equal opportunities.}

$\begin{array}{lcccc} & \text { Strongly disagree } & \text { Disagree } & \begin{array}{c}\text { Neither agree nor } \\ \text { disagree }\end{array} & \text { Agree } \\ \text { MY FATHER would: } & 0 & 0 & 0 & 0 \\ \text { I: } & 0 & 0 & 0 & 0\end{array}$

\section{Both sexes can participate in athletic activities.}

\begin{tabular}{|c|c|c|c|c|c|}
\hline & Strongly disagree & Disagree & $\begin{array}{c}\text { Neither agree nor } \\
\text { disagree }\end{array}$ & Agree & Strongly agree \\
\hline MY FATHER would: & 0 & 0 & $\mathrm{O}$ & $\mathrm{O}$ & 0 \\
\hline I: & 0 & 0 & 0 & 0 & 0 \\
\hline $\begin{array}{l}\text { I have PASSED this value } \\
\text { onto my oldest son: }\end{array}$ & 0 & 0 & 0 & 0 & 0 \\
\hline \multicolumn{6}{|c|}{ 8. Both sexes can be assertive. } \\
\hline & Strongly disagree & Disagree & $\begin{array}{c}\text { Neither agree nor } \\
\text { disagree }\end{array}$ & Agree & Strongly agree \\
\hline MY FATHER would: & 0 & 0 & 0 & 0 & 0 \\
\hline I: & 0 & 0 & 0 & 0 & 0 \\
\hline $\begin{array}{l}\text { I have PASSED this value } \\
\text { onto my oldest son: }\end{array}$ & 0 & 0 & 0 & 0 & 0 \\
\hline
\end{tabular}

\section{Both sexes can have careers outside of the home.}

\begin{tabular}{|c|c|c|c|c|c|}
\hline & Strongly disagree & Disagree & $\begin{array}{c}\text { Neither agree nor } \\
\text { disagree }\end{array}$ & Agree & Strongly agree \\
\hline MY FATHER would: & 0 & 0 & 0 & 0 & 0 \\
\hline I: & 0 & 0 & 0 & 0 & 0 \\
\hline $\begin{array}{l}\text { I have PASSED this value } \\
\text { onto my oldest son: }\end{array}$ & 0 & 0 & 0 & 0 & 0 \\
\hline & Strongly disagree & Disagree & $\begin{array}{c}\text { Neither agree nor } \\
\text { disagree }\end{array}$ & Agree & Strongly agree \\
\hline MY FATHER would: & 0 & 0 & 0 & 0 & 0 \\
\hline I: & 0 & 0 & 0 & 0 & 0 \\
\hline $\begin{array}{l}\text { I have PASSED this value } \\
\text { onto my oldest son: }\end{array}$ & 0 & 0 & 0 & 0 & 0 \\
\hline
\end{tabular}

\section{Both sexes can participate in intellectually-stimulating activities.}

$\begin{array}{lcccc} & \text { Strongly disagree } & \text { Disagree } & \begin{array}{c}\text { Neither agree nor } \\ \text { disagree }\end{array} & \text { Agree } \\ \text { MY FATHER would: } & 0 & 0 & 0 & 0 \\ \text { I: } & 0 & 0 & 0\end{array}$


Father-Son Communication \& Gender Ideologies: Version 1

12. When men and women choose careers, they should not let gender role stereotypes influence their choices.

Strongly disagree

MY FATHER would:

I:

I have PASSED this value onto my oldest son:
Disagree

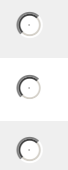

Neither agree nor disagree

Agree

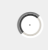

C

0
(1)

13. Both sexes can tell others that they care about them.

$\begin{array}{lcccc} & \text { Strongly disagree } & \text { Disagree } & \begin{array}{c}\text { Neither agree nor } \\ \text { disagree }\end{array} & \text { Agree } \\ \text { MY FATHER would: } & 0 & 0 & 0 & 0 \\ \text { I: } & 0 & 0 & 0 & 0 \\ \begin{array}{l}\text { I have PASSED this value } \\ \text { onto my oldest son: }\end{array} & 0 & 0 & \end{array}$

\section{Both sexes can participate in competitive activities.}

$\begin{array}{lcccc} & \text { Strongly disagree } & \text { Disagree } & \begin{array}{c}\text { Neither agree nor } \\ \text { disagree }\end{array} & \text { Agree } \\ \text { MY FATHER would: } & 0 & 0 & 0 & 0\end{array}$

\section{Society should not look down on people for doing activities that are traditionally} performed by the other sex.

Strongly disagree

MY FATHER would:

I:

I have PASSED this value

onto my oldest son:
Neither agree nor disagree

Agree

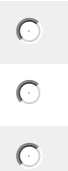

16. Both sexes can express feelings of fear.

Strongly disagree

MY FATHER would:

I:

I have PASSED this value onto my oldest son:
Disagree
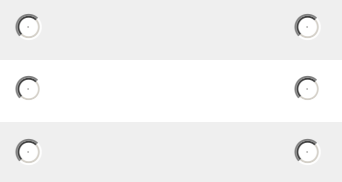

Neither agree nor disagree
O

0

C
Agree

o

0
Strongly agree

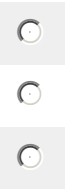




\section{Father-Son Communication \& Gender Ideologies: Version 1}

\section{Both sexes can make good leaders.}

Strongly disagree

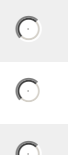

I have PASSED this value onto my oldest son:
Neither agree nor disagree

Agree

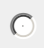
○
○
6

○

C

C

O

○

\section{Both sexes can participate in creative activities.}

Strongly disagree

MY FATHER would:

I:

I have PASSED this value onto my oldest son:
Neither agree nor disagree

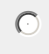

O

○
Agree

0

0

O
Strongly agree
○
O
○

\section{It is ok for both sexes to cry at sad movies.}

$\begin{array}{lcccc} & \text { Strongly disagree } & \text { Disagree } & \begin{array}{c}\text { Neither agree nor } \\ \text { disagree }\end{array} & \text { Agre } \\ \text { MY FATHER would: } & 0 & 0 & 0 & 0 \\ \text { I: } & 0 & 0 & 0 & 0 \\ \begin{array}{l}\text { I have PASSED this value } \\ \text { onto my oldest son: }\end{array} & 0 & 0 & & 0\end{array}$




\section{Father-Son Communication \& Gender Ideologies: Version 1}

Directions: The following scale addresses similarities between you and your father.
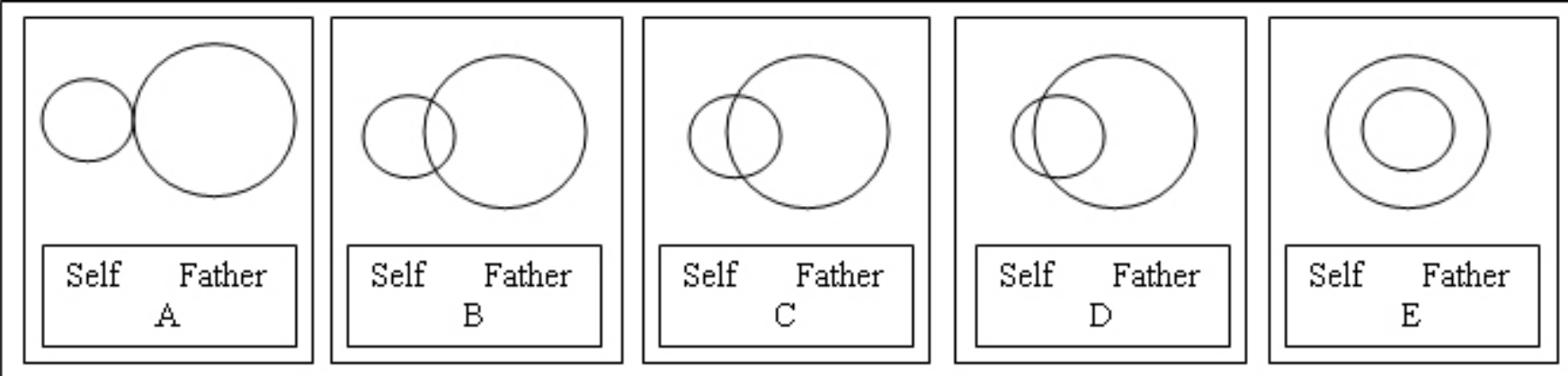

1. Choose the letter that corresponds with the picture above that best represents how similar you feel to your father.

( A

O B

$\circ \mathrm{c}$

O D

O $E$ 


\section{Father-Son Communication \& Gender Ideologies: Version 1}

Directions: The following scale addresses your satisfaction with life. Please answer the following questions based on your present agreement or disagreement with each statement.

\section{In most ways my life is close to my ideal.}

Strongly disagree

Disagree

Neither agree nor

Agree disagree

\section{The conditions of my life are excellent.}

Strongly disagree

Disagree
Neither agree nor disagree

\section{I am satisfied with my life.}

Strongly disagree $\quad$ Disagree

Neither agree nor $\bigcirc$ Agree
disagree

Strongly agree

4. So far I have gotten the important things I want in life.

Strongly disagree Disagree

Neither agree nor disagree

\section{If I could live my life over, I would change almost nothing.}

Strongly disagree

Disagree
Neither agree nor disagree

Strongly agree 


\section{Father-Son Communication \& Gender Ideologies: Version 1}

Directions: The following scale will address gender values. Each item on the scale will be associated with three separate questions: your perceptions of YOUR FATHER'S level of agreement with the value, YOUR level of agreement with the value, and your level of agreement regarding your PASSING of the value onto your oldest son.

\section{It is more appropriate for a male to be a teacher than a principal.}

$\begin{array}{lcccc} & \text { Strongly disagree } & \text { Disagree } & \begin{array}{c}\text { Neither agree nor } \\ \text { disagree }\end{array} & \text { Agr } \\ \text { MY FATHER would: } & 0 & 0 & 0 & 0 \\ \text { I: } & 0 & 0 & 0 & 0 \\ \text { I have PASSED this value } & 0 & 0 & 0 & 0 \\ \text { onto my oldest son: } & & & & \end{array}$

\section{When someone's feelings are hurt, a man should try to make them feel better.}

$\begin{array}{lccccc} & \text { Strongly disagree } & \text { Disagree } & \begin{array}{c}\text { Neither agree nor } \\ \text { disagree }\end{array} & \text { Agree } & \text { Strongly agree } \\ \text { MY FATHER would: } & 0 & 0 & 0 & 0 & 0 \\ \text { I: } & 0 & 0 & 0 & 0 & 0 \\ \begin{array}{l}\text { I have PASSED this value } \\ \text { onto my oldest son: }\end{array} & 0 & 0 & 0 & 0 & 0\end{array}$

\section{A man should marry an older woman.}

$\begin{array}{lccccc} & \text { Strongly disagree } & \text { Disagree } & \begin{array}{c}\text { Neither agree nor } \\ \text { disagree }\end{array} & \text { Agree } & \text { Strongly agree } \\ \text { MY FATHER would: } & 0 & 0 & 0 & 0 & 0 \\ \text { I: } & 0 & 0 & 0 & 0 & 0 \\ \begin{array}{l}\text { I have PASSED this value } \\ \text { onto my oldest son: }\end{array} & 0 & 0 & 0 & 0 & 0\end{array}$

\section{A man should make less money than his partner.}

Strongly disagree

MY FATHER would:

I:

I have PASSED this value onto my oldest son:

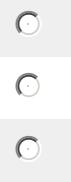
Disagree
Neither agree nor disagree

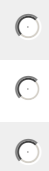

Agree

Strongly agree

\section{If a man and his partner choose to have an abortion, he should not feel guilty.}

$\begin{array}{lccccc} & \text { Strongly disagree } & \text { Disagree } & \begin{array}{c}\text { Neither agree nor } \\ \text { disagree }\end{array} & \text { Agree } & \text { Strongly a } \\ \text { MY FATHER would: } & 0 & 0 & 0 & 0 & 0 \\ \text { I: } & 0 & 0 & 0 & 0 & 0 \\ \begin{array}{l}\text { I have PASSED this value } \\ \text { onto my oldest son: }\end{array} & 0 & 0 & 0 & 0 & 0\end{array}$


Father-Son Communication \& Gender Ideologies: Version 1

6. Men should have women make decisions for them.

Strongly disagree

Disagree

Neither agree nor disagree

Agree

Strongly agree

MY FATHER would:

I:

I have PASSED this value

onto my oldest son:

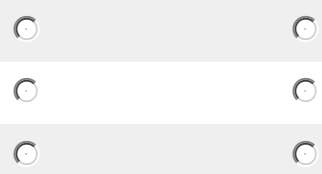

7. An appropriate male occupation is nursing.

Strongly disagree

MY FATHER would:

I:

I have PASSED this value onto my oldest son:
Disagree

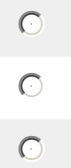

Neither agree nor disagree

O

○

c
0

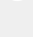

\section{A man should feel comfortable when his partner initiates sex.}

$\begin{array}{lcccc} & \text { Strongly disagree } & \text { Disagree } & \begin{array}{c}\text { Neither agree nor } \\ \text { disagree }\end{array} & \text { Agree } \\ \text { MY FATHER would: } & 0 & 0 & 0 & 0 \\ \text { I: } & 0 & 0 & 0 & 0 \\ \begin{array}{l}\text { I have PASSED this value } \\ \text { onto my oldest son: }\end{array} & 0 & 0 & 0\end{array}$

\section{A man's worth should be measured by the success of his partner.}

$\begin{array}{lcccc} & \text { Strongly disagree } & \text { Disagree } & \begin{array}{c}\text { Neither agree nor } \\ \text { disagree }\end{array} & \text { Agree } \\ \text { MY FATHER would: } & 0 & 0 & 6 & 0 \\ \text { I: } & 0 & 0 & 0 & 0 \\ \begin{array}{l}\text { I have PASSED this value } \\ \text { onto my oldest son: }\end{array} & 0 & 0 & & 0\end{array}$

10. Men should make career decisions that make him appear like the marrying kind.

Strongly disagree

MY FATHER would:

I:

I have PASSED this value

onto my oldest son:
Neither agree nor disagree

Disagree

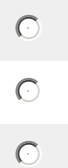

\section{A man should expect to be unsatisfied by his sexual partner.}

Strongly disagree

MY FATHER would:

I:

I have PASSED this value onto my oldest son:
Disagree

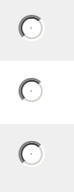

○

○

0
Neither agree nor disagree

Agree

Strongly agree

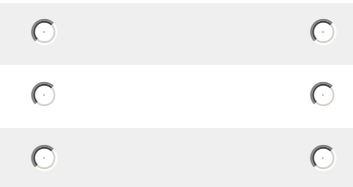

Strongly agree

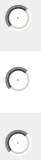




\section{Father-Son Communication \& Gender Ideologies: Version 1}

12. A man should refrain from swearing.

Strongly disagree

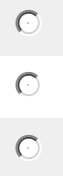

Disagree

MY FATHER would:

I:

I have PASSED this value

onto my oldest son:
Neither agree nor disagree

Agree

$$
0
$$

\section{A man should be uncompetitive.}

Strongly disagree

MY FATHER would:

I:

I have PASSED this value onto my oldest son:
Disagree

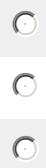

\section{A man should know how people are feeling.}

$\begin{array}{lcccc} & \text { Strongly disagree } & \text { Disagree } & \begin{array}{c}\text { Neither agree nor } \\ \text { disagree }\end{array} & \text { Agree } \\ \text { MY FATHER would: } & 0 & 0 & 0 & 0 \\ \text { I: } & 0 & 0 & 0 & 0 \\ \begin{array}{l}\text { I have PASSED this value } \\ \text { onto my oldest son: }\end{array} & 0 & 0 & 0\end{array}$

\section{A man should remain a virgin until he is married.}

Strongly disagree

Disagree

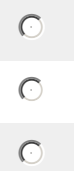

Neither agree nor disagree
Agree

0
Strongly agree

$$
\begin{aligned}
& 0 \\
& 0
\end{aligned}
$$

MY FATHER would:

I:

I have PASSED this value

onto my oldest son:

\section{A man should consider his career less important than a woman's.}

Strongly disagree

MY FATHER would:

I:

I have PASSED this value

onto my oldest son:
Disagree
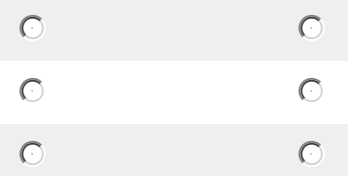

Neither agree nor disagree

17. A man's natural role should be the caregiver of the family.

Strongly disagree

MY FATHER would:

I:

I have PASSED this value onto my oldest son:
Disagree

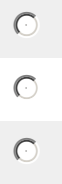

Neither agree nor disagree

Agree

Agree

Strongly agree

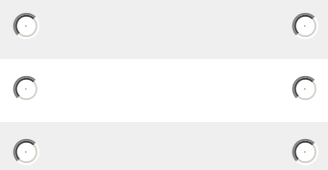

Strongly agree

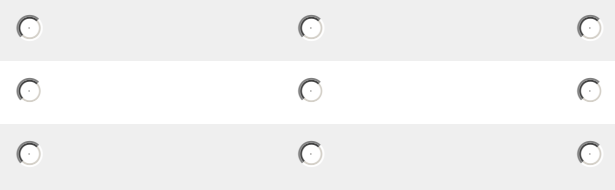




\section{Father-Son Communication \& Gender Ideologies: Version 1}

18. Men should act helpless to attract a woman.

Strongly disagree

Disagree

Neither agree nor disagree

Agree

Strongly agree

MY FATHER would:

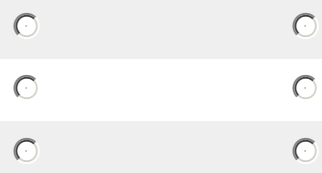
O

o

I:

I have PASSED this value

onto my oldest son:

19. A man should wear attractive clothing, even if not comfortable.

Strongly disagree

MY FATHER would:

I:

I have PASSED this value

onto my oldest son:
Disagree

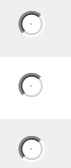

\section{Men should be gentle.}

$\begin{array}{lcccc} & \text { Strongly disagree } & \text { Disagree } & \begin{array}{c}\text { Neither agree nor } \\ \text { disagree }\end{array} & \text { Agree } \\ \text { MY FATHER would: } & 0 & 0 & 0 & 0 \\ \text { I: } & 0 & 0 & 0 & 0 \\ \begin{array}{l}\text { I have PASSED this value } \\ \text { onto my oldest son: }\end{array} & 0 & 0 & \end{array}$

\section{A man should be dependent on religion/spirituality for guidance.}

\begin{tabular}{|c|c|c|c|c|c|}
\hline & Strongly disagree & Disagree & $\begin{array}{c}\text { Neither agree nor } \\
\text { disagree }\end{array}$ & Agree & Strongly agree \\
\hline MY FATHER would: & 0 & 0 & 0 & 0 & 0 \\
\hline I: & 0 & 0 & 0 & O & 0 \\
\hline $\begin{array}{l}\text { I have PASSED this value } \\
\text { onto my oldest son: }\end{array}$ & 0 & 0 & $\mathrm{O}$ & 0 & 0 \\
\hline & Strongly disagree & Disagree & $\begin{array}{c}\text { Neither agree nor } \\
\text { disagree }\end{array}$ & Agree & Strongly agree \\
\hline MY FATHER would: & O & 0 & O & 0 & 0 \\
\hline $\mathrm{I}:$ & 0 & 0 & 0 & 0 & 0 \\
\hline $\begin{array}{l}\text { I have PASSED this value } \\
\text { onto my oldest son: }\end{array}$ & 0 & 0 & 0 & 0 & 0 \\
\hline
\end{tabular}

\section{A man should be responsible for making and organizing family plans.}

Strongly disagree

MY FATHER would:

।

I have PASSED this value onto my oldest son:
Disagree

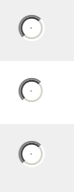

Neither agree nor disagree

Agree

Strongly agree

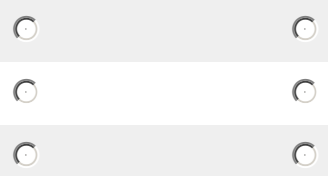

Strongly agree

$$
\text { O }
$$$$
\text { ○ }
$$ 
Father-Son Communication \& Gender Ideologies: Version 1

\section{Men should refrain from reading pornographic material.}

$\begin{array}{lcccc} & \text { Strongly disagree } & \text { Disagree } & \begin{array}{c}\text { Neither agree nor } \\ \text { disagree }\end{array} & \text { Agree } \\ \text { MY FATHER would: } & 0 & 0 & 0 & 6 \\ \text { I: } & 0 & 0 & 0 & 0\end{array}$

\section{It is unacceptable for a man to masturbate.}

\begin{tabular}{|c|c|c|c|c|c|}
\hline & Strongly disagree & Disagree & $\begin{array}{c}\text { Neither agree nor } \\
\text { disagree }\end{array}$ & Agree & Strongly agree \\
\hline MY FATHER would: & O & O & O & O & O \\
\hline I: & 0 & 0 & 0 & 0 & 0 \\
\hline $\begin{array}{l}\text { I have PASSED this value } \\
\text { onto my oldest son: }\end{array}$ & 0 & 0 & 0 & 0 & 0 \\
\hline & Strongly disagree & Disagree & $\begin{array}{c}\text { Neither agree nor } \\
\text { disagree }\end{array}$ & Agree & Strongly agree \\
\hline MY FATHER would: & 0 & 0 & 0 & 0 & 0 \\
\hline I: & 0 & O & $\mathrm{O}$ & 0 & 0 \\
\hline $\begin{array}{l}\text { I have PASSED this value } \\
\text { onto my oldest son: }\end{array}$ & 0 & 0 & 0 & 0 & 0 \\
\hline
\end{tabular}

\section{Men should have soft voices.}

\begin{tabular}{|c|c|c|c|c|c|}
\hline & Strongly disagree & Disagree & $\begin{array}{c}\text { Neither agree nor } \\
\text { disagree }\end{array}$ & Agree & Strongly agree \\
\hline MY FATHER would: & 0 & 0 & 0 & 0 & 0 \\
\hline I: & 0 & 0 & 0 & 0 & 0 \\
\hline \multirow[t]{3}{*}{$\begin{array}{l}\text { I have PASSED this value } \\
\text { onto my oldest son: }\end{array}$} & 0 & 0 & 0 & 0 & 0 \\
\hline & aly tell cle & & & & \\
\hline & Strongly disagree & Disagree & $\begin{array}{l}\text { Neither agree nor } \\
\text { disagree }\end{array}$ & Agree & Strongly agree \\
\hline MY FATHER would: & 0 & O & 0 & $\mathrm{O}$ & 0 \\
\hline $\mathrm{I}:$ & 0 & 0 & 0 & 0 & 0 \\
\hline $\begin{array}{l}\text { I have PASSED this value } \\
\text { onto my oldest son: }\end{array}$ & O & 0 & 0 & $\mathrm{O}$ & 0 \\
\hline
\end{tabular}

29. A boy should be taught how to catch a wife.

$\begin{array}{lcccc} & \text { Strongly disagree } & \text { Disagree } & \begin{array}{c}\text { Neither agree nor } \\ \text { disagree }\end{array} & \text { Agree } \\ \text { MY FATHER would: } & 0 & 0 & 0 & 0 \\ \text { I: } & 0 & 0 & 0 \\ \begin{array}{l}\text { I have PASSED this value } \\ \text { onto my oldest son: }\end{array} & 0 & & \end{array}$


Father-Son Communication \& Gender Ideologies: Version 1

30. A man should wait to have children until he is married.

Strongly disagree

Disagree

Neither agree nor disagree

Agree

Strongly agree

MY FATHER would:
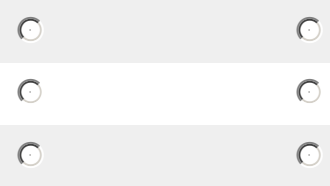

I have PASSED this value

onto my oldest son:

31. It is expected that men will think illogically.

$\begin{array}{lcccc} & \text { Strongly disagree } & \text { Disagree } & \begin{array}{c}\text { Neither agree nor } \\ \text { disagree }\end{array} & \text { Agree } \\ \text { MY FATHER would: } & 0 & 0 & 0 & 0 \\ \text { I: } & 0 & 0 & 0 & 0\end{array}$

\section{It is expected that men will discuss their feelings with one another.}

$\begin{array}{lcccc} & \text { Strongly disagree } & \text { Disagree } & \begin{array}{c}\text { Neither agree nor } \\ \text { disagree }\end{array} & \text { Agree } \\ \text { MY FATHER would: } & 0 & 0 & 0 & 0 \\ \text { I: } & 0 & 0 & 0 & 0 \\ \begin{array}{l}\text { I have PASSED this value } \\ \text { onto my oldest son: }\end{array} & 0 & 0 & 0\end{array}$

\section{Men should dress conservatively so they do not appear loose.}

$\begin{array}{lcccc} & \text { Strongly disagree } & \text { Disagree } & \begin{array}{c}\text { Neither agree nor } \\ \text { disagree }\end{array} & \text { Agree } \\ \text { MY FATHER would: } & 0 & 0 & 0 & 0 \\ \text { I: } & 0 & 0 & 0 & 0\end{array}$

\section{It is expected that men will have a hard time handling stress without getting} emotional.

Strongly disagree

MY FATHER would:

I:

I have PASSED this value onto my oldest son:
Disagree
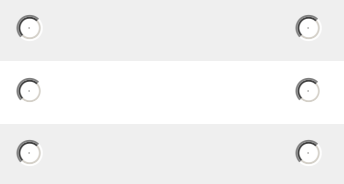

Neither agree nor disagree

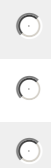

Agree

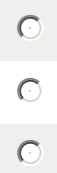

Strongly agree

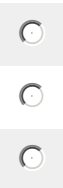


Father-Son Communication \& Gender Ideologies: Version 1

35. It is expected that men in leadership roles will not be taken seriously.

Strongly disagree

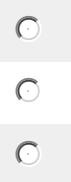

Disagree

MY FATHER would:

I:

I have PASSED this value

onto my oldest son:
Neither agree nor disagree

Agree

Strongly agree

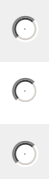

36. A man should be responsible for teaching family values to his children.

$\begin{array}{lcccc} & \text { Strongly disagree } & \text { Disagree } & \begin{array}{c}\text { Neither agree nor } \\ \text { disagree }\end{array} & \text { Agree } \\ \text { MY FATHER would: } & 0 & 0 & 0 & 0 \\ \text { I: } & 0 & 0 & 0 & 0\end{array}$

37. It is expected that a man will be viewed as overly emotional.

$\begin{array}{lcccc} & \text { Strongly disagree } & \text { Disagree } & \begin{array}{c}\text { Neither agree nor } \\ \text { disagree }\end{array} & \text { Agree } \\ \text { MY FATHER would: } & 0 & 0 & 0 & 0 \\ \text { I: } & 0 & 0 & 0 & 0 \\ \begin{array}{l}\text { I have PASSED this value } \\ \text { onto my oldest son: }\end{array} & 0 & & 0\end{array}$

38. It is expected that a single man is less fulfilled than a married man.

$\begin{array}{lcccc} & \text { Strongly disagree } & \text { Disagree } & \begin{array}{c}\text { Neither agree nor } \\ \text { disagree }\end{array} & \text { Agree } \\ \text { MY FATHER would: } & 0 & 0 & 6 & 0 \\ \text { I: } & 0 & 0 & 0 & 0 \\ \begin{array}{l}\text { I have PASSED this value } \\ \text { onto my oldest son: }\end{array} & 0 & 0 & \end{array}$

39. A man should be free from doing mechanical things.

Strongly disagree

MY FATHER would:

I:

I have PASSED this value onto my oldest son:
Neither agree nor disagree

Agree

Strongly agree

$\begin{array}{ll}0 & 0 \\ 0 & 0 \\ 0 & 0\end{array}$

0 
Father-Son Communication \& Gender Ideologies: Version 1

40. It is expected that a man will engage in domestic hobbies such as sewing and decorating.

Strongly disagree

MY FATHER would:

I:

I have PASSED this value onto my oldest son:
Disagree

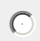

○

6
Neither agree nor disagree

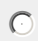

O

C
Agree

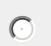

O

O
Strongly agree

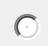

○

o

41. It is likely that a man who gives up custody of his children will lose others' respect.

Strongly disagree

MY FATHER would:

I:

I have PASSED this value onto my oldest son:
Neither agree nor disagree

Agree

0

O

o
Strongly agree

0

O

C 


\section{Father-Son Communication \& Gender Ideologies: Version 1}

Directions: In the space provided below, please describe a memorable message that your father said, wrote, or did to communicate how to be a man. A message would be considered memorable if it has stayed with you over time and has had a lasting impression on the way you think, feel, or act as a man.

Even if the message is memorable, though, that does not mean you necessarily agree with it or that you took the advice your father offered. The memorable message you describe below should merely be a message you remember your father telling you that impacted the way you feel about being a man.

A memorable message might be include:

"Men should get good jobs and take care of themselves instead of relying on others for support."

"Boys do not cry when they get hurt."

"Real men show their love for their families."

"Real men do not show fear or weakness."

"Men show respect for all people no matter their sex, gender, race, or sexual preferences."

"Losing a game is unacceptable. You must try harder the next time so you can win/play better."

Although the hope is that these examples give you a better understanding of what a memorable message might entail, these examples are not the only acceptable answers. Please do not let them limit your thoughts and the messages you report.

\section{In the space below, please write your father's most memorable message about being a man.}




\section{Father-Son Communication \& Gender Ideologies: Version 1}

Directions: The following questions address YOUR level of agreement with the message you wrote about on the previous page.

1. I want to send my oldest son the same message about being a man that my father gave to me.

2. I think that the message my father gave me would be beneficial to my oldest son.
Strongly disagree
Disagree
Neither agree nor
Agree
Strongly agree disagree

3. The memorable message that my father told me about being a man should not be relayed to my oldest son.
Strongly disagree
Disagree
Neither agree nor
Agree
Strongly agree disagree

4. My oldest son needs to hear this memorable message about being a man.
Strongly disagree
Disagree
Neither agree nor
Agree
Strongly agree disagree

5. My oldest son will be better off not learning this memorable message about being a man.
Strongly disagree
Disagree
Neither agree nor disagree
Strongly agree

6. I will be sure to deliver this memorable message to my oldest son.

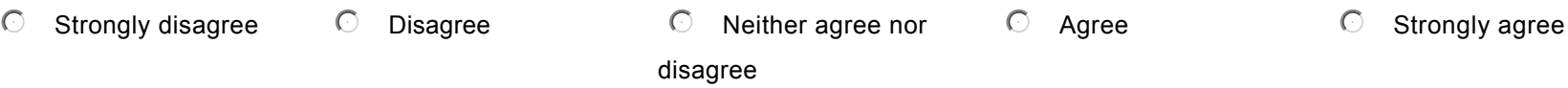




\section{Father-Son Communication \& Gender Ideologies: Version 1}

Please answer the following questions about yourself.

\section{Your age (in years):}

\section{Your current relationship status:}
Single
Married to my son's biological mother
Remarried/married to someone who is not my son's biological mother
Divorced
Widowed

\section{I am my oldest son's:}
Biological father
Stepfather
Adoptive father

Other (please specify)

\section{The ethnicity with which you most closely identify:}
Asian
Hispanic
Black/African American
White/Caucasian
Native American

Other (please specify)

\section{Your oldest son's age (in years):}


Father-Son Communication \& Gender Ideologies: Version 1

\section{The ethnicity with which your oldest son most closely identifies:}

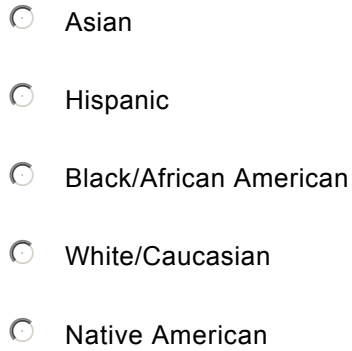

\section{If you have other children, please list them here:}

Age (in years):

Sex (male OR female):

Relation (biological child, stepchild, OR adopted child):

Age (in years):

Sex (male OR female): Relation (biological child, stepchild, OR adopted child):

Age (in years):

Sex (male OR female):

Relation (biological child, stepchild, OR adopted child):

\section{Your annual household income (in dollars):}

\section{The father who raised you was your:}
Biological father
Stepfather
Adopted father

Other (please specify)

10. Is your father currently living?
6 Yes
No 


\section{Father-Son Communication \& Gender Ideologies: Version 1}

11. If your father is still living, what is his age (in years)?

12. Your father's current relationship status:

Single

Married to your biological mother

Remarried/married to someone who is not your biological mother

C Divorced

Widowed

13. The ethnicity with which your father most closely identifies:

Asian

Hispanic

Black/African American

White/Caucasian

Native American

Other (please specify)

14. If you were recruited for this study by a student enrolled in a Communication Studies course at West Virginia University, please complete the following information so he/she can receive extra credit.

Student's First and Last

Name:

Student's Course

Name/Number:

Student's Email Address: 


\section{Father-Son Communication \& Gender Ideologies: Version 1}

Thank you for taking the time to complete our survey. We appreciate your valuable time and input! If you have any questions or concerns, do not hesitate to contact us at kodenwel@mix.wvu.edu. 
KELLY G. ODENWELLER

411 Broadway Avenue Apt 1 | Morgantown, WV 25606 | 614-296-5569 | kodenwel@mix.wvu.edu

\section{EDUCATION}

\section{West Virginia University}

Ph.D., Communication Studies | Anticipated Graduation Date: August 2014

West Virginia University, 2011

MA, Communication Studies | Emphasis in Theory \& Research | Graduated summa cum laude, GPA 3.83

University of Pittsburgh, 2004

BA, Communication | Minor in Writing | Graduated summa cum laude, GPA 3.84

\section{CONFERENCE PRESENTATIONS}

Berkebile, T., La Belle, S., Odenweller, K. G., Saint Aubin, M., \& Thoma, J. (2011, April). Targets of Family Exclusion. In C. E. Rittenour (Chair), Outsiders in their own homes: The excluded, the ostracized, and other black sheet of the family. Symposium conducted at the meeting of Central States Communication Association, Milwaukee.

\section{OTHER RESEARCH EXPERIENCE}

\section{Master's Thesis}

- Topic: Father-Son Family Communication Patterns and Gender Ideologies: A Modeling and Compensation Analysis

- Advisor: Dr. Christine E. Rittenour

- Committee Members: Dr. Maria Brann and Dr. Scott A. Myers

- Will prepare for publication in Fall 2011 semester

\section{Group research project investigating instructor resistance behaviors}

- Conducted and transcribed focus groups, developed codebook, and calculated reliability using Scott's Pi

- Wrote methods and results sections

- Submitted full study for Qualitative Research Methods group project

- Will prepare for publication during Fall 2011 semester

\section{Group research project testing the theory of planned behavior}

- Conducted and transcribed focus groups

- Created code book, qualitatively coded data for themes, and calculated reliability using Scott's Pi

- Compiled literature review and wrote results section for first phase of study

- Submitted for Survey of Human Communication Theory group project

\section{Assisted with Ph.D. students' dissertation research}

- Transcribed focus groups and created codebook 
- Compiled literature review, developed hypotheses, and wrote proposed methods section

- Submitted for Seminar in Family Communication individual class project

- Will complete study during Summer 2011 semester

Research proposal investigating parent-child relational maintenance via computer-mediated communication

- Compiled literature review, developed hypotheses, and wrote proposed methods section

- Submitted for Seminar in Computer-Mediated Communication individual class project

- Will complete study during Fall 2011 semester

Research proposal investigating abusive supervision, retaliatory communication, and gender ideologies

- Compiled literature review, developed hypotheses, and wrote proposed methods section

- Submitted for Seminar in Advanced Organization Communication individual class project

- Will complete study during Fall 2011 semester

Research proposal investigating the matching hypothesis with couple's conflict and discipline styles

- Compiled literature review, developed hypotheses, and wrote proposed methods section

- Submitted for Seminar in Interpersonal Conflict individual class project

- Will complete study during Fall 2011 semester

\section{TEACHING EXPERIENCE}

Instructor | Organizational Communication, West Virginia University | July 2011

- Instructed 30 undergraduate students on basic organization communication theories, applications, and ethical principles

\section{Guest Lecturer | Interpersonal Communication, West Virginia University | April 2011}

- Instructed 200 undergraduate students on social exchange theory

Guest Lecturer | Organizational Communication Theory and Research, West Virginia University | November 2010

- Instructed Master's students on innovative, effective, and easily executable job search strategies

\section{WORK EXPERIENCE}

\section{Graduate Teaching Assistant | Communication Studies Department, West Virginia University | Aug} 2010-May 2011

- Proctored exams and graded written assignments

- Entered student grades into online grading system

- Administered instructor evaluations

- Managed undergraduate teaching assistants

- Alleviated undergraduate students' grade concerns

Peer Tutor | Learning Resource Center, University of Pittsburgh at Johnstown | January 2000-May 2004

- Tutored students in Communication, English Grammar, Spanish, and Psychology courses

- Advised students on writing assignments 


\section{HONORS, AWARDS, and SCHOLARSHIPS}

- West Virginia University Eberly College of Arts and Science's HERF Supplementary Fellowship, 2011

- University of Pittsburgh at Johnstown Student Activities Award, 2004

- University of Pittsburgh at Johnstown College Scholar Award in Communication, 2004

- Who's Who among Students in American Universities and Colleges, 2004

- Homes and Land Publishing Scholarship, 2003

- Dean's List, 2000-2004

- Who's Who among Students in American High Schools, 2000

- Butler Road Race Scholarship, 2000

- Academic Merit Scholarship, 2000

\section{E R T I F I C A T I O NS}

- Collaborative Institutional Training Initiative (CITI), 2010

\section{PROFESSIONAL ORGANIZATIONS}

- Member, National Communication Association, 2011-present

- Member, Central States Communication Association, 2011-present

- Member, Honor Society of Phi Kappa Phi, 2004-present

- Vice President, National Communication Association Honor Society of Lambda Pi Eta, 2003-2004

- President, Honorary Leadership Society of Chi Lambda Tau, 2003-2004

- Member, National Communication Association Honor Society of Lambda Pi Eta, 2002-present

- Member, Honorary Leadership Society of Chi Lambda Tau, 2002-2003

\section{SOFTWARE PROGRAMS}

- PASW 18

- Microsoft Office

- Internet Explorer and Firefox

- Adobe products 